Review

\title{
Recent Progress on Enyne Metathesis: Its Application to Syntheses of Natural Products and Related Compounds
}

\section{Miwako Mori}

Health Sciences University of Hokkaido, Ishikari-Tobetsu, Hokkaido 061-0293, Japan; E-Mail: mori@pharm.hokudai.ac.jp; Tel: +81 11 7876045; Fax: +81 117876045.

Received: 28 December 2009; in revised form: 26 February 2010 / Accepted: 16 March 2010 / Published: 19 March 2010

\begin{abstract}
Olefin metathesis using ruthenium carbene complexes is a useful method in synthetic organic chemistry. Enyne metathesis is also catalyzed by these complexes and various carbo- and heterocycles could be synthesized from the corresponding enynes. Dienyne metathesis, cross enyne metathesis and ring-opening enyne metathesis have been further developed. Various complicated compounds, such as the natural products and the related biologically active substances, could be synthesized using these metatheses reactions. Skeletal reorganization using the transition metals and metallotropic rearrangement are also discussed.
\end{abstract}

Keywords: enyne metathesis; ring-closing enyne metathesis; dienyne metathesis; cross metathesis; ring-opening metathesis; natural product

\section{Table of Content}

Introduction

1. Ring-Closing Enyne Metathesis

2. Ring-Closing Dienyne Metathesis

3. Cross Enyne Metathesis

4. Ring-Opening Enyne Metathesis

5. Skeletal Reorganization Using Transition Metals

6. Metallotropic Rearrangement

Perspective 


\section{Introduction}

Since the discovery of molybdenum and ruthenium carbene complexes by Schrock and Grubbs in 1990 [1] and 1992 [2], synthetic organic chemistry has made rapid progress using metathesis reactions. Grubbs et al. found that molybdenum carbene complex 1a was effective for olefin metathesis [3]. They then synthesized ruthenium-carbene complex 1b for olefin metathesis [2], and synthesized carbo- and heterocyclic compounds using ring-closing olefin metathesis [4-6]. In 1995, Grubbs found that ruthenium-carbene complex $\mathbf{1 c}$ has the same reactivity as that of $\mathbf{1 b}$ [7], and it is now commercially available. Complexes $\mathbf{1 b}$ and $\mathbf{1 c}$ are stable and easy to handle (Figure 1). Thus, many researchers were able to use these catalysts, and various cyclic compounds were synthesized from dienes using ring-closing metathesis (RCM).

Figure 1. Ruthenium catalysts for alkene metathesis.<smiles>CC(C)c1cccc(C(C)C)c1N=[W](OC(C)(C)C(F)(F)F)OC(C)(C)C(F)(F)F</smiles>

$1 \mathbf{a}$

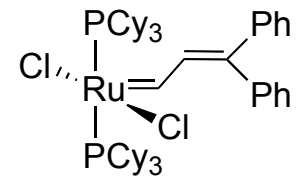

$1 \mathrm{~b}$

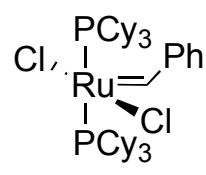

$1 \mathrm{c}$

Figure 2. Ruthemium catalysts for alkene metathesis.

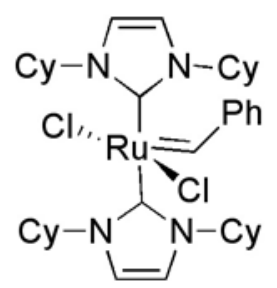

1d (Herrmann)

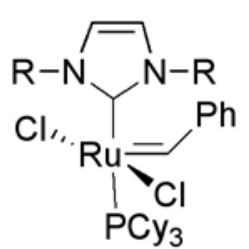

1e $\mathrm{R}=\mathrm{CHMePh}$ (Herrmann) 1f $\mathrm{R}=$ Mes (Grubbs, Nolan)

(Mes = 2,4,6-trimethylphenyl)<smiles>CS(=O)(=O)N1CCN(C(Cl)(Cl)c2ccccc2)C1(Cl)Cl</smiles>

$1 g$ (Grubbs)

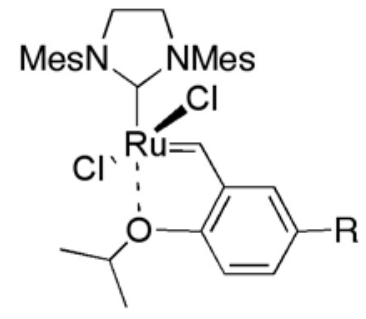<smiles>CC(C)Oc1c(C=[R1](Cl)C2N(C)CCN2C)cccc1-c1ccccc1</smiles>

1j<smiles></smiles>

$1 k$ 
In 1999, Herrmann [8-9], Nolan [10-11] and Grubbs [12-16] found novel ruthenium-carbene complexes 1d-1g having a heterocyclic carbene as a ligand. Since these catalysts, called as the second-generation ruthenium carbene complex, are very effective for olefin metathesis compared with 1b and 1c [14], olefin metathesis has been further progressed by use of these catalysts. Furthermore, cross-metathesis (CM) of alkene and ring-opening metathesis (ROM) have been developed using these complexes. Later, many ruthenium carbene complexes 1h-k [17-22] having various ligands were synthesized (Figure 2).

Metathesis of enynes having alkene and alkyne moieties in a molecule is an extremely interesting reaction [23-27]. In this reaction, the double bond of enyne $\mathbf{2}$ is cleaved and a carbon-carbon bond is formed between the double and triple bonds, and the cleaved alkylidene part of the double bond migrates onto the alkyne carbon to produce a cyclic compound $\mathbf{3}$ having a 1,3-diene moiety (Scheme 1).

Scheme 1. Ring-opening enyne metathesis.

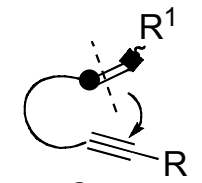

2

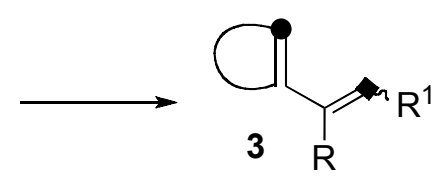

The first enyne metathesis was reported by Katz [28-30], who used a Fischer tungsten-carbene complex. Then Mori reported a chromium-catalyzed enyne metathesis [31-34]. It was later found that the ruthenium-carbene complex $\mathbf{1 b}$ or $\mathbf{1 c}$ was very effective for enyne metathesis [35-36]. The reaction would proceed via a [2+2] cycloaddition of a ruthenium-carbene complex with an alkyne part to produce ruthenacyclobutene $\mathbf{4}$, and ring-opening of this affords a ruthenium carbene complex $\mathbf{5}$, which reacts with an alkene part to produce ruthenacyclobutane 6, and ring-opening of this gives a cyclized compound 3 and a ruthenium-carbene complex is regenerated (Scheme 2, Route 1). In some cases, metathesis products via complexes 4' were obtained. The other mechanism also considered involves at first reaction of the alkene part of enyne 2 with ruthenium carbene complex to afford a new ruthenium carbene complex 7 . The latter species reacts with the alkyne part to produce ruthenacyclobutene $\mathbf{8}$ and its subsequent ring-opening gives ruthenium carbene 9, that undergoes intermolecular [2+2] cycloaddition with the alkene part of enyne 2 to produce ruthenacyclobutane 10. Ring-opening of this gives cyclic compound $\mathbf{3}$ and ruthenium carbene complex 7 is regenerated (Scheme 2, Route 2).

Later, the detailed study on the reaction mechanism was shown by Lippstreu and Straub, who described that the reaction would proceeds via Route 2, and ruthenacyclobutene 4, generated from an alkyne part of enyne $\mathbf{2}$ and ruthenium carbene complex, do not exist as local minimum in the catalytic cycle [37].

Using ruthenium carbene complexes $\mathbf{1 b}$ and $\mathbf{1 c}$, various carbo- and heterocycles could be synthesized from the corresponding enynes [35-36]. Furthermore, dienyne metathesis, cross enyne metathesis and ring-opening enyne metathesis have been developed. As the results, the novel route for the synthesis of various complicated compounds, such as the natural products and the related biologically active substances, were pioneered. Skeletal reorganization using the transition metals and metallotropic rearrangement will be discussed. 
Scheme 2. Ring-closing enyne metathesis.

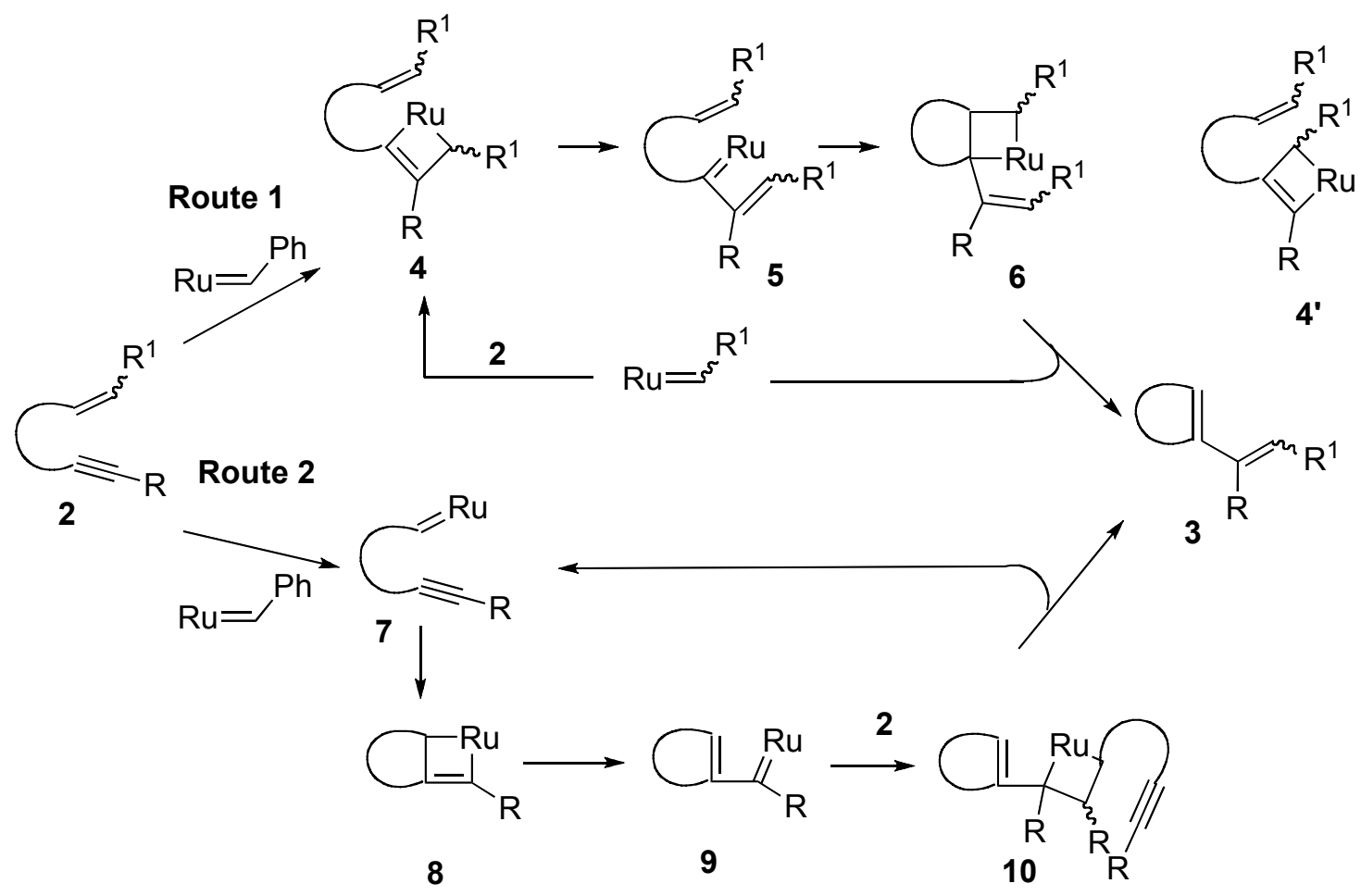

\section{Ring-Closing Enyne Metathesis (RCM)}

Mori reported the synthesis of heterocycles having a diene moiety using enyne metathesis [35-36]. Enynes $\mathbf{1 1}$ were treated with $1 \mathrm{~mol} \%$ of Grubbs catalyst $\mathbf{1 b}$ at room temperature to afford heterocycles 12 in high yields. Using this procedure, five- to nine-membered heterocycles could be synthesized (Scheme 3).

Scheme 3. Synthesis of heterocycles using ruthenium catalyst.

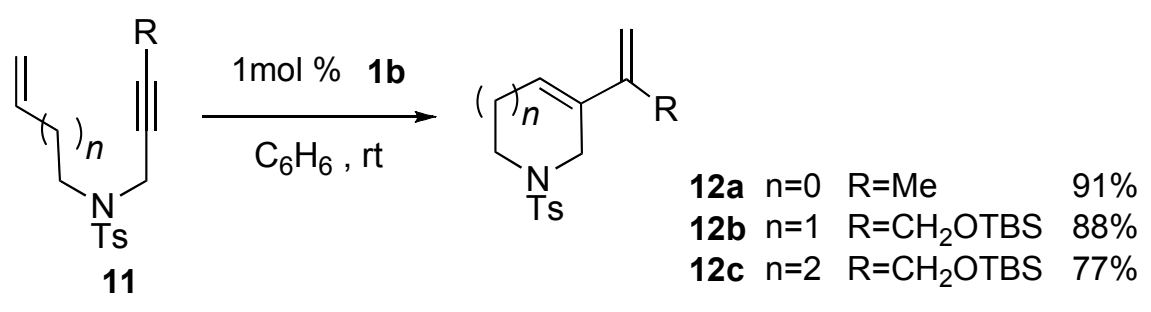<smiles>C=C(C)C1=CCN(C)CC[Al]C1</smiles>

12d $95 \%$<smiles>C=C(C)C1=CCN([AsH3])c2ccccc2OC1</smiles>

12 e $84 \%$<smiles>[3H]N1CC=C(C(=C)C)CN([3H])c2ccccc21</smiles>

12f $97 \%$<smiles>C=C(C)/C1=C/C=[SH](=S)NCCCOC1</smiles>

$12 \mathrm{~g} 74 \%$

Single isomer

In this reaction, enynes $\mathbf{1 1}(\mathrm{R}=\mathrm{H})$, having a terminal alkyne, did not give a satisfactory result [38]. For example, RCM of enyne $\mathbf{1 1 h}$ afforded cyclic compound $\mathbf{1 2 h}$ in only $21 \%$ yield. It is reasoned that an alkene part in product $\mathbf{1 2} \mathbf{h}$ further reacts with ruthenium carbene methylidene complex $\mathbf{1 l}$ to afford 
ruthenium carbene $\mathbf{1 4}$, which would be coordinated by the alkene part to produce 15 . Thus, the catalytic activity would decrease (Scheme 4). In fact, when the reaction of $11 \mathrm{~h}$ using $1 \mathrm{c}$ was carried out under ethylene gas, the catalytic activity was much larger to afford $\mathbf{1 2 h}$ in $90 \%$ yield, even with the use of $1 \mathrm{~mol} \%$ of the ruthenium catalyst 1c. The higher reactivity observed in enyne metathesis in the presence of ethylene gas has often been advantageous in applications to natural product synthesis.

Scheme 4. Metathesis of enyne having terminal alkyne under ethylene gas.

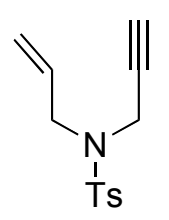

$11 \mathrm{~h}$

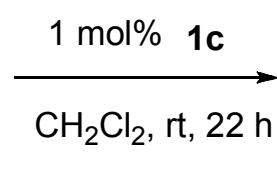

under Ar under Ethylene

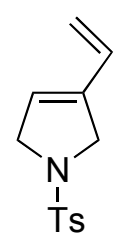

$12 h$

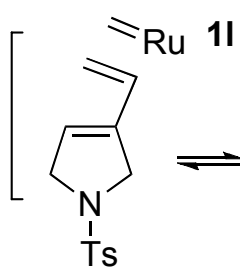

$12 \mathrm{~h}$<smiles>[R1]C1CCC1C1=CCN([AsH])C1</smiles>

13

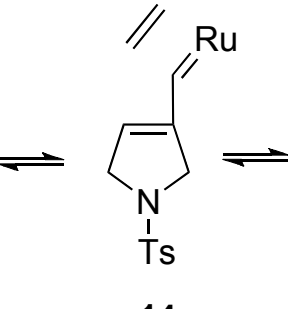

14

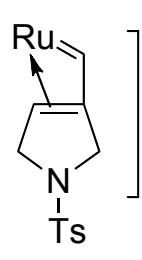

15

When the second-generation ruthenium carbene complexes were used for enyne metathesis, unprecedented results were shown [39-40]. The reaction of enyne 16a or $16 \mathbf{b}$ was carried out using 5 mol $\%$ of $\mathbf{1 f}$ to afford expected metathesis product $17 \mathbf{a}$ or $\mathbf{1 7} \mathbf{b}$ along with six-membered compound $18 \mathbf{a}$ or $\mathbf{1 8 b}$. Use of other second-generation ruthenium carbene complex $1 \mathrm{~g}$ to the reaction of 16a gave a similar result. Presumably, when ruthenium carbene methylidene complex 11 reacts with the alkyne moiety in 16, two regiochemically different pathways are possible (Scheme 5, path A and B). Each carbene complex 19 or $\mathbf{2 0}$ gives a different product 17 or $\mathbf{1 8}$, respectively. On the other hand, if 11 reacts with an alkene moiety (path A'), compound $\mathbf{1 7}$ is formed. In this case, the path B' is a non-productive process. Thus, compound $\mathbf{1 8}$ should be formed via path B. However, it is not clear why two products $\mathbf{1 7}$ and 18 were formed when the second-generation ruthenium carbene complexes were used.

Recently, it was reported that cyclobutene derivative $\mathbf{2 2}$ could be synthesized from enyne 21 using ruthenium carbene complex $1 \mathrm{~g}$ under microwave irradiation conditions with 58\% yield (Scheme 6) [41].

Two synthetic methods of highly functionalized conjugated diene $\mathbf{2 6}$ using ring-closing enyne metathesis were reported (Scheme 7). The reaction of propargyl alcohol 23 and allylboronate $\mathbf{2 4}$ in the presence of 1c gave cyclic boronic ester 25a. In this reaction, enyne 27a should be formed as an intermediate. Treatment of cyclic boronic ester 25a with $\mathrm{H}_{2} \mathrm{O}_{2}$ in aqueous $\mathrm{NaOH}$ gave diol 26a [42-43]. Silicon-tethered ring closing enyne metathesis of $\mathbf{2 7} \mathbf{b}$ by ruthenium carbene catalyst $\mathbf{1 c}$ gave $\mathbf{2 5} \mathbf{b}$, which was subjected to Tamao oxidation to afford diol $\mathbf{2 6 b}$ [44-45]. 
Scheme 5. Enyne metathesis using second generation ruthenium catalysts.<smiles>C=C(C)CC(F)(F)CC#CC</smiles>

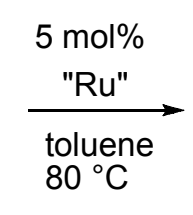<smiles>C=C(C)C1=C(C)CC(F)(F)C1</smiles><smiles>C=C1CC(F)(F)CC(C)=C1C</smiles>

$16 a$ $\mathrm{E}=\mathrm{CO}_{2} \mathrm{Et} \quad$ 1f

$17 a$

$18 \mathrm{a}$

1 . $42 \%$

$42 \%$

$41 \%$<smiles>CC#CCN(C)CC=C(C)C</smiles>

$16 b$

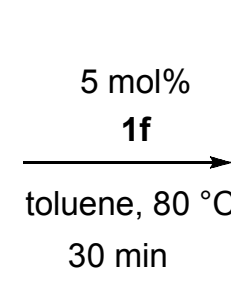<smiles>CC(C)=C(C)C1=CCN(S)C1</smiles>

17b $56 \%$<smiles>CC1=CCN(S)CC1=C(C)C</smiles>

18b $32 \%$

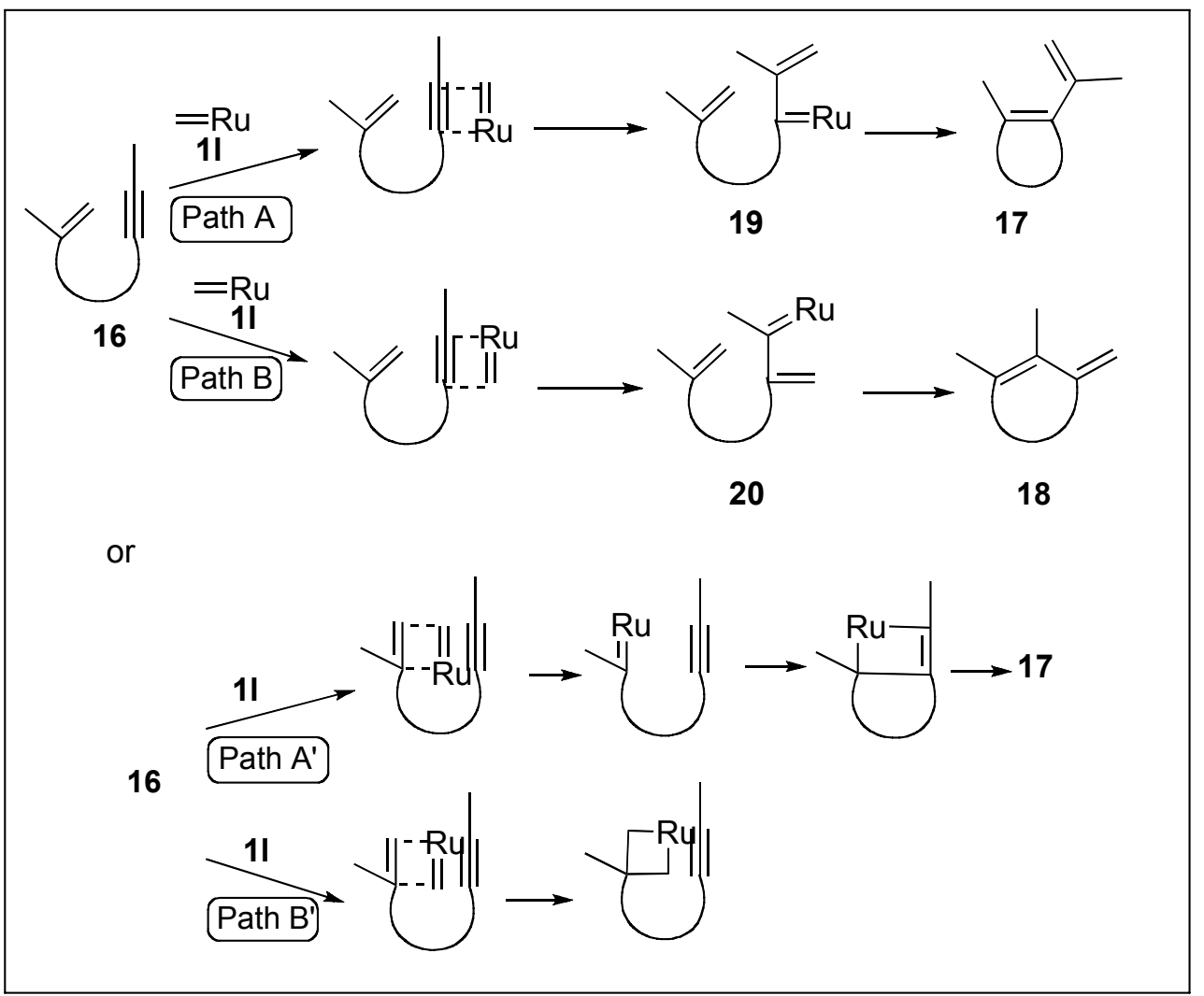

Scheme 6. 1,5-Enyne metathesis.<smiles>C=CCC(C#CBr)c1ccccc1</smiles>

21<smiles>C=C(Br)C1=CCC1c1ccccc1</smiles>

22 
Scheme 7. Synthesis of functionalized diene.

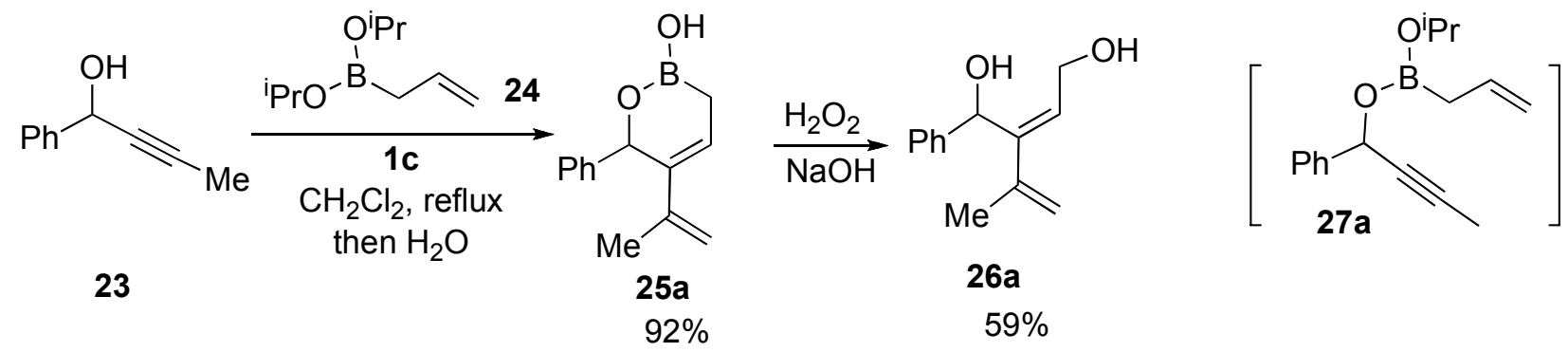<smiles>C=CC[Si](C)(C)OC(C#CCO[Na])CCc1ccccc1</smiles>

Enyne 28a having a silyl ynol ether on the alkyne gave cyclic compound 29a having a silyl enol ether moiety, which was converted into 1-acetylcyclopentene 30a by desilylation. In a similar manner, enyne 28b afforded bicyclic methyl ketone 29b in 68\% yield after deprotection of the silyl group [46]. However, ynoate $\mathbf{2 8 c}$ and yne-phosphonate $\mathbf{2 8 d}$ did not give cyclized compounds. Ene-alkynyl ether 31a or $\mathbf{3 1 b}$ afforded cyclic enol ethers 32a or 32b in good to moderate yield (Scheme 8) [47].

Scheme 8. Metathesis of ene-alkynyl ether.

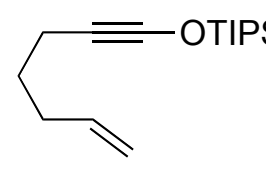

28a<smiles>C=CCC1[C@H](CC#C[OH+][S-])CCC12OCCO2</smiles>

$28 b$

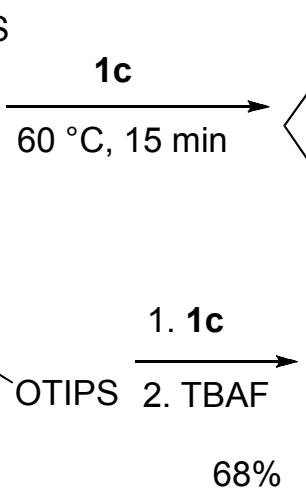

$68 \%$

$29 a$

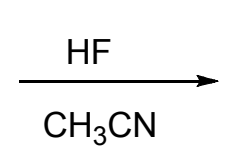

$98 \%$<smiles>CC(=O)C1=CC[C@@H]2[C@H]([CH]1)CCC21OCCO1</smiles>

$29 b$<smiles>CC(=O)C1=CCCC1</smiles>

$30 a$<smiles>C#CO[C@H]1CCC([18OH])O[C@H]1[14CH2]C=C</smiles>

$31 a$

$31 \mathrm{~b}$

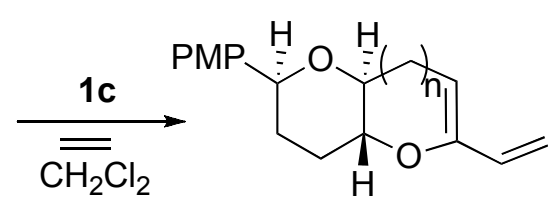

$\begin{array}{lll}\text { 32a } & \mathrm{n}=1 & 77 \% \\ \text { 32b } & \mathrm{n}=2 & 20 \%\end{array}$

RCM of ene-alkynyl amide 33a using $1 \mathrm{~g}$ gave pyrrolidine derivative 34a, which afforded indole derivative 35a by Diels-Alder reaction [48-49]. In a similar manner, one-pot RCM of ene-alkynyl 
amide 33b, a one carbon-elongated homolog, followed by Dield-Alder reaction, gave quinoline derivative 35b in a high yield (Scheme 9) [48-51].

Metathesis of enyne 36a containing conjugated ene-yne using ruthenium catalyst $\mathbf{1 k}$ gave cycloheptene derivative 37a having a triene unit. This reaction did not proceed by first or second-generation ruthenium catalyst $\mathbf{1 c}$ or $\mathbf{1 g}$ (Scheme 10) [52]. Enynes 36b and 36c having internal alkyne and diene afforded eight-membered ring compounds $37 \mathbf{b}$ and $37 \mathbf{c}$ in high yields [53].

The synthesis of substituted styrene 39 was achieved by ring-closing enyne metathesis (Scheme 11). As an application of this method, 1,1'-binaphthyl derivative 41 was prepared [54-55].

Metathesis of allene-yne 42 using molybdenum catalyst 1a gave cyclic compound 43 having an allene moiety. RCM of 42-D gave 43-D, which indicates that the vinylallene skeleton was constructed by a metathesis-type reaction between the alkyne moiety and the proximal carbon-carbon double bond of the allene moiety (Scheme 12) [56].

Scheme 9. Ring-closing metathesis of ene-alkynyl amide.
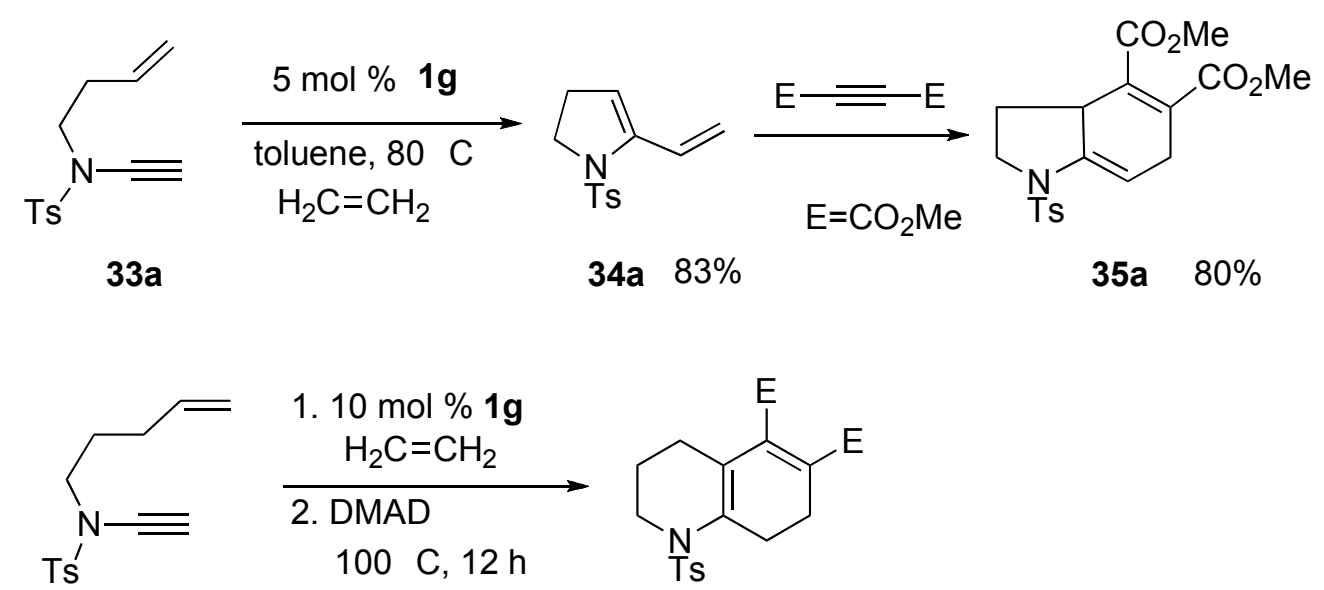<smiles>[13CH3]N1CCCC2=C1CCC(F)=C2F</smiles>

$33 b$

35b $71 \%$

Scheme 10. Reaction of enyne containing diene-yne.
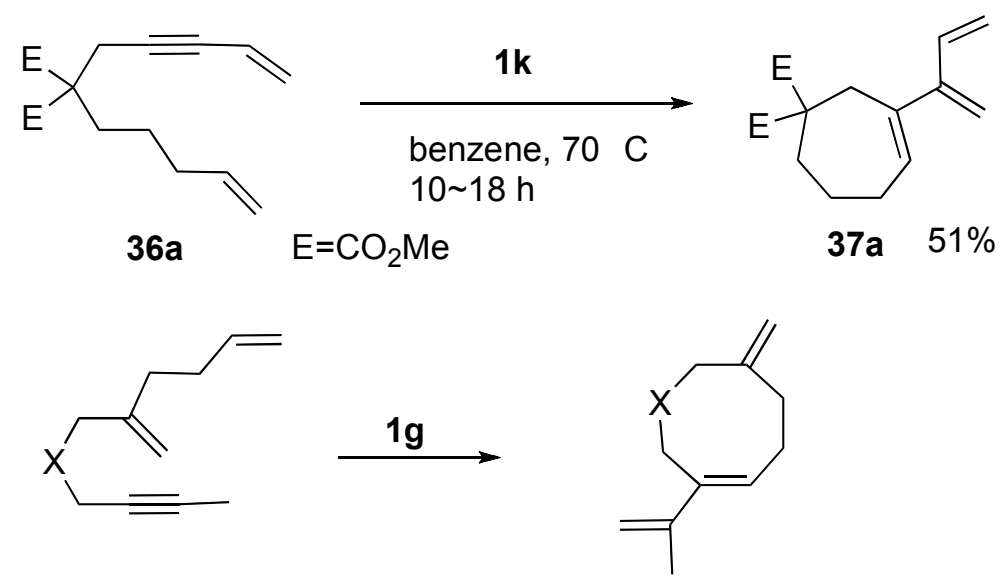

$\begin{array}{llll}\text { 36bX=NTs } & \mathrm{CH}_{2} \mathrm{Cl}_{2}, 50 \mathrm{~min} & \mathbf{3 7 b} & 70 \% \\ \text { 36c } \mathrm{X}=\mathrm{C}\left(\mathrm{SO}_{2} \mathrm{Ph}\right)_{2} & \mathrm{PhCH}_{3}, 24 \mathrm{~h} & \mathbf{3 7 c} & 82 \%\end{array}$


Scheme 11. Synthesis of carbocyclic aromatic ring-closing metathesis.<smiles>C=CC/C(CCC)=C(\CC)C(C#Cc1ccccc1)OC(C)=O</smiles>

38<smiles>C=CCC(O)c1cc(F)ccc1C#Cc1cc2c(cc1C(O)CC=C)OCO2</smiles>

40

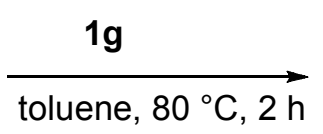

$99 \%$

1. $7,5 \mathrm{~mol} \%$

$1 \mathrm{~g}=$ toluene, $80^{\circ} \mathrm{C}, 2 \mathrm{~h}$

2. $\mathrm{TsOH} \cdot \mathrm{H}_{2} \mathrm{O}$ $\mathrm{rt}, 1 \mathrm{~h}$<smiles>C=C(c1ccccc1)c1ccc(Br)c(Br)c1</smiles>

39

Scheme 12. Ring-Closing Enyne Metathesis (RCM) of allene-yne<smiles>[R]C#CCN([Te])CC=[IH]=C(C)C</smiles>

42 42-D $\quad R=D$

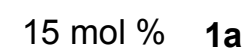

toluene, rt, $3 \mathrm{~h}$

$89 \%$<smiles>Fc1ccc2cccc(-c3cccc4cc5c(cc34)OCO5)c2c1</smiles>

41

Syntheses of Natural Products and Related Compounds Using Ring-Closing Enyne Metathesis (RCM)

The first example of the total synthesis of a natural product using ring-closing enyne metathesis is the synthesis of (-)-stemoamide [57-58]. (-)-Pyroglutamic acid was converted into enyne $\mathbf{4 4}$ having an ester group on the alkyne, and RCM of enyne 44 was carried out in the presence of 4 mol \% of ruthenium-carbene complex $1 \mathrm{c}$ to afford bicyclic compound $\mathbf{4 5}$ in 87\% yield. Conversion of $\mathbf{4 5}$ into 46 smoothly proceeded. From this compound 46, (-)-stemoamide could be synthesized (Scheme 13).

Scheme 13. Total synthesis of (-)-stemoamide.

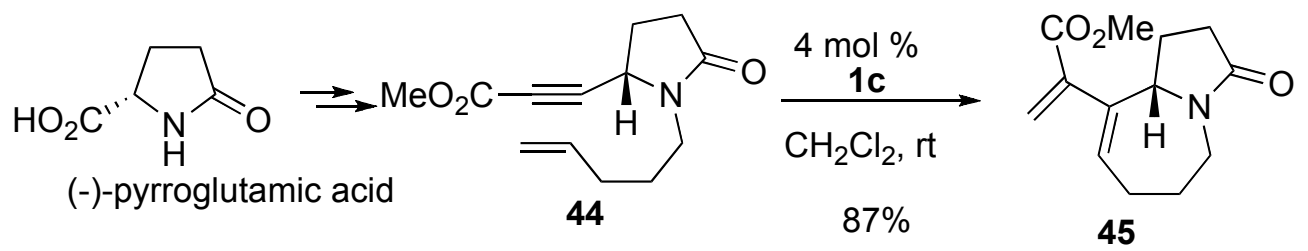

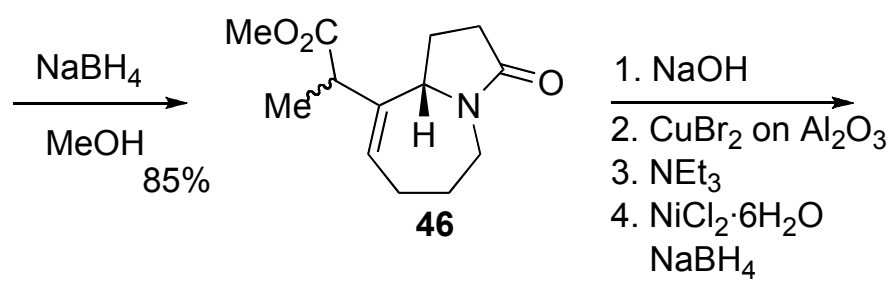<smiles>[Y4][C@]12CCC(=O)N1CCC[C@H]1OC(=O)[C@@H](C)[C@H]12</smiles>

(-)-Stemoamide 
Carbacephem 49a and carbapenem 49b were synthesized from enynes $48 \mathrm{a}$ and $\mathbf{4 8 b}$, which were prepared from 4-acetoxy-azetidinone 47 . The yield of the latter compound $49 \mathrm{~b}$ is lower compared with that of 49a because of the highly strained fused 4,5-membered ring system (Scheme 14) [59-60].

$( \pm)$-Differolide could be easily synthesized by enyne metathesis [61]. Enyne 50 was reacted with 1c to give lactone 51, which was spontaneously dimerized to afford ( \pm )-differolide (Scheme 15).

Scheme 14. Construction of carbacephem and carbepenem skeleton.<smiles>CO[C@H](C)[C@H]1C(=O)N[C@@H]1OC(C)=O</smiles>

47<smiles>C=CCC1C([C@H](C)OC)C(=O)N1CC#CC</smiles>

$48 a$<smiles>C=C(C)C1=CC[C@@H]2[C@H]([C@H](C)OCCCC)C(=O)N2C1</smiles>

$49 a$<smiles>C#CC1[C@H]([C@H](C)O)C(=O)N1CC=C</smiles>

Scheme 15. Synthesis of $( \pm)$-differolide.<smiles>C#CC(=O)OCC=C</smiles>

50

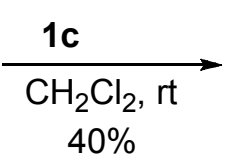
$40 \%$<smiles>C=CC1=CCOC1=O</smiles>

51<smiles></smiles>

( \pm )-Differolide

An enantioselective biomimetic synthesis of longithorone A was accomplished on the basis of the proposed biosynthesis [62]. Two [12]-paracyclophanes 52 and 53 were synthesized from common intermediate 54 by applying enyne metathesis macrocyclization in $42 \%$ and $31 \%$ yields, respectively. Intermolecular Diels-Alder reaction of 52 and 53 provided 59. Deprotection followed by oxidation gave 60, which spontaneously gave longithorone A via transannular Diels-Alder reaction (Scheme 16).

The total synthesis of (+)-anatoxin-a was achieved by Martin [63-64] and Mori [65-66] by the same strategy. The key step is the construction of an azabicyclo[4.2.1]nonene ring system. For that purpose, the 2,5-cis-disubstituted pyrrolidine derivative $\mathbf{6 1}$ having cis-substituents was synthesized from $(+)$-pyroglutamic acid. Enyne metathesis of $\mathbf{6 1}$ was carried out using $\mathbf{1 g}$ to form this ring system. From this azabicyclic compound 62, anatoxin-a could be synthesized (Scheme 17). 
Scheme 16. Total synthesis of (-)-longithorone A.

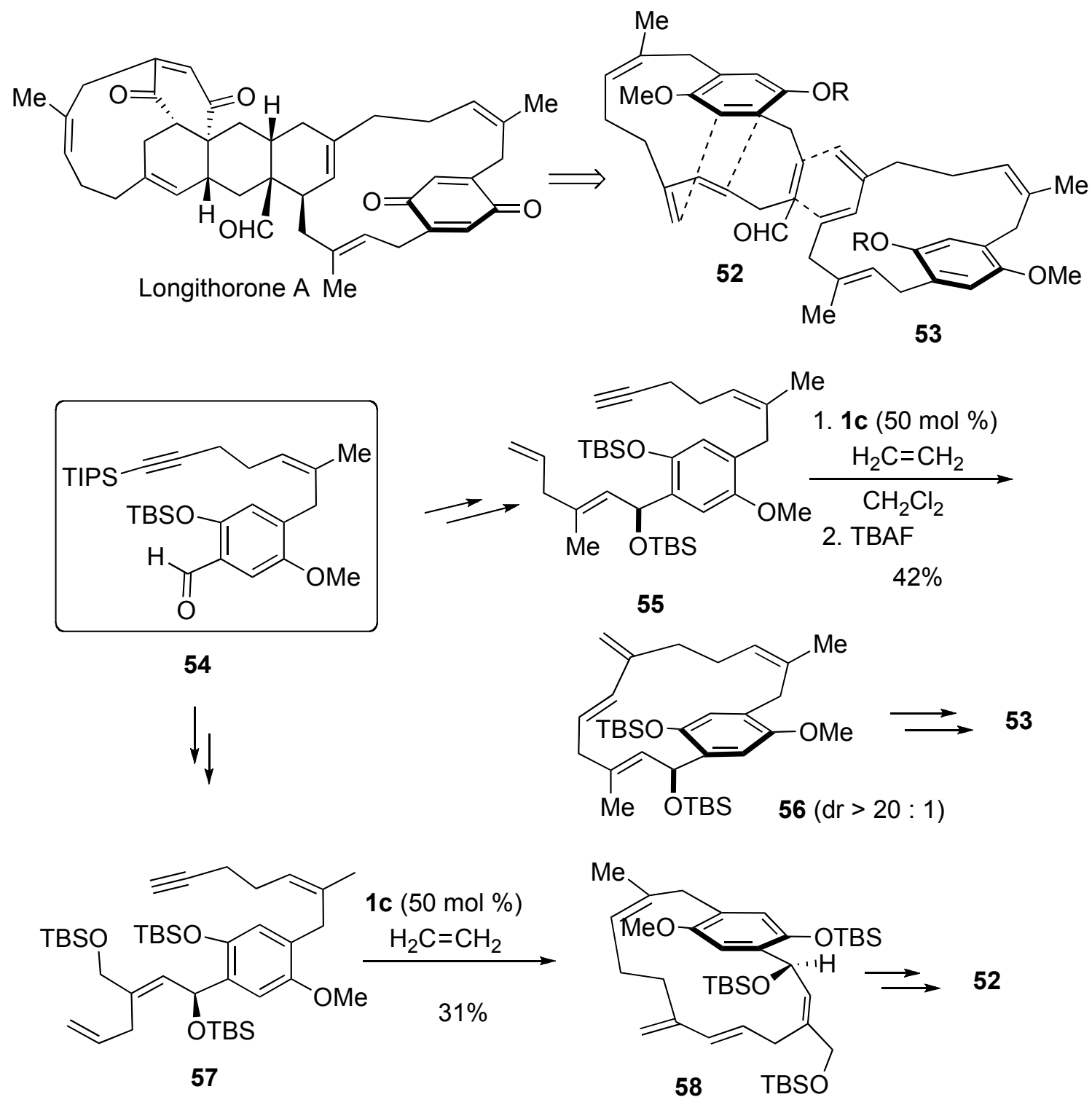

$52+53$

$(E / Z=3.9: 1, d r=1: 1.4)$

$\mathrm{Me}_{2} \mathrm{AICl}$

$\mathrm{CH}_{2} \mathrm{Cl}_{2},-20^{\circ} \mathrm{C}$

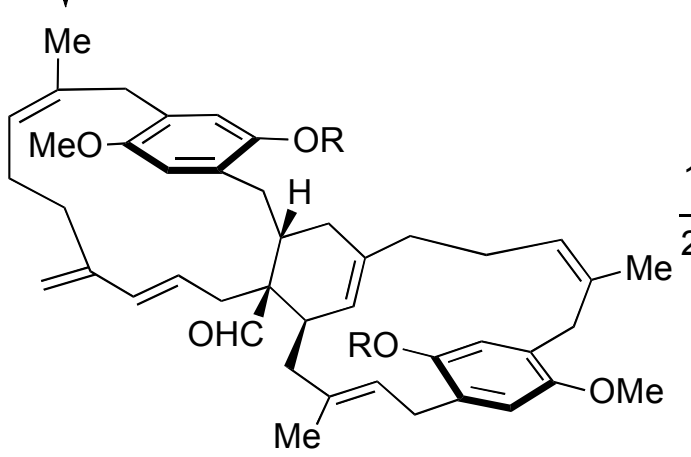

59 : R=TBS

$(\mathrm{dr}=1: 1.4)$

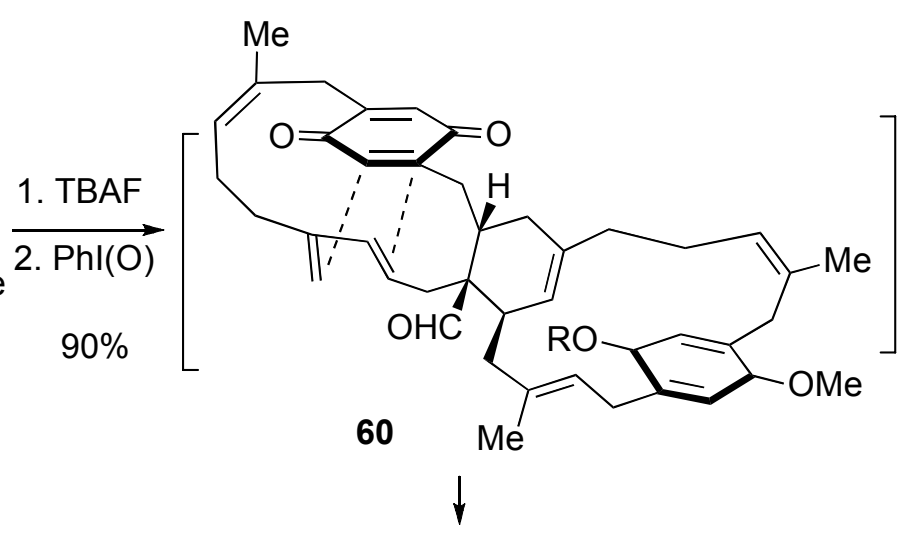

(-)-Longithorone A 
Scheme 17. Total synthesis of anatoxin-A.<smiles></smiles><smiles>CC(=O)C1=CCCC2CCC1N2</smiles>

63

$(+)$-Anatoxin-a· $\mathrm{HCl}$

By a similar procedure, (+)-ferruginine was synthesized from (-)-pyroglutamic acid [67]. Construction of the azabicyclo[3.2.1] octane ring system was carried out using enyne metathesis of 64 . Wacker oxidation to the resultant diene $\mathbf{6 5}$ afforded methyl ketone, and then deprotection followed by methylation gave (+)-ferruginine (Scheme 18).

Scheme 18. Synthesis of (+)-ferruginine.

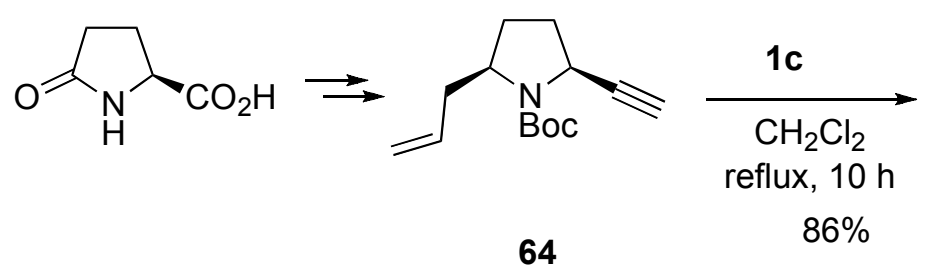

64<smiles></smiles>

65

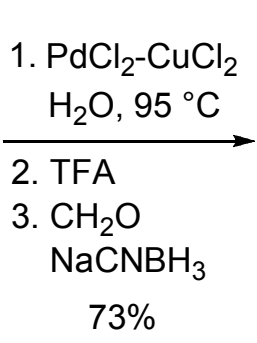

$(+)$-Ferruginine

Kozmin developed a highly efficient synthesis of cyclic compound bearing the methyl ketone functionality from enyne having a silyloxy group on the alkyne (Scheme 8) [46]. As an application of this method, they succeeded in the synthesis of eremophilane [68]. RCM of enyne 66a having a silyloxy group on the alkyne followed by treatment with HF gave cycloalkene $\mathbf{6 8 b}$ having the methyl ketone functionality. Hydrogenation of the double bond in compound $68 \mathrm{~b}$ gave 69. From this compound 69, $\alpha$ - and $\beta$-eremophilane could be synthesized (Scheme 19).

New allocolchinoids functionalized at $\mathrm{C} 10$ or C11 in the C ring were synthesized using the RCM of enyne $\mathbf{7 0}$ for the construction of the seven-membered ring. The reaction proceeded smoothly to give $\mathbf{7 1}$ using 19 in 92\% yield. Deprotection followed by PCC oxidation gave 72, which was subjected to a Diels-Alder-aromatization sequence to form 73. Amination of $\mathbf{7 3}$ followed by acetylation gave allocholchicines (Scheme 20) [69]. 
Scheme 19. Total synthesis of eremophilane.

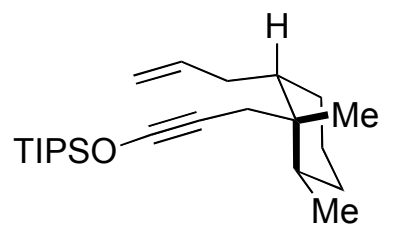

$66 a$

69

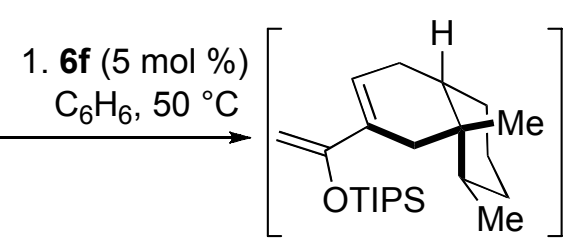

$67 a$

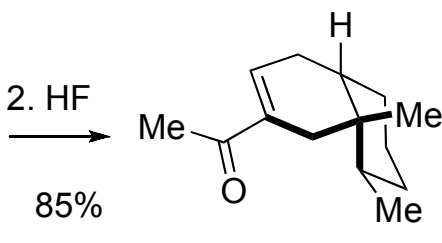

$68 b$

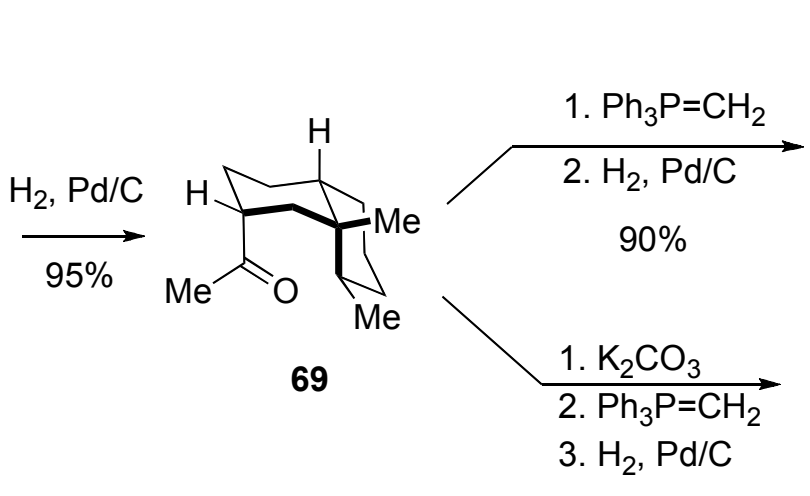

$77 \%$

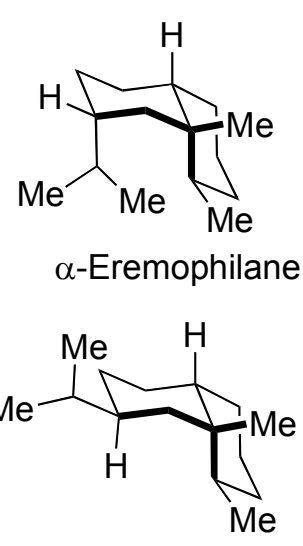

$\beta$-Eremophilane

Scheme 20. Synthesis of allo-colchicine.<smiles>C#CC([Se]C(=O)O)c1c(CCC=C)cc(OC)c(OC)c1OC</smiles>

70<smiles>C=CC1=CCCc2cc(OC)c(OC)c(OC)c2C1[18OH]</smiles>

71<smiles>C=CC1=Cc2c(cc(OC)c(OC)c2OC)CCC1=O</smiles>

72

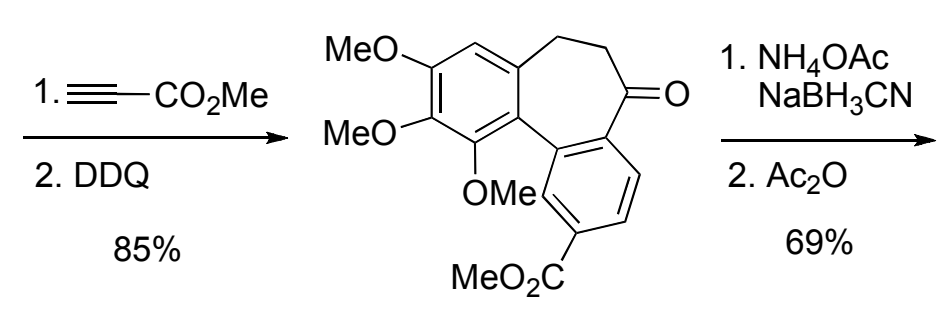

73<smiles>CNCCN[C@@H]1CCc2cc(OC)c(OC)c(OC)c2-c2cc(C(C)=O)ccc21</smiles>

allo-Colchicine

The agalacto-spirolactone B subunit of quartromicins has been synthesized using the Claisen-Ireland/ RCM of enyne approach by Haudrechy et al. [70]. Enyne $\mathbf{7 4}$ was treated with $\mathbf{1 g}$ in toluene at $80{ }^{\circ} \mathrm{C}$ to afford $\mathbf{7 5}$ in $73 \%$ yield. From this compound $\mathbf{7 5}$, subunit B of quartromicin was synthesized (Scheme 21).

An enantioselective synthesis of (-)-galanthamine was realized in 11 steps starting from isovanillin (Scheme 22). The enyne 76 (92\% ee) underwent an efficient RCM reaction in the presence of $3 \mathrm{~mol} \%$ of $\mathbf{1 c}$ to give diene $\mathbf{7 7}$ in $85 \%$ yield. Hydroboration of the terminal alkene of $\mathbf{7 7}$ followed by oxidation gave homoallylic alcohol $\mathbf{7 8}$ in excellent yield, and palladium-catalyzed cyclization followed by $\mathrm{SeO}_{2}$ oxidation gave 79. Mesylation of 79 followed by deprotection afforded (-)-galanthamine [71]. 
Scheme 21. Synthesis of subunit of quartromicin.

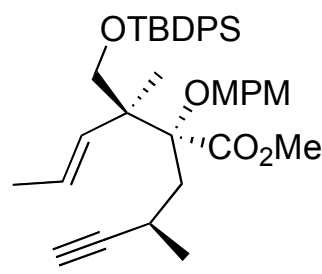

74

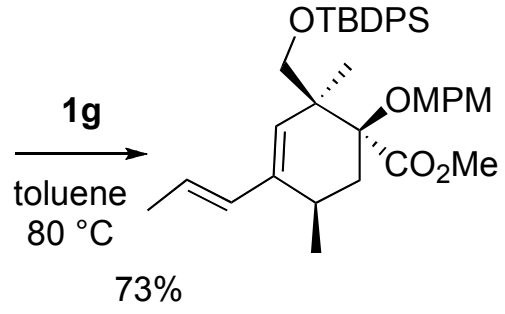

75<smiles></smiles>

subunit B of Quartromicin

Scheme 22. Total synthesis of galanthamine.<smiles>C#CC(CCC=C)Oc1c(OC)ccc(CN(C)C(C)=O)c1I</smiles>

76<smiles>CC(C)[GeH3]</smiles>
$85 \%$<smiles>C=C/C=C\CC1(Oc2c(OC)ccc(CN(C)C(C)=O)c2I)CCCC1</smiles>
77<smiles>COc1ccc(CN(C)C(C)=O)c(I)c1OC1CCCC=C1CCO</smiles>

78

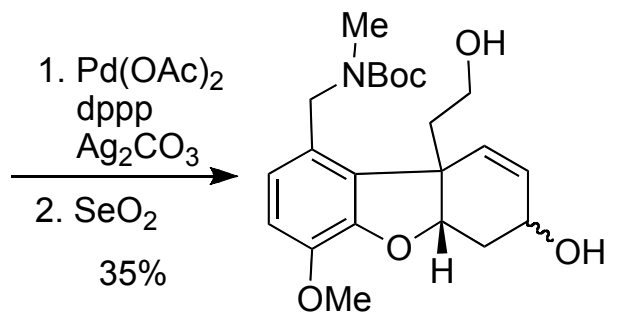

$79 \alpha: \beta=4.8: 1$<smiles>CCC12C=C[C@@H](O)C[C@H]1Oc1c(OC)ccc(CNC)c12</smiles>

(-)-Galanthamine

For the synthesis of angucyclinone-type natural products, a concise and highly enantioselective route was developed (Scheme 23). Chiral vinylcyclohexene derivative 81 was synthesized using RCM of enyne $\mathbf{8 0}$ under an atmosphere of ethylene in high yield. Intermolecular Diels-Alder reaction of $\mathbf{8 1}$ and $\mathbf{8 2}$ followed by aromatization gave compound $\mathbf{8 3}$ having benz[a]anthraquinone skeleton. Utilization of this strategy, total synthesis of YM-181741, (+)-ochromycinone, (+)-rubiginone $\mathrm{B}$ have been accomplished [72].

Stereoselective total synthesis of $(+)$-valienamine was reported utilizing ring-closing enyne metathesis (Scheme 24) [73]. 
Scheme 23. Synthesis of benz[a]anthraquinone skeleton.

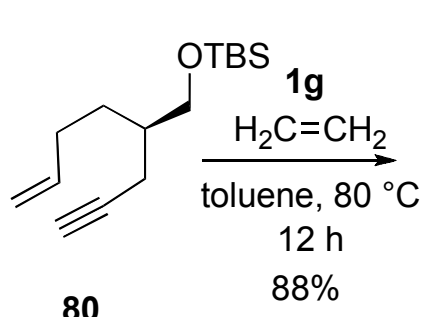

80<smiles>C=CC1=CCCC(C[O])C1</smiles>

81<smiles>COc1cccc2c1C(=O)C=C(Br)C2=O</smiles>

3. hv, $\mathrm{O}_{2}$

4. TBAF<smiles>O=C1c2cccc(O)c2C(=O)c2c1ccc1c2CC[C@H](CO)C1</smiles>

$34 \%$<smiles>O=C1c2ccc3c(c2C(=O)c2cccc(O)c21)C(=O)C[C@H](CO)C3</smiles>

YM-181741<smiles>CC1CC(=O)c2c(ccc3c2C(=O)c2cccc(O)c2C3=O)C1</smiles>

(+)-ochromycinone<smiles>[Y4]C1CC(=O)c2c(ccc3c2C(=O)c2cccc(OC)c2C3=O)C1</smiles>

(+)-rubiginone $\mathrm{B}_{2}$

Scheme 24. Synthesis of (+)-valienamine.<smiles>C#C[C@H](OC)[C@@H](OC)[C@@H](OC)C(C=C)NC(=O)O</smiles>

84

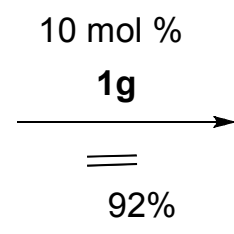
MON<smiles>C=CC1=CC(NC=O)C(OC)[C@H](OC)C1OC</smiles>

85

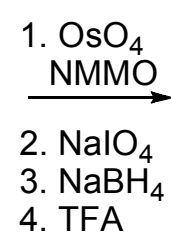

$42 \%$<smiles>NC1C=C(CO)C(O)[C@H](O)C1O</smiles>

$(+)$-Valienamine

An interesting acceleration effect of an allylic hydroxy group on ring-closing enyne metathesis has been demonstrated. Ring-closing enyne metathesis of terminal alkynes possessing an allylic hydroxy group proceeded smoothly. The synthesis of $(+)$-isofagomine with the aid of this efficient reaction has been demonstrated [74].

Grubbs demonstrated the synthesis of various fused polycyclic compounds using tandem metathesis reaction. A steroidal skeleton could be constructed using tandem enyne metathesis. Treatment of polyenyne $\mathbf{8 6}$ having double and triple bonds at the appropriate positions in the carbon chain gave compound $\mathbf{8 7}$ in high yield in one step, although many processes were contained in this reaction as shown in Scheme 25 [75].

Tandem ring-closing enyne metathesis followed by cross olefin metathesis is interesting and useful because the reaction process is shortened and the yield is raised compared with that of the stepwise reaction. One-pot RCM-CM reaction was realized by Royer et al. (Scheme 26). The RCM of $\mathbf{8 8}$ in the presence of an excess amount of methyl acrylate using ruthenium carbene complex $\mathbf{1 g}$ gave cyclic compound $\mathbf{8 9}$ in good yield. The reaction would proceed via the formation of $\mathbf{9 0}$ and subsequent CM with methyl acrylate to produce 89 [76]. 
Scheme 25. Construction of a steroidal skeleton.

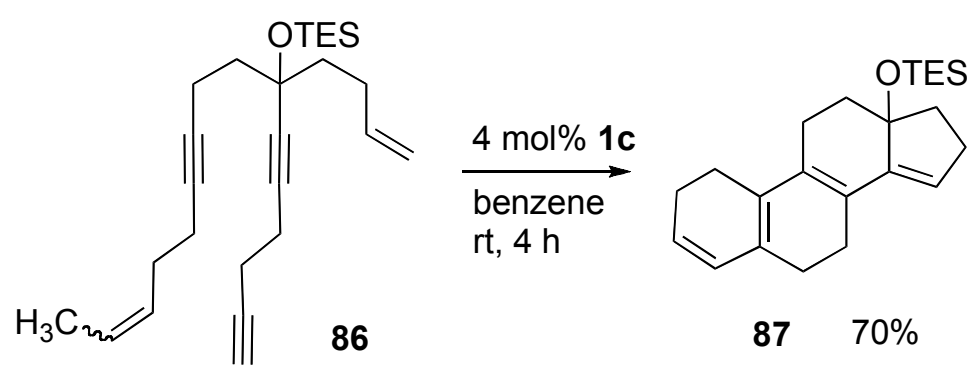

\section{$\underline{\text { Reaction Course }}$}

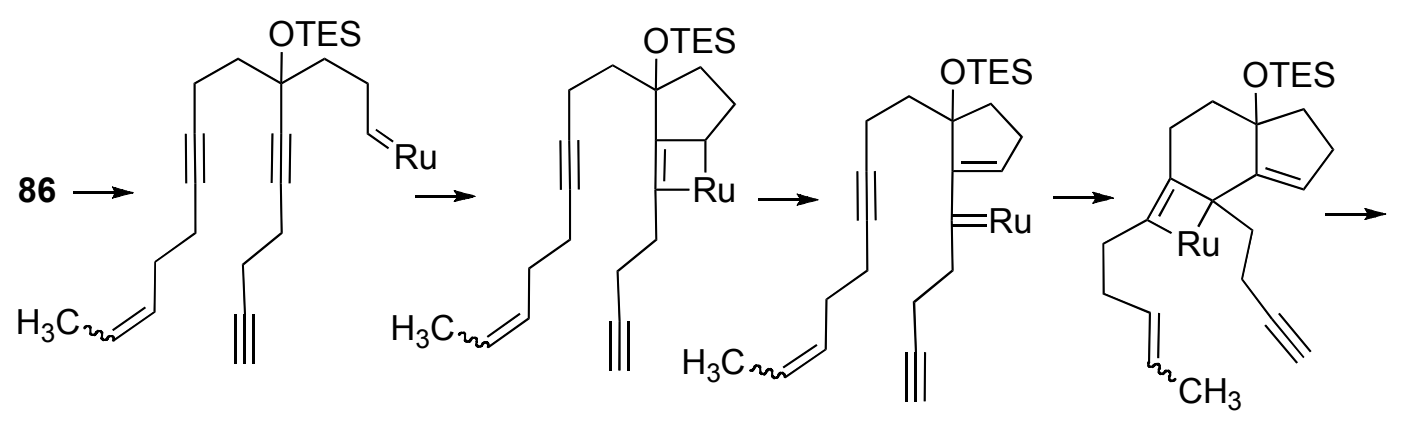

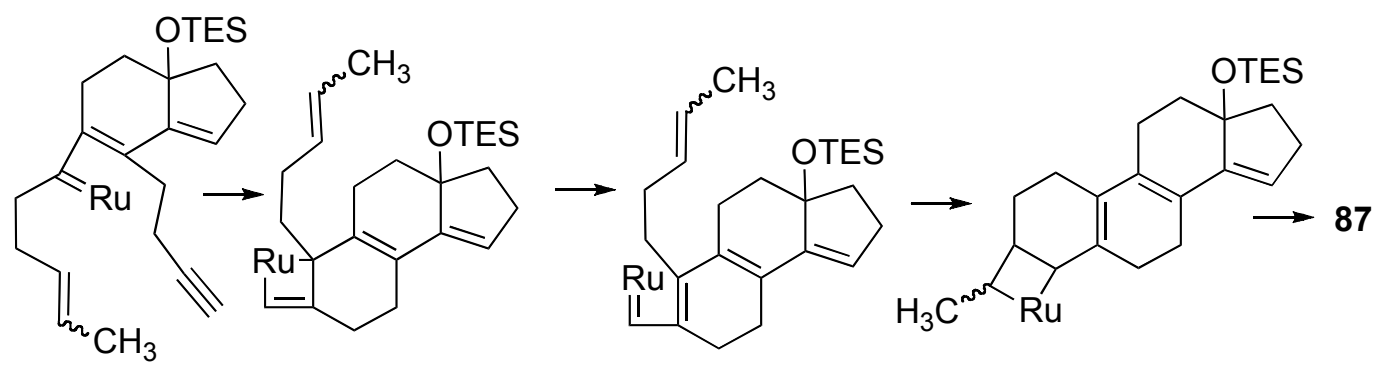

Scheme 26. One-pot reaction of RCM-CM.<smiles>C#CC([OH2+])c1ccccc1OCC=C</smiles>

88

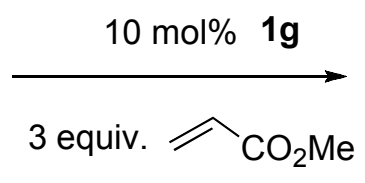

$\mathrm{CH}_{2} \mathrm{Cl}_{2}, 40 \mathrm{C} 12 \mathrm{~h}$<smiles>CC(=O)C=CC1=CCOc2ccccc2C1OC(C)(C)C</smiles>

89<smiles>C=CC1=CCOc2ccccc2C1OC(C)(C)C</smiles>

90

Synthesis of anthramycine derivative 99a was achieved using RCM and CM (Scheme 27) [77]. L-Methionine was converted into enyne 91, and RCM of 91 using 1c gave pyrrolidine derivative 92. Deprotection followed by condensation with commercially available acid chloride $\mathbf{9 3}$ gave $\mathbf{9 4}$. Reductive cyclization of 94 using $\mathrm{Zn}-\mathrm{AcOH}$ followed by treatment with dilute $\mathrm{HCl}$ gave pyrrolo-1,4-benzodiazepinone 95. To convert the vinyl group into an $\alpha, \beta$-unsaturated ester group, olefin cross metathesis with ethyl acrylate was carried out using catalyst $\mathbf{1 j}$ [20-21]. The reaction proceeded smoothly to give compound 96 in $60 \%$ yield. Isomerization of the double bond in the pyrrolidine ring using $\mathrm{RhCl}_{3} \cdot \mathrm{H}_{2} \mathrm{O}$ afforded desired compound 97, the amide group of which was converted into aminal 
98. Conversion of 98 into ester 99a was achieved. Stille has already reported the conversion of $99 \mathbf{b}$ into $(+)$-anthramycin.

Scheme 27. Synthesis of anthramycin derivative.

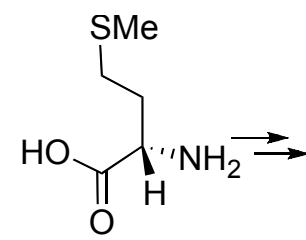

L-methionine

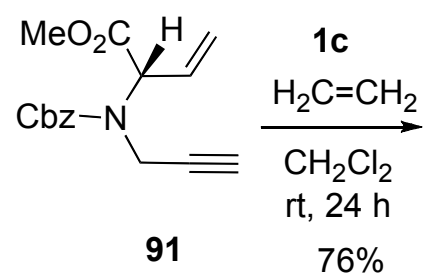<smiles>C=CC1=C[C@H](C(C)=O)N(C(=O)OCc2ccccc2)C1</smiles>

92

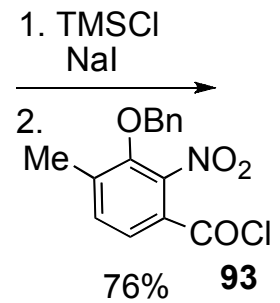<smiles>C=CC1=CC(C(C)=O)(C(C)=O)N(C(=O)c2ccc(C)c(OCc3ccccc3)c2[N+](=O)[O-])C1</smiles><smiles>C=CC1=C[C@H]2C(=O)Nc3c(ccc(C)c3OCc3ccccc3)C(=O)N2C1</smiles>

$10 \mathrm{~mol} \mathrm{\%}$

1j<smiles>C=CC(=O)OCC</smiles>

95

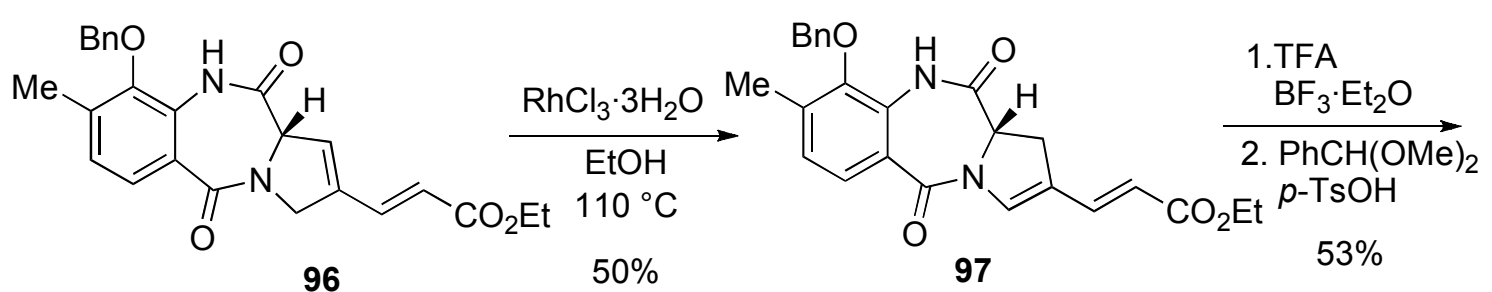<smiles>[R]C=CC1=CN2C(=O)c3ccc(C)c4c3N(C(c3ccccc3)O4)C(O)[C@H]2CC2=CN1C(=CN1C(=O)c3ccc(C)c4c3N(C(=O)[C@H]1[2H])C(c1ccccc1)O4)C=CC=C2</smiles><smiles>Cc1ccc2c(c1O)N[C@H](O)[C@H]1CC(/C=C/C(N)=O)=CN1C2=O</smiles>

(+)-Anthramycin

Scheme 28. Synthesis of (-)-dihydroxanthatin.<smiles>C#C[C@H](C)C[C@H]1OC(=O)C[C@@H]1CC=C</smiles>

100<smiles>C=CC1=CC[C@H]2[C@@H](C[C@@H]1C)OC(=O)[C@@H]2C</smiles>

101<smiles>C=CC(=O)CCCCCC(C)=O</smiles>

(-)-Dihydroxanthatin

Morken and Evans succeeded in the synthesis of (-)-dihydroxanthatin using RCM and CM [78]. Enyne metathesis of $\mathbf{1 0 0}$ using $\mathbf{1 g}$ followed by methylation gave bicyclic compound 101. Cross metathesis of $\mathbf{1 0 1}$ and methyl vinyl ketone in the presence of $\mathbf{1 g}$ afforded (-)-dihydroxanthatin (Scheme 28). 
Martin succeeded in the first total synthesis of the novel sesquiterpene 8-epi-xanthatin [79]. Palladium-catalyzed carbonylation of $\mathbf{1 0 2}$ followed by desilylation gave lactone 104. The total synthesis of 8-epi-xanthatin was directly achieved by tandem RCM-CM of lactone 104 using $\mathbf{1 h}$ in the presence of an excess amount of methyl vinyl ketone in one step (Scheme 29).

Scheme 29. Synthesis of 8-epi-xanthatin.

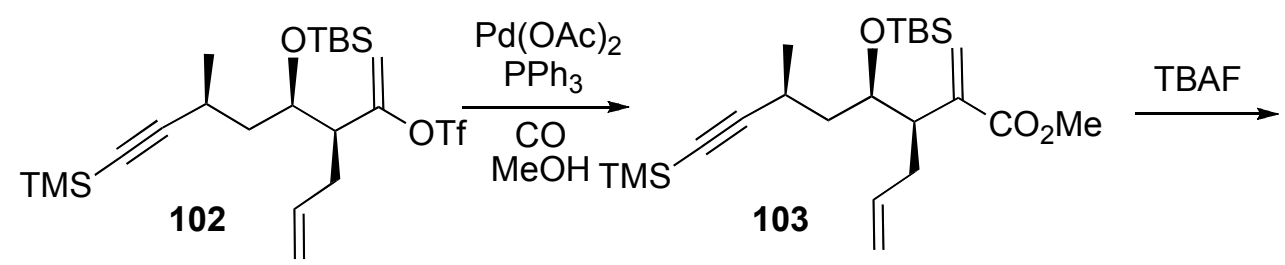<smiles>C#CC(C)CC1OC(=O)C(=C)C1CC(C)C</smiles><smiles>C=C1C(=O)OC2C[C@H](C)C(/C=C/C(C)=O)=CCC12</smiles>

8-epi-Xanthatin

Scheme 30. Construction of $A B C$ ring of lancifodilactone $\mathrm{G}$.

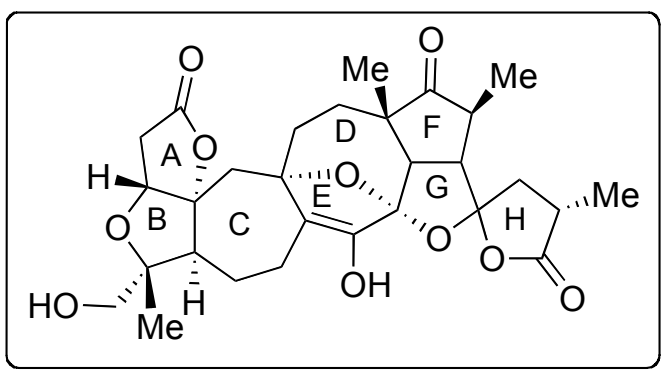

Lancifodilactone $\mathrm{G}$

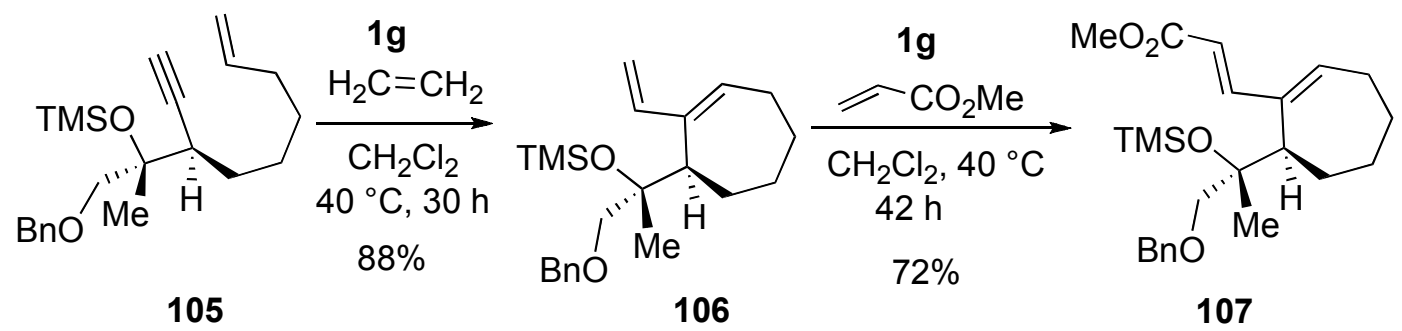

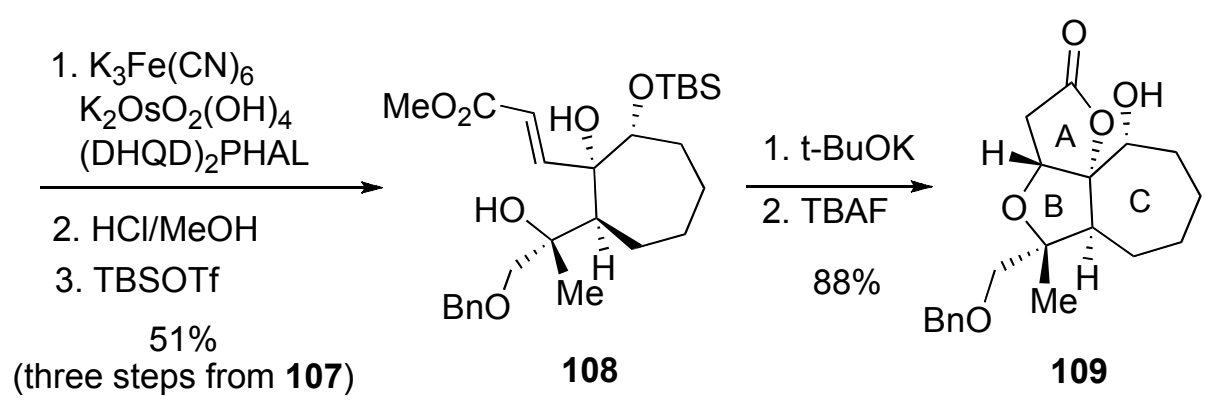


Lancifodilactone $\mathrm{G}$ has eight rings with complicated cyclic connectivity. Paquette synthesized ABC segment 109 of lancifodilactones $\mathrm{G}$ using ring-closing enyne metathesis and then cross metathesis as the key steps (Scheme 30) [80]. Ring-closing enyne metathesis of 105 using $1 \mathrm{~g}$ in $\mathrm{CH}_{2} \mathrm{Cl}_{2}$ gave cycloheptene derivative 106, which was subjected to cross metathesis with methyl acrylate to give $\alpha, \beta$-unsaturated ester 107. From this compound 107, target compound 109 was obtained.

\section{Ring-Closing Dienyne Metathesis}

Grubbs reported an ingenious method for synthesizing bicyclic compounds from dienynes taking advantage of the metathesis reaction (Scheme 31) [81-82]. When a benzene solution of dienyne 110a was stirred in the presence of $3 \mathrm{~mol} \%$ of $\mathbf{1 b}$, bicyclic compound 111a was obtained in $95 \%$ yield in one operation. In the case of $\mathbf{1 1 0 b}$, two bicyclic compounds $\mathbf{1 1 1 b}$ and $\mathbf{1 1 2 b}$ were formed. Furthermore, dienyne 110c gave tricyclic compound 111c in a quantitative yield. Probably, ruthenium carbene methylidene complex 11 reacts with an alkene moiety in dienyne $\mathbf{1 1 0 b}$ to give ruthenium carbene complex 113 and/or 116, which reacts with an alkyne part to give ruthenacyclobutene 114 and/or 117. Ring opening of this complex gives ruthenium carbene complex 115 and/or 118, which reacts with the alkene part intramolecularly to give ruthenacyclobutane. Ring opening of this complex gives bicyclic compounds, 111 and/or 112.

Scheme 31. Dienyne metathesis.
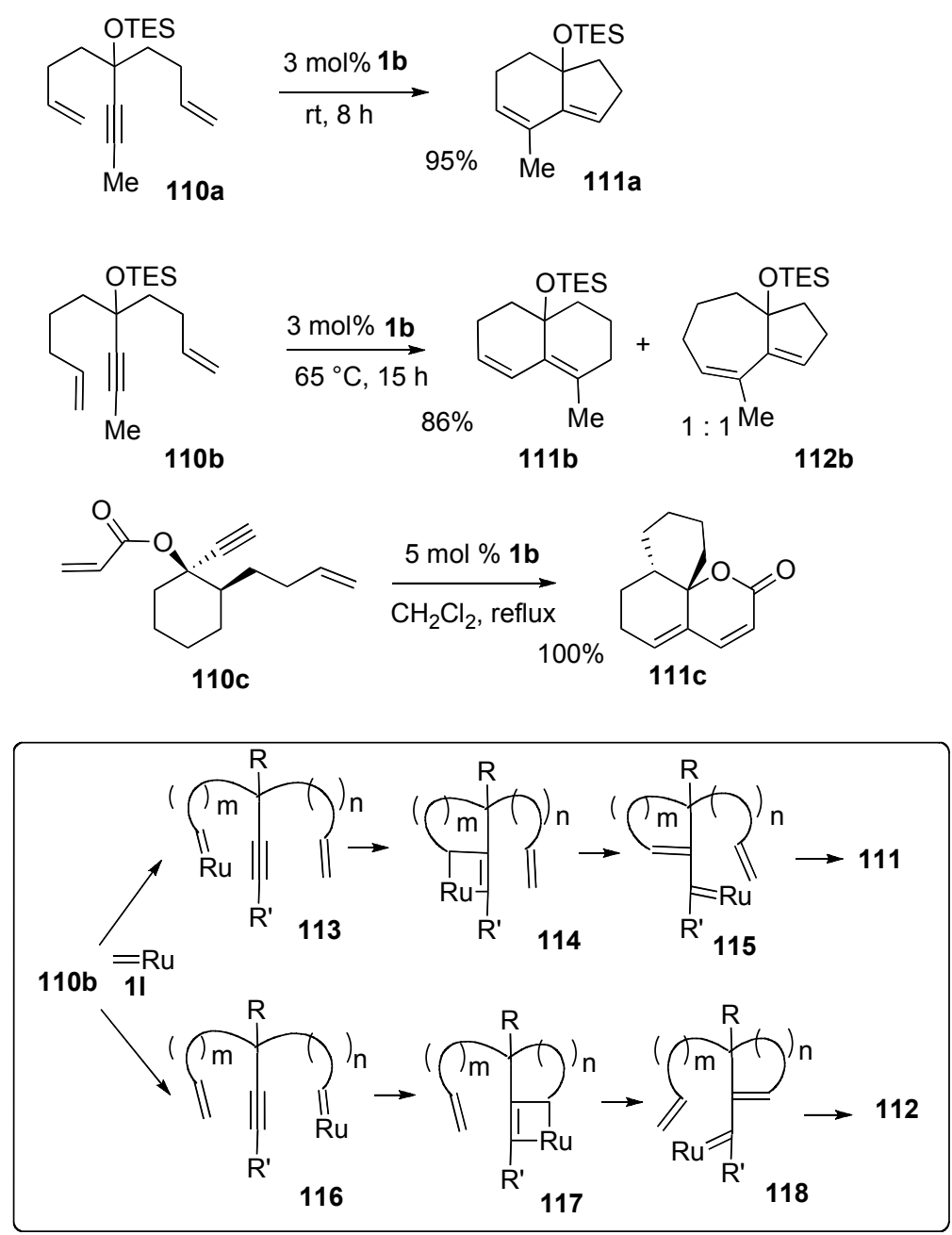
The transformation of dienyne into the bicyclic vinylboronate is shown in Scheme 32 . Alkynylboronate 119 cleanly underwent ruthenium-promoted metathesis in 70\% yield. The resultant bicyclic dialkenylboronic ester 120 was efficiently oxidized to corresponding enoate $\mathbf{1 2 1}$ by treatment with $\mathrm{Me}_{3} \mathrm{NO}$ in refluxing THF. In the presence of $\mathrm{CsF}$, reaction of $\mathbf{1 2 0}$ with 3-bromobenzonitrile under the catalysis of $\mathrm{PdCl}_{2}$ (dppf) furnished cross-coupling product 122 (Scheme 32) [83].

A versatile route for the synthesis of a phosphorus oxide template was presented (Scheme 33). Dienyne metathesis using $1 \mathrm{~g}$ on substrate $\mathbf{1 2 3}$ led to the formation of bicyclic phosphorus heterocycles 124 [84].

Scheme 32. Reaction of eneyne having alkynyl boronate.

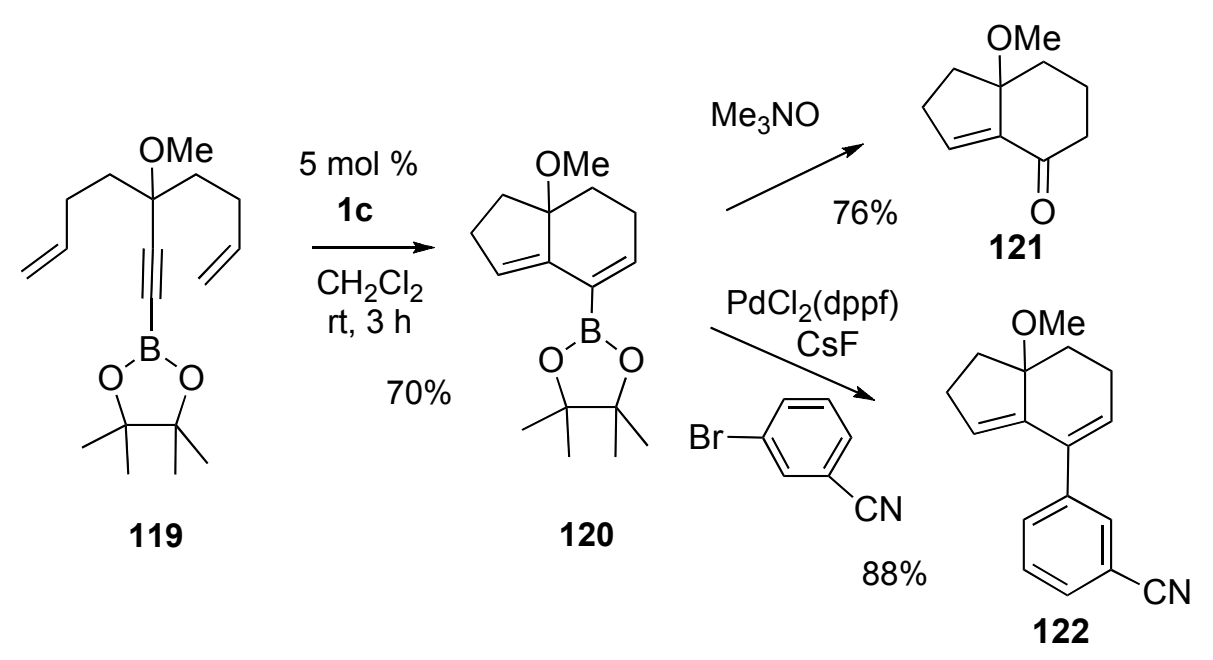

Scheme 33. Synthesis of phosphorous mono- and bicycles by RCM.

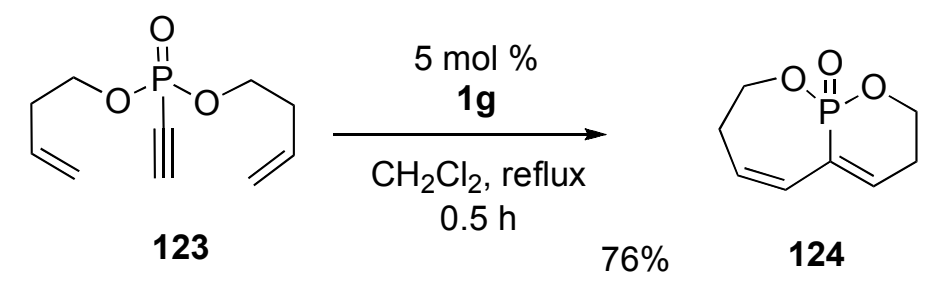

Base-promoted isomerization of propargyl amide 125 gave alkynyl amide 126, dienyne metathesis of which gave bicyclic compounds $\mathbf{1 2 7}$ and $\mathbf{1 2 8}$ in a ratio of 1:1 (Scheme 34) [85].

Scheme 34. Base-promoted isomerization of propargyl amide followed by RCM.

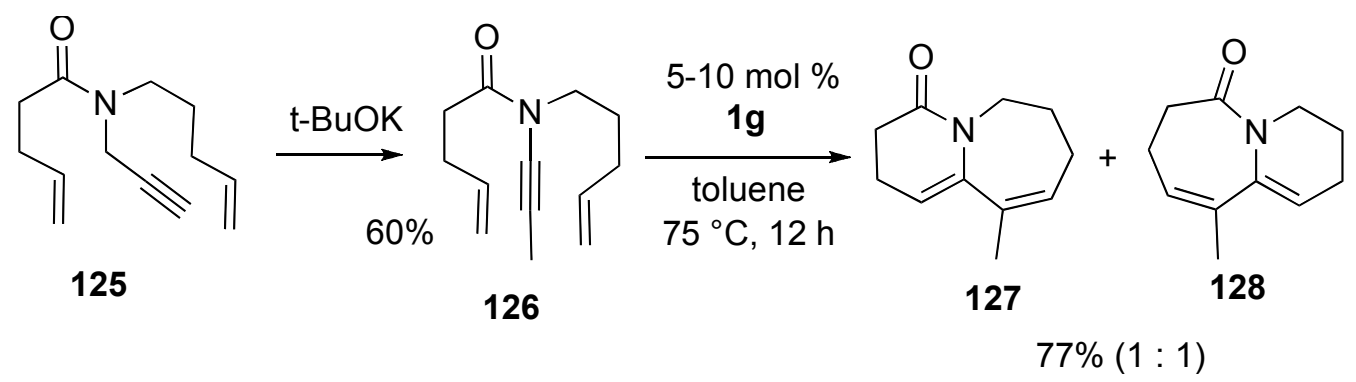


Dienyne metathesis of $\beta$-carboline derivative 130 afforded oxidized pentacyclic compound 131 related to alkaloids containing a $\beta$-carboline unit. The starting material 129 was readily synthesized from tryptamine derivative (Scheme 35) [86].

Scheme 35. Dienyne metathesis of $\beta$-carboline derivative.

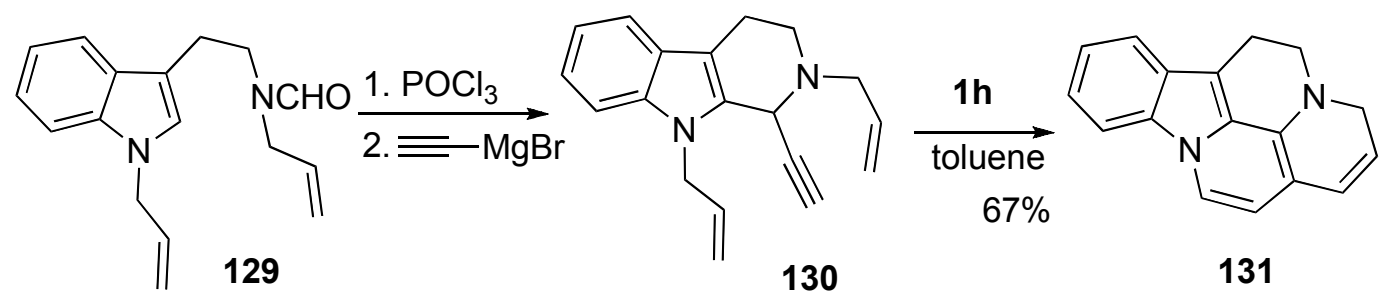

Syntheses of Natural Products and Related Compounds Using Dienyne Metathesis

Dienyne metathesis is a useful method for the synthesis of fused bicyclic or polycyclic compounds in one step, and many bond fissions and bond formations occur during the dienyne metathesis. Therefore, when dienyne metathesis is used for the total synthesis of natural products, retro synthetic analysis for them is unique, and the reaction process is generally shortened.

A new approach to the synthesis of a linearly fused 6-8-6 tricarbocyclic ring system was realized using dienyne metathesis [87]. This ring system is a carbon framework analogous to the proposed transition state of isomerization of previtamin $\mathrm{D}_{3}$ to vitamin $\mathrm{D}_{3}$. The starting dienyne 134, which was prepared by condensation of indenone 132 and alkyne 133 followed by deprotection and then introduction of an allyl group, was reacted with 1c to give target molecule $\mathbf{1 3 5}$ as a diastereomeric mixture at the $\mathrm{C}-10$ position in $48 \%$ yield (Scheme 36 ).

Scheme 36. Synthesis of a [6.4.0]carbocyclic system.
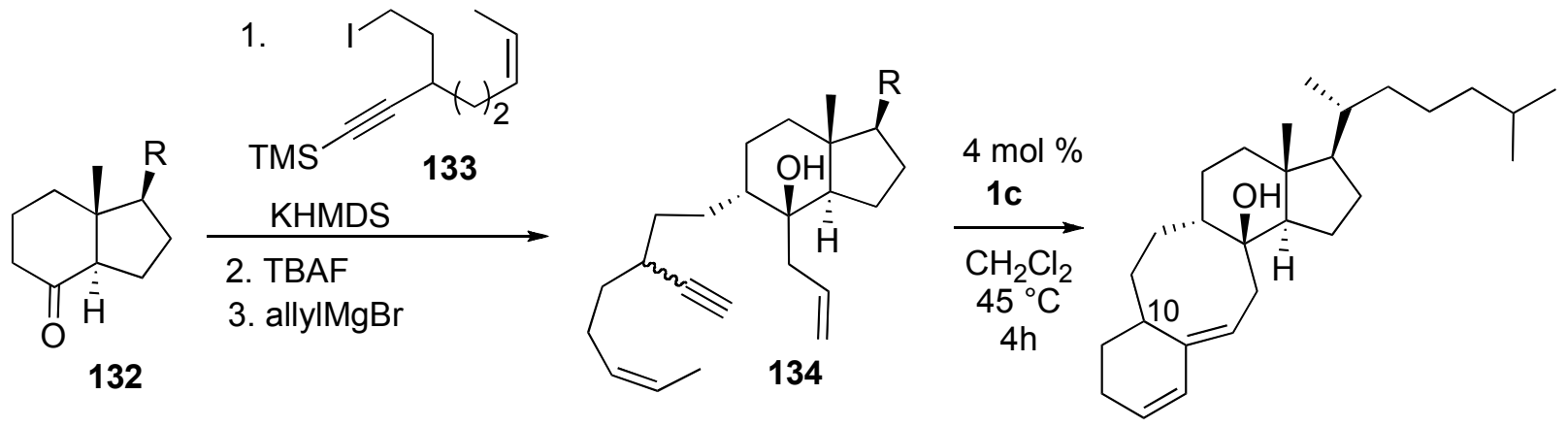

$13548 \%$ (6.5: 1 at C10 isomer)

A concise route to a key intermediate in the total synthesis of guanacastepene A using dienyne metathesis was reported [88]. The main feature includes the construction of fused seven- and six-membered rings. Metathesis of dienyne 136 was carried out using $1 \mathrm{~g}$ and a mixture of tricyclic compounds 137 was obtained in a ratio of 1 to 1 . Selective epoxidation followed by introduction of an allyloxy group in the presence of $\mathrm{Yb}(\mathrm{OTf})_{3}$ gave 138a and 138b. Protection of the hydroxyl group of 138a gave 139a, and then it was led to compound 140, which was already converted into ( \pm )-guanacastepene A (Scheme 37). 
Scheme 37. Synthesis of $( \pm)$-guanacastephene A.
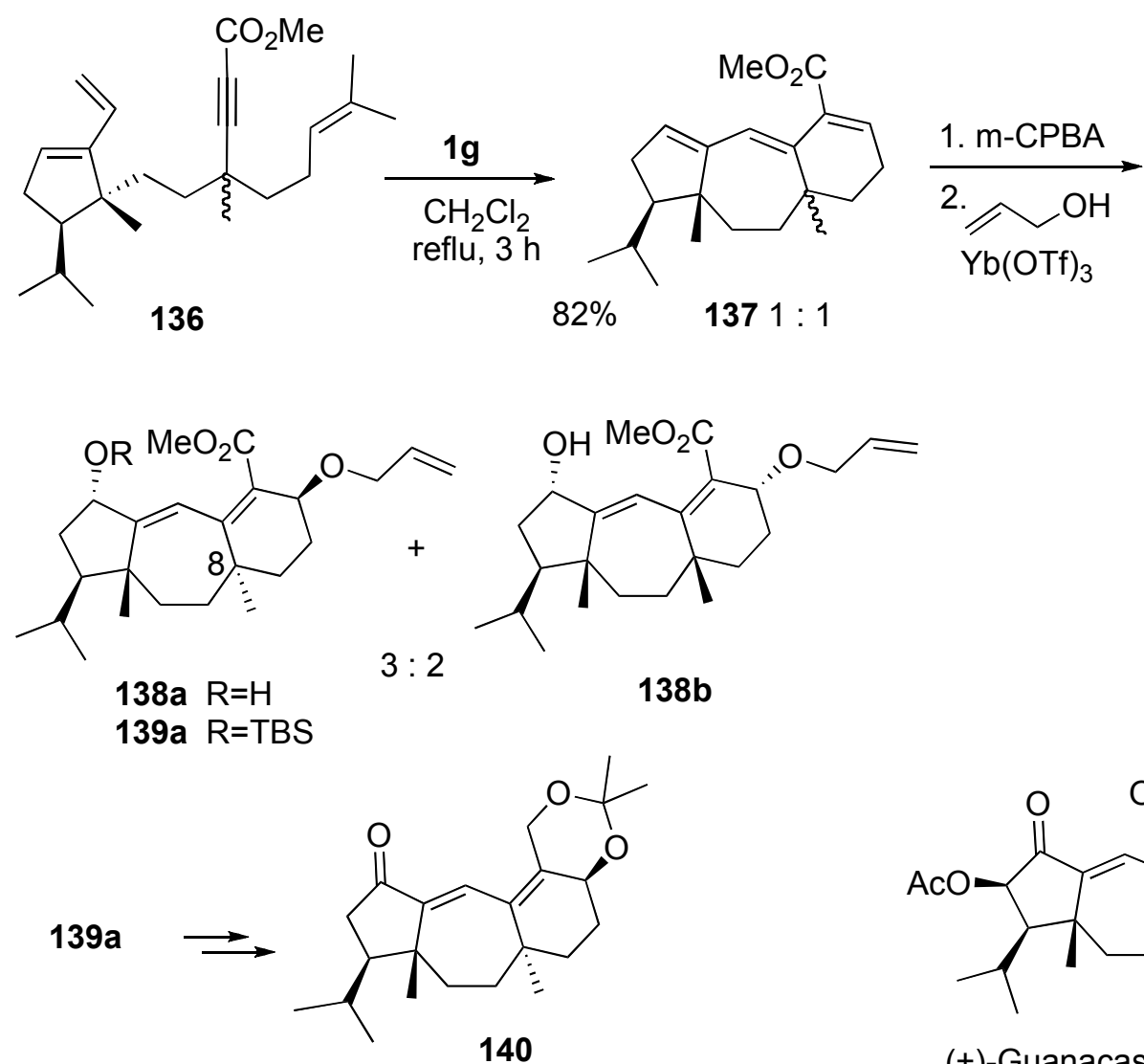

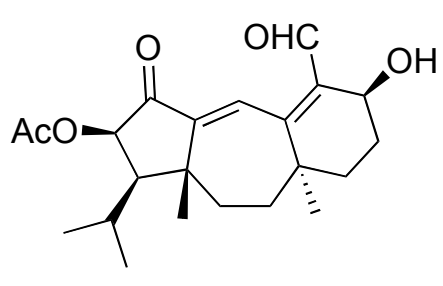

( \pm -Guanacastepene A

Krishna reported the synthetic study toward the stereoselective total synthesis of ilexlactone, the structure of which was already assigned as 143a. Bicyclic ring system was constructed from dienyne 142a using $5 \mathrm{~mol} \%$ of $\mathbf{1 g}$ in $74 \%$ yield. Deprotection of the MOM group afforded the target molecule 143a. However, the spectral data of this compound was found to be different from those of ilexlactone reported in the literature. Thus, the authors further synthesized ent-143a and 143b from 142b in a similar procedure. However, the spectral data of ent-143a and 143b were found to be different from those of ilexlactone. Thus, the authors concluded that the structure proposed ilexlactone was incorrect (Scheme 38) [89].

Total synthesis of $( \pm)$-erythrocarine was achieved by Mori using dienyne metathesis [90]. Synthesis of trisubstituted alkene $\mathbf{1 4 6}$ was achieved with a regio- and stereoselective introduction of carbon dioxide and an alkynyl group onto the terminal alkyne of $\mathbf{1 4 5}$ followed by desilylation. Hetero-Michael reaction of 146 gave isoquinoline derivative 147, which was converted into dienyne 149. Since the tertiary amine of $\mathbf{1 4 9}$ coordinates to the ruthenium catalyst and the catalytic activity is decreased, dienyne metathesis of $\mathbf{1 4 9} \cdot \mathbf{H C l}$ was carried out using ruthenium catalyst 1c to give tetracyclic compounds as a diastereomeric mixture in a ratio of 1:1 in quantitative yield. Deacetoxylation of $\alpha$-isomer gave erythrocarine (Scheme 39). Hatakeyama succeeded in total synthesis of erythravine using a similar procedure [91]. 
Scheme 38. Synthetic study directed toward the total synthesis of ilexlactone.

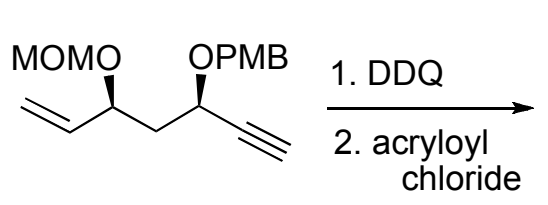

141

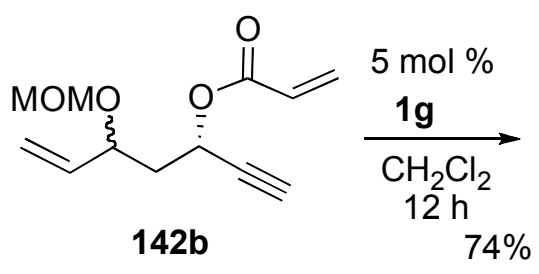

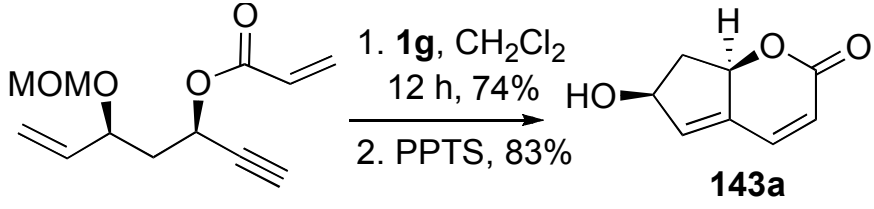

$142 a$<smiles>CO[C@H]1C=C2C=CC(=O)O[C@@H]2C[C@H]1O</smiles>

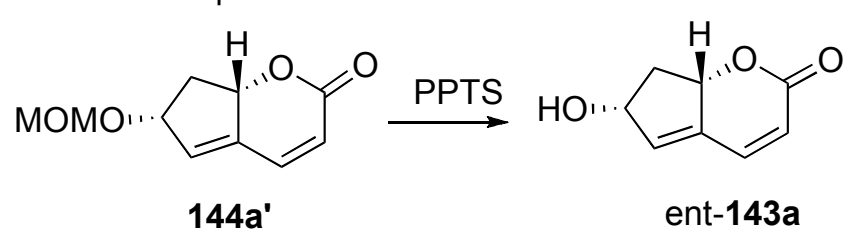

Scheme 39. Total synthesis of erythrocarine.

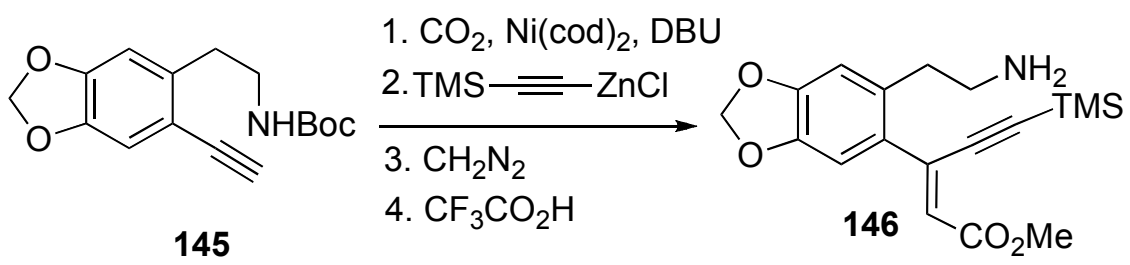

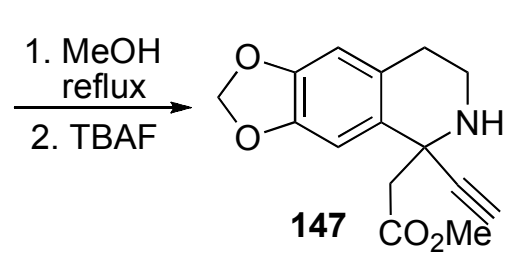

1. $\mathrm{Br}$

2. $\mathrm{LiAlH}_{4}$

$\underset{\text { 3. Swern Ox. }}{\longrightarrow}$

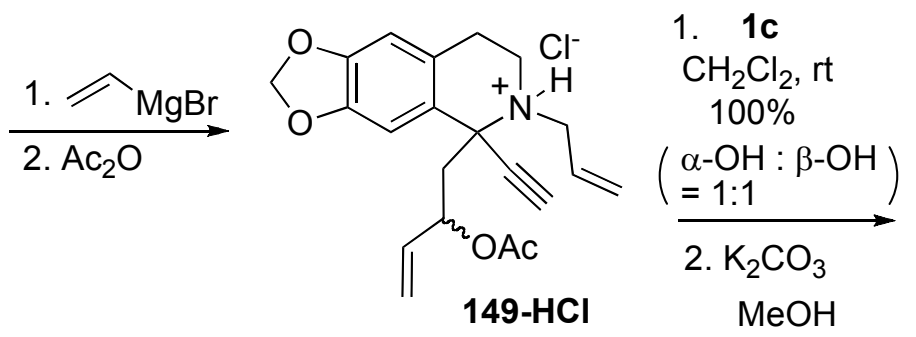<smiles>C#CC1(CC=C)c2cc3c(cc2CCN1CC=[18O])OCO3</smiles>

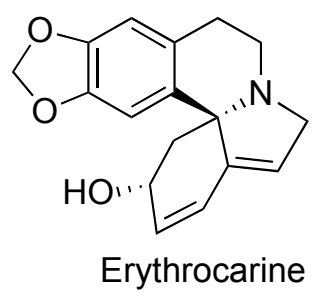

Honda et al. succeeded in a diastereoselective total synthesis of (-)-securinine in an optically pure form by employing RCM of the corresponding dienyne $\mathbf{1 5 0}$ as a key step [92]. They synthesized dienyne 150 having terminal alkene and disubstituted alkene parts from (+)-pipecolinic acid, because ruthenium-carbene complex would at first react with the terminal alkene to form a furan ring. Thus, dienyne metathesis of $\mathbf{1 5 0}$ was carried out using 1i [18] to give bicyclic compound $\mathbf{1 5 1}$ in good yield. Oxidation of 151 with $\mathrm{CrO}_{3}$ gave lactone 152, which was treated with NBS and then TFA to produce (-)-securinine (Scheme 40). They also synthesized viroallosecurinine in a similar manner [93]. 
Scheme 40. Total synthesis of (-)-securinine.

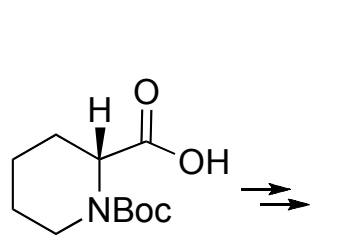

(+)-Pipecolinic acid<smiles>C#CC(CC/C=C\CC)[C@H]1CCCCN1C(=O)O</smiles>

150<smiles>[CH-]CC</smiles>

$74 \%$

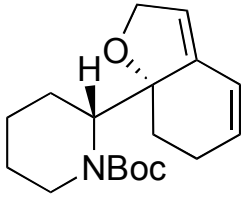

151<smiles>COC(=O)[NH+]1CCCC[C@H]1C12CCC=CC1=CC(=O)O2</smiles>

152
1. NBS, AIBN

2. TFA

3. $\mathrm{K}_{2} \mathrm{CO}_{3}$<smiles>O=C1C=C2C=C[C@H]3C[C@@]2(O1)[C@H]1CCCCN31</smiles>

(-)-Securinine<smiles>O=C1C=C2C=C[C@@H]3C[C@@]2(O1)[C@H]1CCCCN31</smiles>

(+)-Viroallosecurinine

Hatakeyama succeeded in the total synthesis of erythroidine [94]. Construction of C and D rings was begun from amino acid 153, which was led to dienyne 158. Dienyne metathesis was carried out using 1c to give erythroidine in $42 \%$ yield along with compound 159 in $4 \%$ yield. In this case, $1 \mathrm{~g}$ turned out to be less effective and gave erythroidine in less than $30 \%$ yield (Scheme 41 ).

Scheme 41. Total synthesis of (+)--erythroidine.<smiles>C#C[C@](N)(CC(C=C)OC)C(C)=O</smiles>

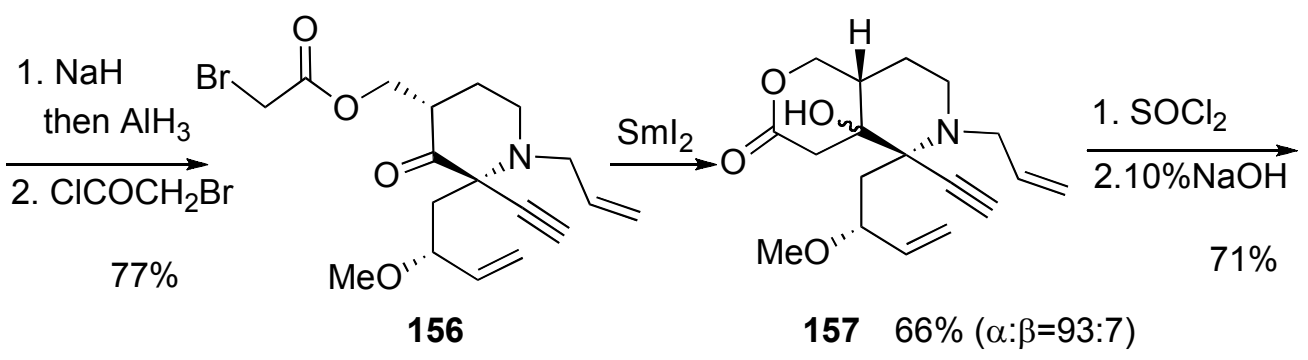<smiles>C#C[C@]1(C[C@@H](C)OC)C2=CC(=O)OC[C@H]2CCN1CC=C</smiles>

The successful enantioselective syntheses of (-)-acylfulvene and (-)-irofulven was achieved by use of ring-closing metathesis strategy [95]. Synthesis of these compounds began through coupling of readily 
available aldehyde $(+)-160$ and enyne 161 . Treatment of 162a with $1 \mathrm{~g}$ catalyst (15 mol \%) in toluene at $90{ }^{\circ} \mathrm{C}$ afforded desired 163a in $90 \%$ yield, which was readily converted into the key triol 164a $(3 \mathrm{~S} / 3 \mathrm{R}=6: 1)$ after desilylation. When trienyne $\mathbf{1 6 2} \mathbf{b}$ was treated in a similar manner, desired $\mathbf{1 6 4 b}$ was obtained in 52\% yield along with minor by-product 165 in $20 \%$ yield. The key triol 164a was converted into triene 166. Diene metathesis of 166 using $\mathbf{1 g}$ (15 mol \%) proceeded smoothly to give bicyclic compound 167, crude product of which was directly converted into (-)-acylfulvene. According to the known method, (-)-acylfulvene was converted into (-)-irofulven (Scheme 42).

Scheme 42. Synthesis of (-)-acylfulvene and (-)-irofulven.

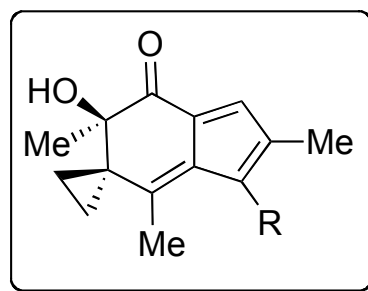

(-)-Acylfulvene $\mathrm{R}=\mathrm{H}$

(-)-Irofluven $\quad \mathrm{R}=\mathrm{CH}_{2} \mathrm{OH}$<smiles>[R]C=C(C)CC#CCCCCCC(=O)C(C)C</smiles>

$(+)-160$<smiles>[R]C=C(C)CC1=C(C)[C@@H]2CC2[C@](C)(O)[C@H]1O</smiles>

164a $\mathrm{R}=\mathrm{Ph}$

164b $\mathrm{R}=\left(\mathrm{CH}_{2}\right)_{2} \mathrm{Ph}$

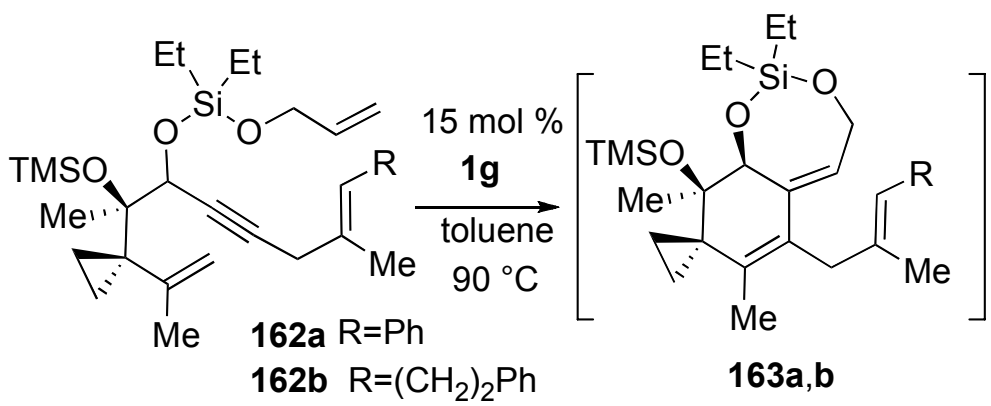<smiles>C=C(C/C(C)=C/CO)C1=C(C)[C@@H]2CC[C@]2(C)[C@@H](O)[C@@H]1O</smiles>

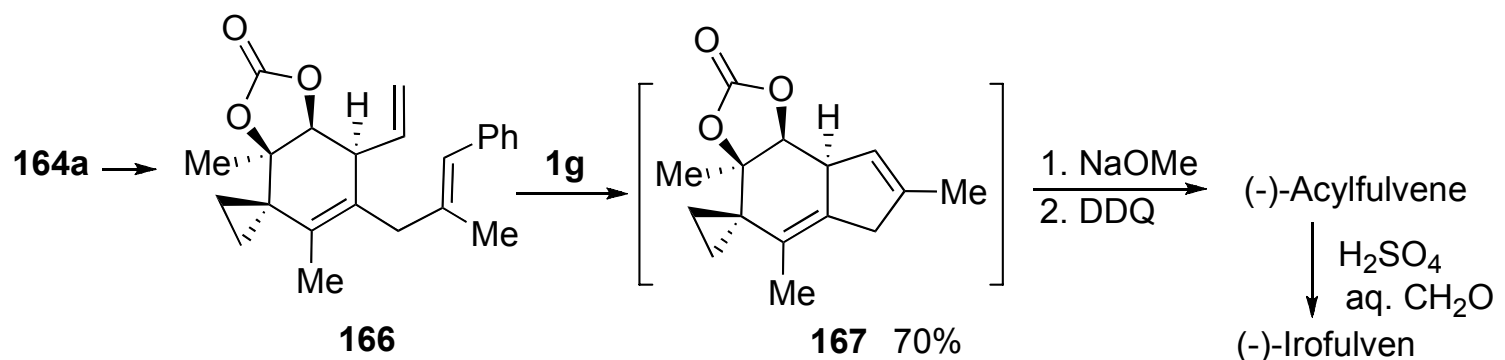

For the synthesis of (-)-cochleamycin, conjugate diene 174 was synthesized from 172 by dienyne metathesis as a key step. The reaction of alcohol 168 with trialkyne 169 gave alcohol 170, which was further reacted with alcohol 171 to give dienyne 172. A tandem ring-closing metathesis of dienyne substrate $\mathbf{1 7 2}$ proceeded to provide a bicyclic siloxane 173. Removal of the silicon tether of $\mathbf{1 7 3}$ afforded 
an $(E, Z)$-1,3-dienediol 174, which was converted into the key compound $\mathbf{1 7 7}$ for the synthesis of (-)-cochleamycin (Scheme 43) [96].

Scheme 43. Formal total synthesis of (-)-cochleamycin A using dienyne metathesis.<smiles>C=CC[C@@H](O)CC1(CC(CC)OCC)SCCCS1</smiles>

168

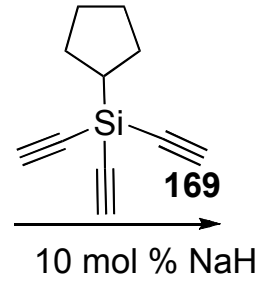

$81 \%$<smiles>C#C[Si](C#C)(O[C@@H](CC=C)CC1(CC(OCC)OCC)CCCS1)C1CCCC1</smiles>

170<smiles></smiles>

$68 \%$

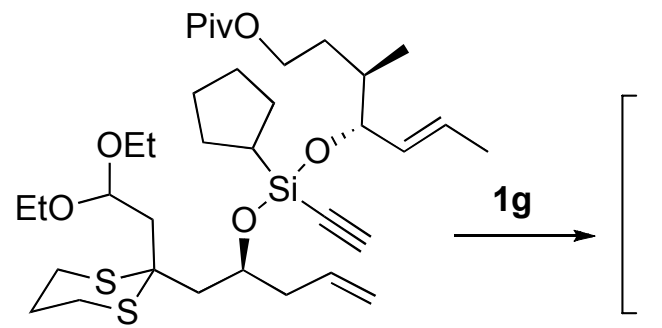

172<smiles>CCOC(CC1(C[C@H]2CC=C3C=C[C@H]([C@@H](C)CCO[Pb])[C@@H](O3)[Si]2(OCC)C2CCCC2)CCCC1)OCC</smiles>

173

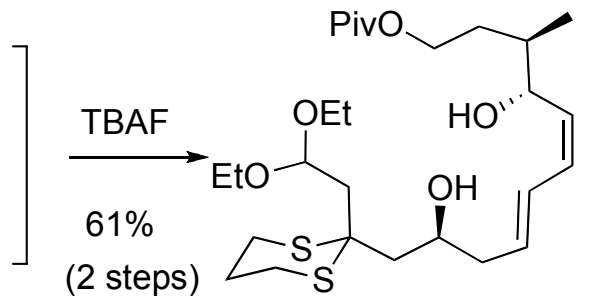

174
1. Mel, collidine

2. cyclohex ${ }_{2} \mathrm{BCl}$ $\stackrel{{ }^{i} \mathrm{Pr}_{2} \mathrm{NEt}, \mathrm{LiBH}_{4}}{\longrightarrow}$

3. $\mathrm{TBSCl}$

4. DIBAL-H

$44 \%$

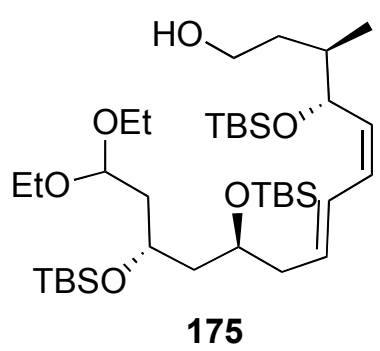

1. $\mathrm{SO}_{3} \cdot \mathrm{Py}, \mathrm{DMSO}$

$\frac{\mathrm{iPr}_{2} \mathrm{NEt}_{2}}{\text { 2. } \mathrm{EtO}_{2} \mathrm{CCH}_{2} \mathrm{P}(\mathrm{O})(\mathrm{OEt})_{2}}$ BuLi

3. DIBAL-H

4. $\mathrm{ClCO}_{2} \mathrm{Me}$ $72 \%$

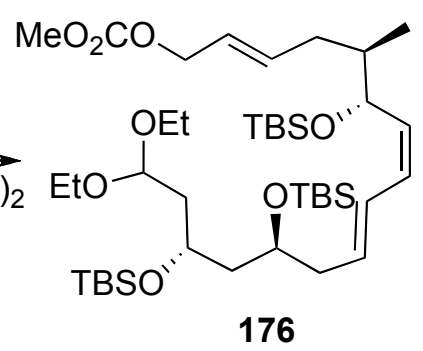

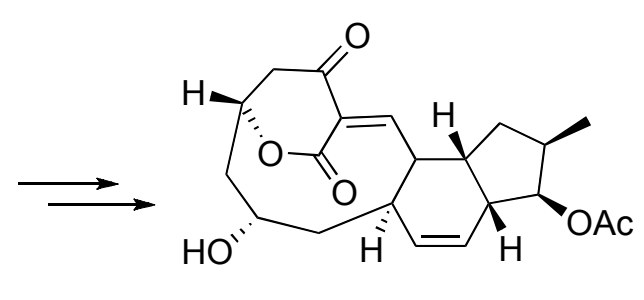

(-)-Cochleamycin A

\section{Cross Enyne Metathesis}

A novel synthetic procedure of 1,3-diene from alkyne and ethylene using cross enyne metathesis was developed in 1997 by Mori [97-98]. When a $\mathrm{CH}_{2} \mathrm{Cl}_{2}$ solution of alkyne 178a was stirred under an atmosphere of ethylene at room temperature in the presence of 1c, 1,3-diene 179a was obtained in $62 \%$ yield. It is interesting that, formally, the double bond of ethylene is cleaved and each methylene part of ethylene is introduced onto the alkyne carbon to produce 1,3-diene 179 (Scheme 44). The possible reaction course was shown in Scheme 45. Reaction of ruthenium carbene methylidene complex 11, generated from 1c and ethylene, with alkyne 178 gives ruthenacyclobutene 180, ring-opening of which gives ruthenium carbene 181. It reacts with ethylene to afford ruthenacyclobutane 182, ring-opening of which gives 1,3-diene 179, and $\mathbf{1 1}$ is reproduced. If $\mathbf{1 l}$ reacts with ethylene, this is non-productive process 
and 11 would be reproduced. However, this method has a problem, that is: propargyl ester 178a or amide 178b gave good results, while homopropargyl amide 178c led to 1,3-diene 179c in only 11\% yield (Scheme 44). Presumably, a heteroatom at the propargylic position is important, and the ruthenium catalyst would be coordinated by the heteroatom at first and then the reaction proceeds.

When the second-generation ruthenium-carbene complex $1 \mathrm{~g}$ was used for this reaction, an alkyne 178 lacking heteroatoms at the propargylic positions, gave 1,3-dienes 179 in good yield (Table 1) [99-103]. Furthermore, the reaction was more rapid and the functional groups on the alkyne were tolerated.

Cross metathesis between terminal alkynes $\mathbf{1 7 8 i}$ and terminal alkenes was subsequently developed by Blechert, and 1,3-disubstituted diene 183i was obtained in high yield [104]. Phenylalanine derivative 184 could be synthesized by use of this procedure followed by Diels-Alder reaction (Scheme 46) [104-105].

Scheme 44. Synthesis of 1,3-diene using cross metathesis.
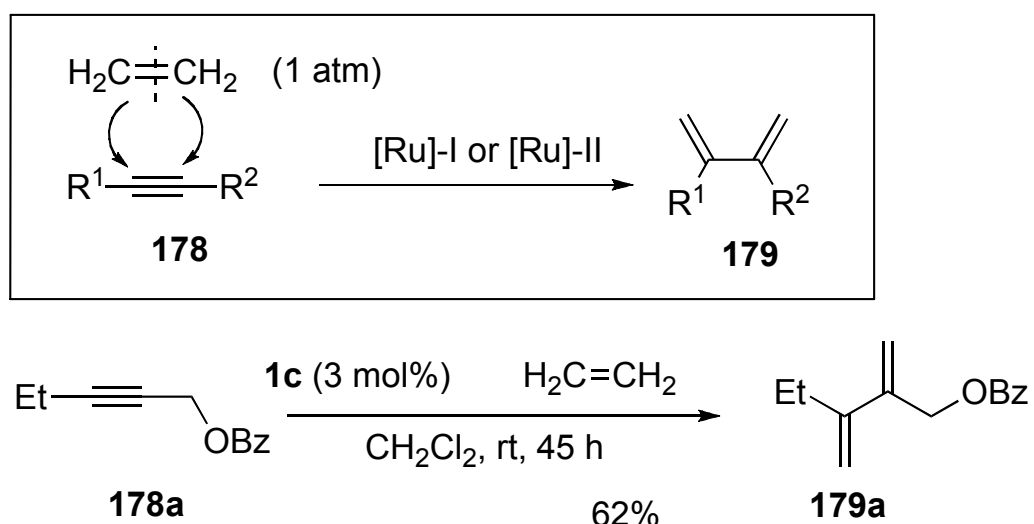

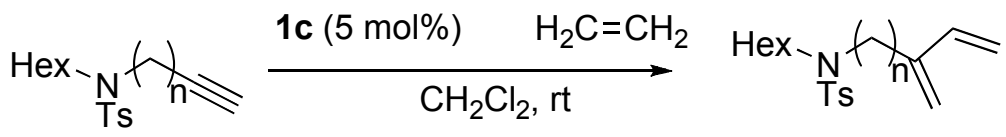

$$
\begin{aligned}
& 178 b: n=1 \quad 179 b 81 \% \\
& 178 \mathrm{c}: \mathrm{n}=2 \quad 179 \mathrm{c} 11 \%
\end{aligned}
$$

Scheme 45. Possible reaction course for formation of 1,3-diene.

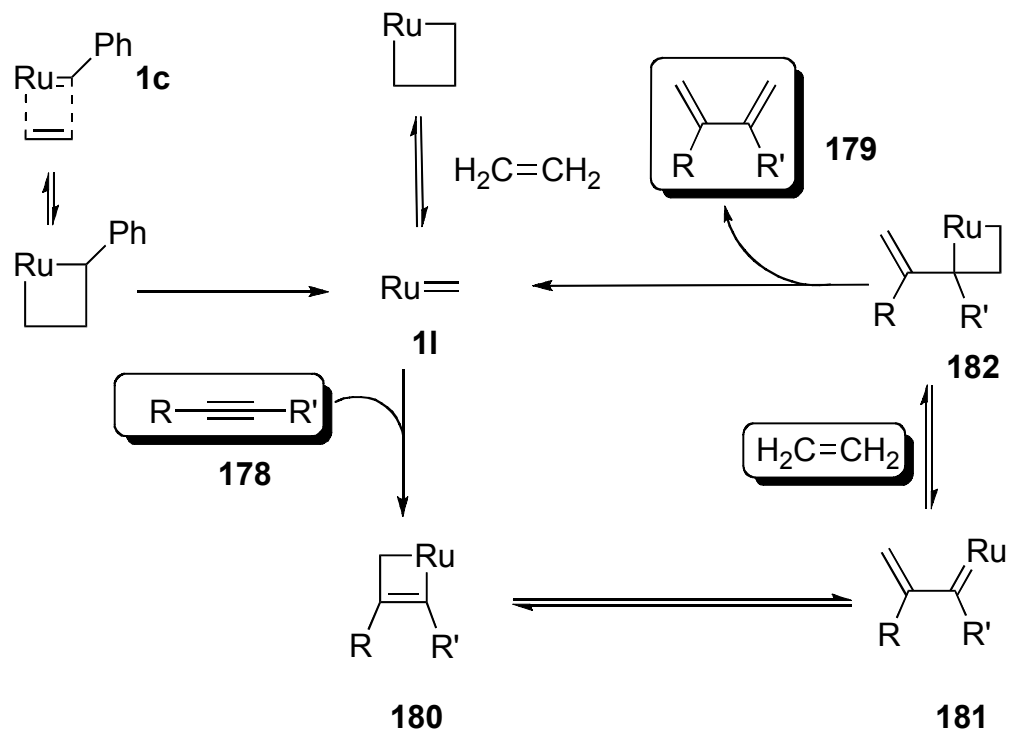


Table 1. Synthesis of Various 1,3-dienes from alkyne and alkene using 1g. ${ }^{\text {a }}$

entry

${ }^{\text {a }}$ All reactions were carried out using $5 \mathrm{~mol} \%$ of $1 \mathrm{~g}$ under $1 \mathrm{~atm}$. pressure of ethylene gas in toluene at $80{ }^{\circ} \mathrm{C} .{ }^{\mathrm{b}}$ The starting material was recovered in $10 \%$ (entry 4 ) and $34 \%$ (entry 5) yields, respectively.

Scheme 46. Synthesis of alanine derivative.
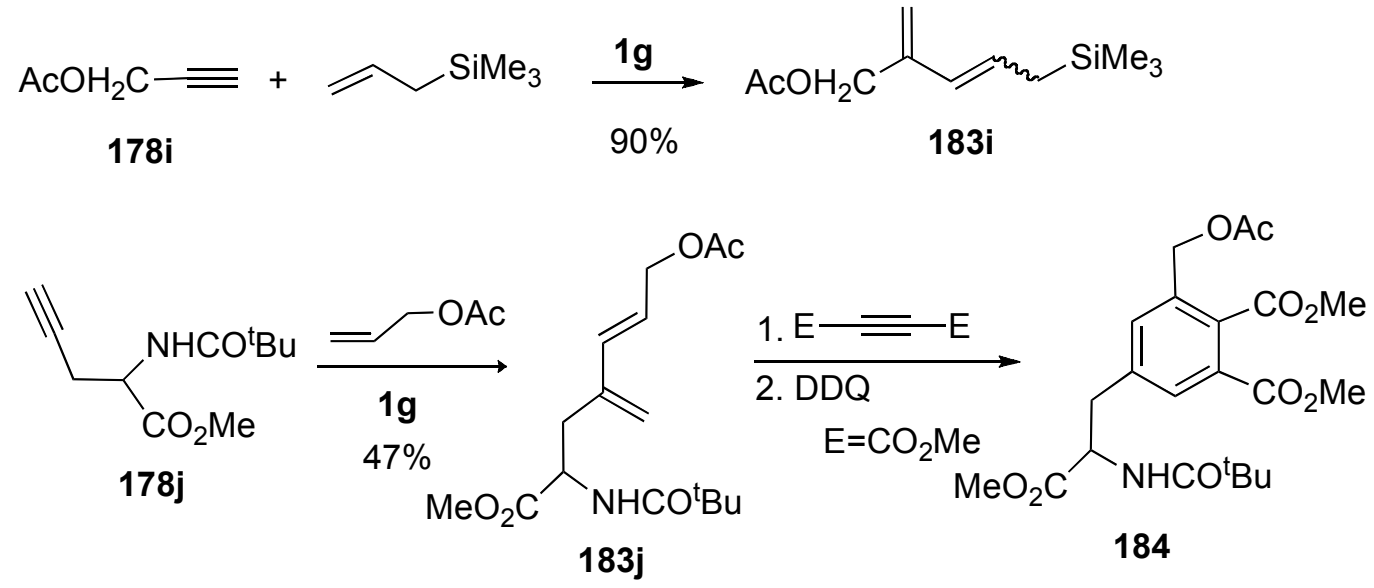

A short and efficient synthesis of highly substituted tetrahydropyridines was achieved from a monosubstituted alkyne, a terminal alkene, and an imine by a combination of cross enyne metathesis and aza-Diels-Alder reaction under high pressure. Cross metathesis of terminal alkyne and alkene afforded diene 185, which was reacted with imine to give pipecolinic acid derivative 186 in high yield (Scheme 47) [106]. 
Scheme 47. One-step synthesis of pipecolinic acid.

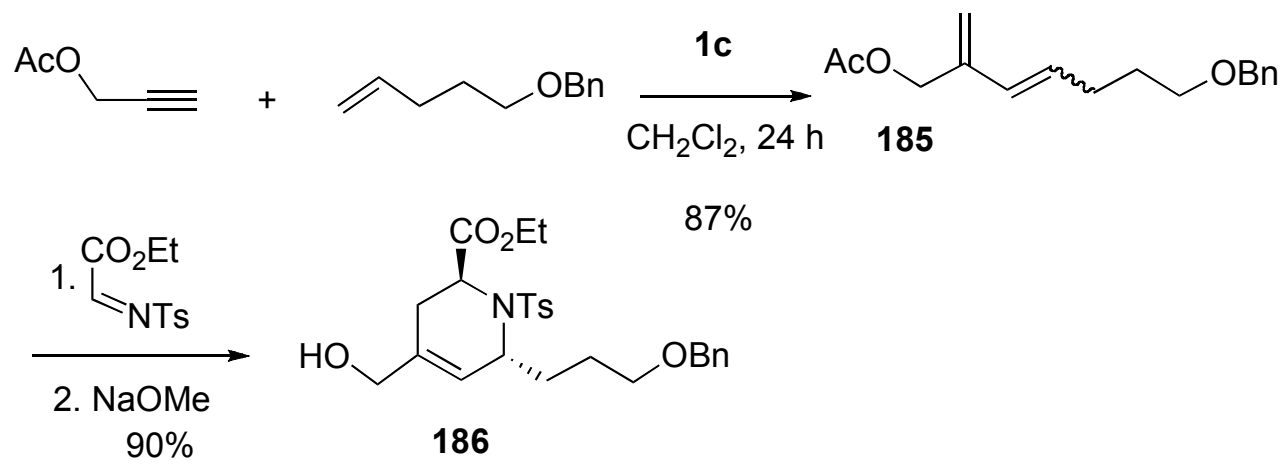

The reaction was further extended to intramolecular Diels-Alder reaction, and cis-hexahydro- $1 H$-indene 189 was synthesized from diene 187 and terminal alkyne in one operation [107]. The intermediate would be 190, which was spontaneously converted into $\mathbf{1 8 8}$. Deprotection of the silyl group followed by PCC oxidation gave indanone 189 (Scheme 48).

Scheme 48. Synthesis of cic-fused carbo-bicycles.<smiles>C#Cc1ccc(OC)cc1</smiles>

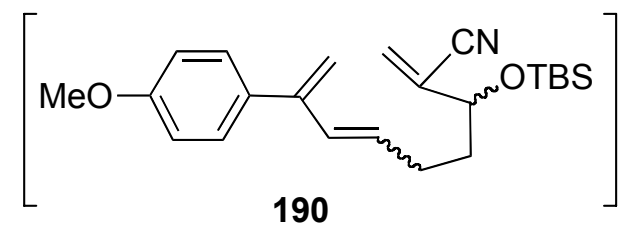

One pot synthesis of nitrogen and oxygen heterocycles was reported using intermolecular cross enyne metathesis in the presence of Bronsted acid (Scheme 49) [108].

Scheme 49. One pot synthesis of nitrogen heterocycles using cross metathesis.

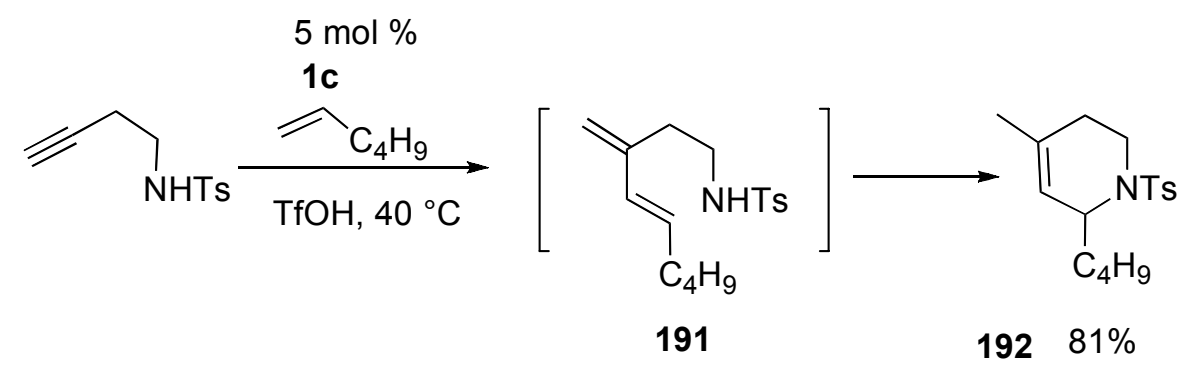

Diver reported cross metathesis of terminal alkyne and cyclopentene using 1g [109]. Ruthenium-carbene complex 11 reacts with the terminal alkyne to produce ruthenium-carbene complex 
194, which reacts with cyclopentene to produce ruthenium-carbene complex 195. It reacts with the alkene part to afford a cycloheptadiene derivative 193 (Scheme 50).

Scheme 50. Cross metathesis of cyclopentene and alkyne.

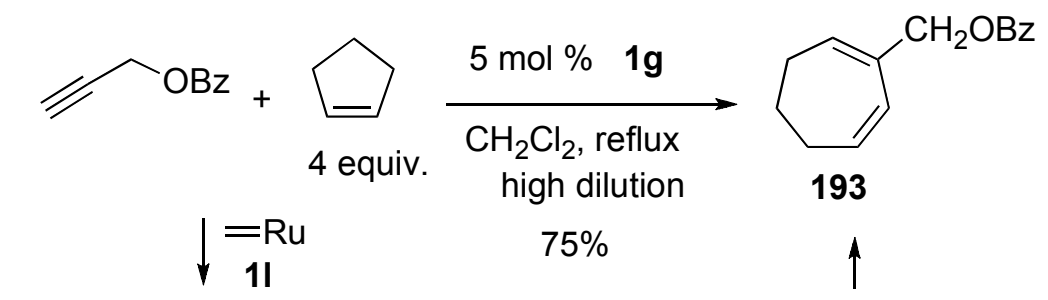<smiles>C=C(C)C1=C2CCCC2=C1COC(=O)O</smiles>

194

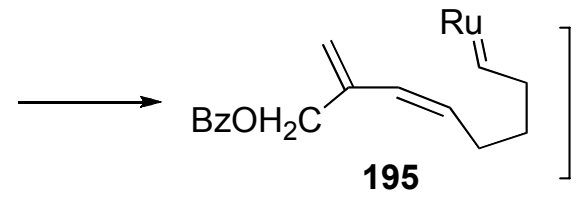

195

Synthesis of Natural Products and Related Compounds Using Cross Metathesis

Synthesis of natural products using cross metathesis is interesting because 1,3-diene moiety is constructed onto the alkyne carbons at the later step. Anolignans were synthesized using cross metathesis of enyne as a key step. 1,3-Diene 197 could be synthesized from alkyne 196 by treatment with $1 \mathrm{~g}$ under ethylene gas. Palladium-catalyzed deacetoxylation followed by deprotection gave anolignan A. Anolignan B could be synthesized in a similar manner. It was interesting that two methylene parts of the anolignan skeleton could be introduced at a later stage of the total synthesis using cross metathesis (Scheme 51) [110].

Scheme 51. Synthesis of anolignan A using cross enyne metathesis.<smiles>COc1ccc(C(C#CC(OC(C)=O)c2ccc3c(c2)OCO3)OC)c(OC)c1</smiles><smiles>C=C(C(=O)OC(C(C)=O)c1ccc2c(c1)OCO2)C(OC(C)=O)c1ccc(OC)cc1OC</smiles><smiles>C=C(Cc1ccc2c(c1)OCO2)C(=O)Cc1ccc(O)cc1O</smiles><smiles>C=C(Cc1ccc(O)cc1)C(=O)Cc1ccc(O)cc1O</smiles>

Novel vitamin D receptor antagonists, 24,24-ethanovitamine D3-26,23-lactones 198a and 198b and their analogs were synthesized (Scheme 52) [111]. The CD-ring precursors 203a and 203b were efficiently synthesized via ruthenium-catalyzed intermolecular enyne metathesis of $\mathbf{2 0 0}$ with ethylene as a key step. Cyclopropanation of resultant enyne metathesis product $\mathbf{2 0 1}$ followed by treatment with DIBAL-H and then deprotection gave compounds 203a and 203b. Oxidation of 203a and 203b followed 
by palladium-catalyzed coupling reaction with 204 and then deprotection afforded 198a and 198b, respectively.

Scheme 52. Synthesis of 24,25-ethanovitamine D3 lactones.<smiles>C=C1/C(=C\C=C2/CCC[C@]3(C)[C@@H]2CC[C@H]3[C@H](C)CCCC(C)(C)O)C[C@@H](O)C[C@H]1O</smiles>

1 $\alpha, 25$-Dihydroxyvitamin $\mathrm{D}_{3}$<smiles></smiles>

$198 a$<smiles></smiles>

$198 b$

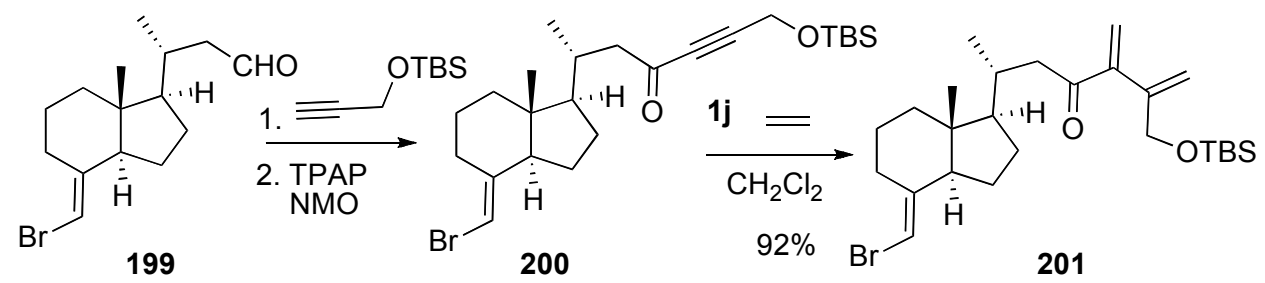

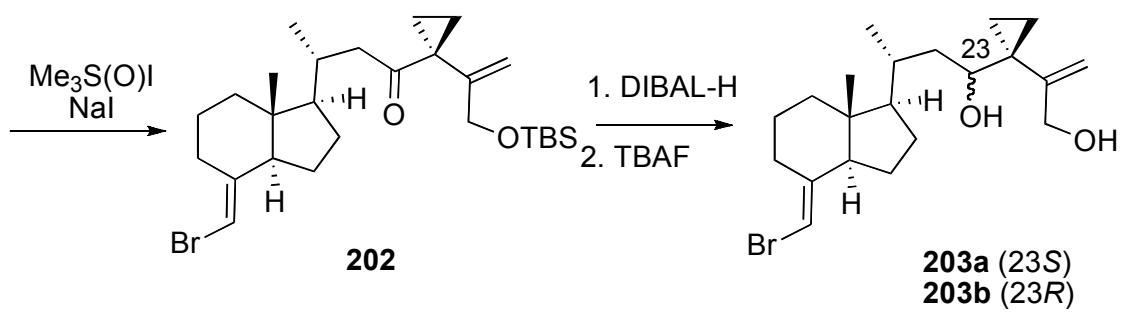

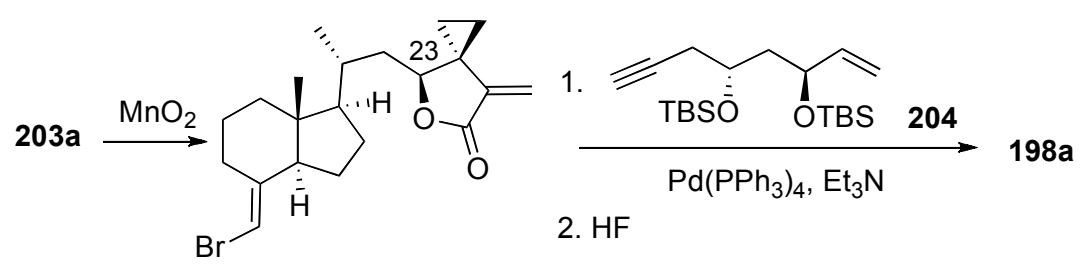

203b

$198 b$

Scheme 53. Synthesis of C-aryl glycoside.

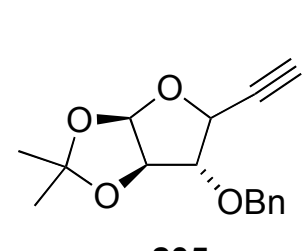

205<smiles>C=CC(=C)C1OC2OC(C)(C#CC)O[C@H]2C1OCCC</smiles>

$89 \%$<smiles>O=C1C=CC(=O)C2CCCCC12</smiles>

$80{ }^{\circ} \mathrm{C}$<smiles>CC1(C)O[C@@H]2OC(c3ccc4c(c3)C(=O)c3ccccc3C4=O)[C@H](OCc3ccccc3)[C@@H]2O1</smiles>

207

A versatile strategy for the synthesis of C-aryl glycoside was successfully developed. An intermolecular enyne metathesis of C-alkynyl glycoside 205 with ethylene gave diene 206, which 
was followed by Diels Alder reaction and then aromatization to provide C-aryl glycoside 207 (Scheme 53) [112].

Lee succeeded in the total synthesis of (-)-amphidinolide E, whose side chain was constructed using cross enyne metathesis [113-114]. Alkyne 208 was first reacted with ethylene in the presence of $\mathbf{1 g}$ to give 209, which was further engaged in situ in a chemoselective cross metathesis with 2-methyl-1,4-pentadiene to give triene $\mathbf{2 1 0}$ in $65 \%$ yield along with diene $\mathbf{2 0 9}$ in $19 \%$ yield. Isolated diene $\mathbf{2 0 9}$ was further recycled and reacted with 2-methyl-1,4-pentadiene in the presence of $\mathbf{1 g}$ to afford triene 210, which was further elaborated into 211. Condensation of 211 and 212 afforded compound 213. From this compound 213, total synthesis of amphidinolide E was achieved (Scheme 54).

Scheme 54. Synthesis of amphidinolide E.

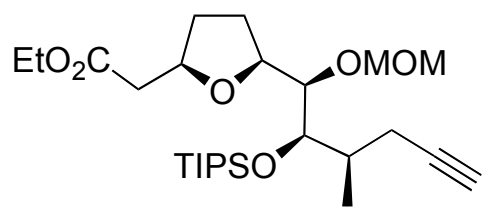

208

$\downarrow \begin{aligned} & \mathbf{1 g} \mathrm{H}_{2} \mathrm{C}=\mathrm{CH}_{2} \\ & \mathrm{CH}_{2} \mathrm{Cl}_{2}\end{aligned}$

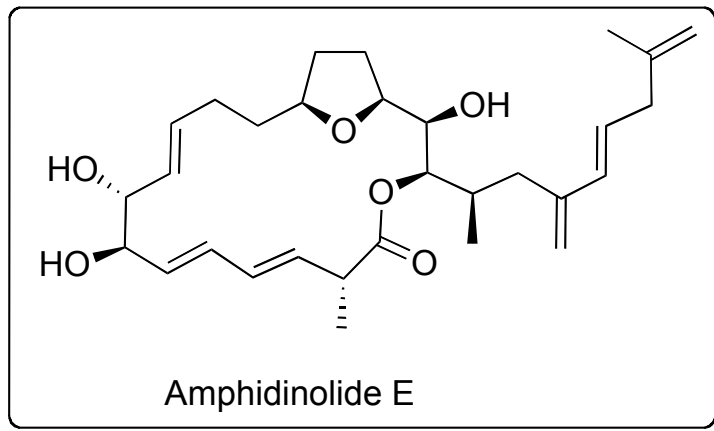

Amphidinolide $E$

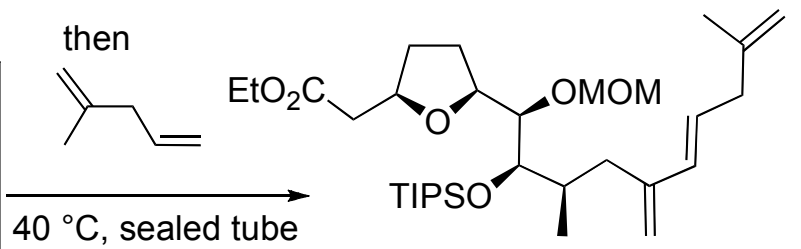

210

(209 19\%)

$65 \%$

209<smiles>CC([O+])CC=CC=CC1OC(C)(C)O[C@@H]1C=O</smiles>

211

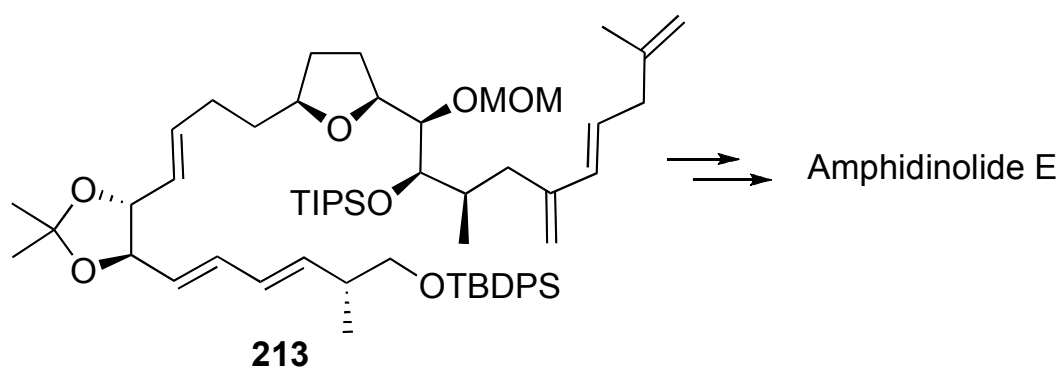


Recently, same group succeeded in the total synthesis of amphidinolide K using intramolecular cross enyne metathesis in the key step [115].

Fürstner succeeded in the total synthesis of amphidinolide $\mathrm{V}$ using ring-closing alkyne metathesis for the construction of the macrocycle (Scheme 55). Dialkyne 214 was treated with molybdenum complex 215 to give macrocycle 216 in $84 \%$ yield. Then an intermolecular enyne metathesis of the resulting cycloalkyne 216 with ethene was used to set the vicinal exo-methylene branches. From this compound 217, amphidinolide $\mathrm{V}$ was synthesized. As the result, the absolute configuration of amphidinolide $\mathrm{V}$ was determined to be as $8 R, 9 S, 10 S, 13 R$ [116-117].

Scheme 55. Synthesis of amphidinolide V.
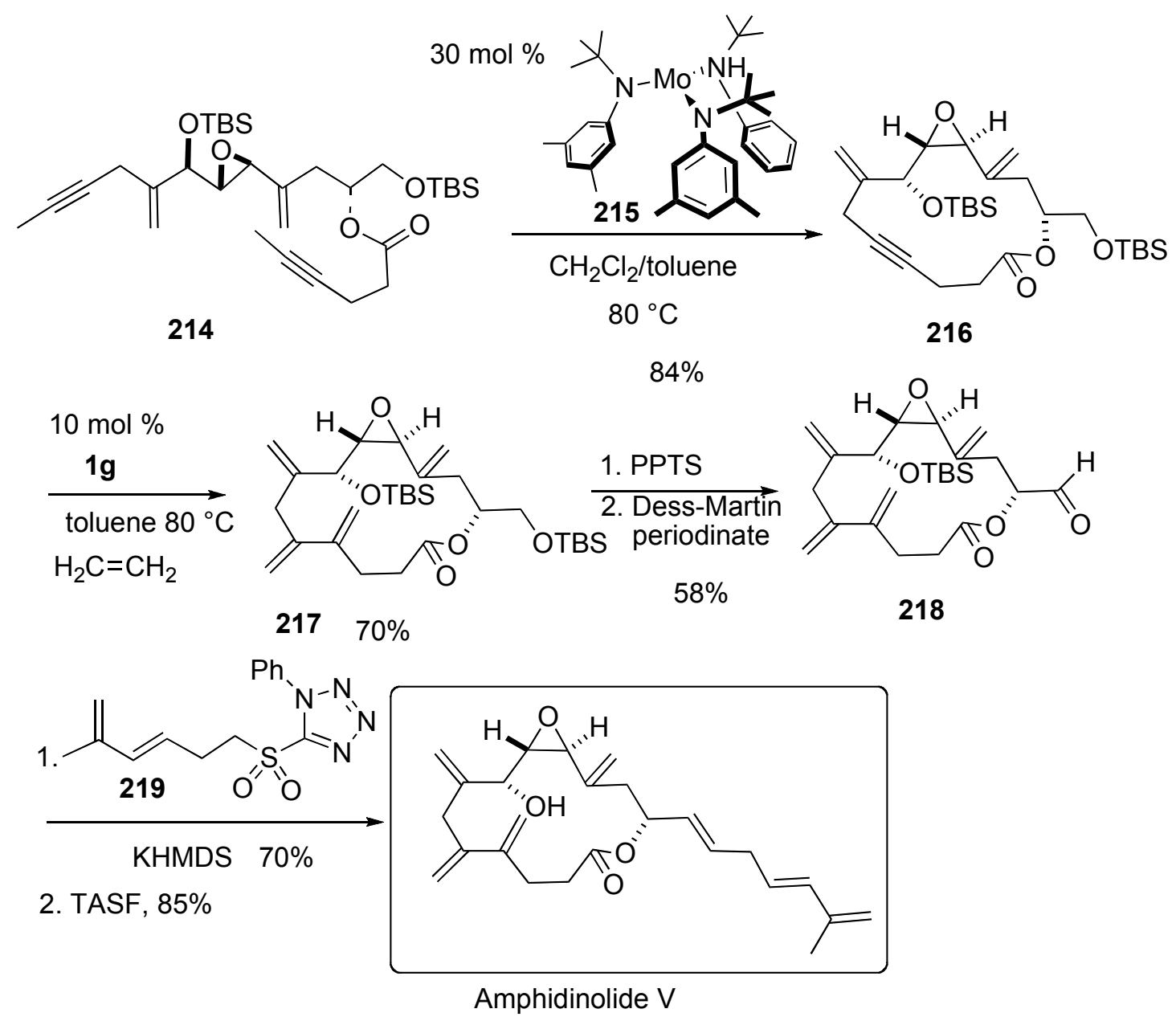

\section{Ring-Opening Enyne Metathesis}

Tandem metathesis of cycloalkene-ynes is a unique reaction because different cyclic compound is formed from the starting cycloalkene via many steps by a one operation. These reactions are contained ring opening metathesis (ROM), ring closing metathesis (RCM) and/or cross metatheses (CM). Mori reported the ROM of cycloalkene-yne [118]. When cycloheptene-yne 220a, the substituent of which was placed at the 3-position of cycloalkene, was reacted with the first generation ruthenium carbene complex 1c in $\mathrm{CH}_{2} \mathrm{Cl}_{2}$ under ethylene gas at room temperature for $24 \mathrm{~h}$, pyrrolidine derivative 221 a was obtained in 56\% yield (Table 2, entry 1). Various cycloalkene-ynes $\mathbf{2 2 0}$ gave pyrrolidine derivatives 221 in high yields by a one-pot operation. Formally, in this reaction, the double bonds of ethylene and cycloalkene 
were cleaved and each methylene part of ethylene was introduced onto the alkyne and cycloalkene carbons, respectively, and a carbon-carbon double bond was formed between the alkyne and cycloalkene carbons to form a pyrrolidine ring (Figure 3). In each case, pyrrolidine ring is formed and the length of the substituent corresponds to the initial ring size minus 1 . The possible reaction course for formation of 221 from 220 was shown in Scheme 56.

Table 2. ROM-RCM of cydoalkene-yne.

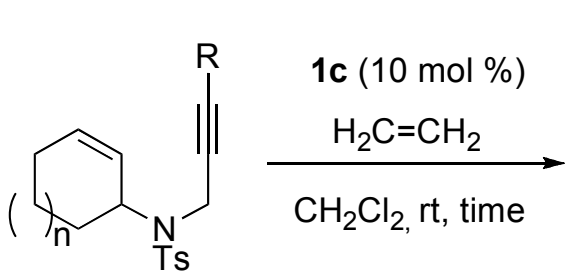

220

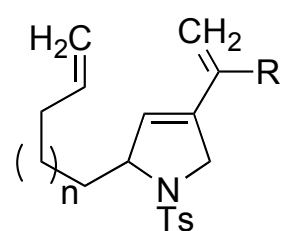

221

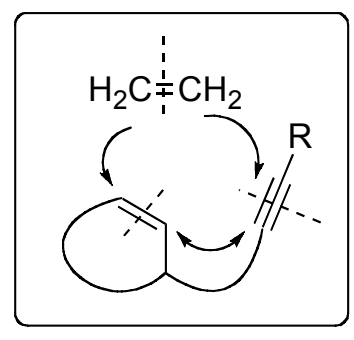

Figure 3

\begin{tabular}{clcccl}
\hline entry & R & ring size & $\mathrm{n}$ & time $(\mathrm{h})$ & ${\text { yield }(\%)^{a}}^{a}$ \\
\hline 1 & 220a Me & 7 & 2 & 24 & 221a $56^{b}$ \\
2 & 220b H & 6 & 1 & 4 & 221b 78 \\
3 & 220c $\mathrm{H}$ & 7 & 2 & 1 & 221c 70 \\
4 & 220d H & 8 & 3 & 1 & 221d 75 \\
\hline
\end{tabular}

${ }^{\mathrm{a}}$ Yields were calculated from $1 \mathrm{H}$ NMR. ${ }^{\mathrm{b}} \mathbf{2 2 0 a}$ was recovered in $36 \%$ yield.

Scheme 56. Possible reaction course for ROM of 220.

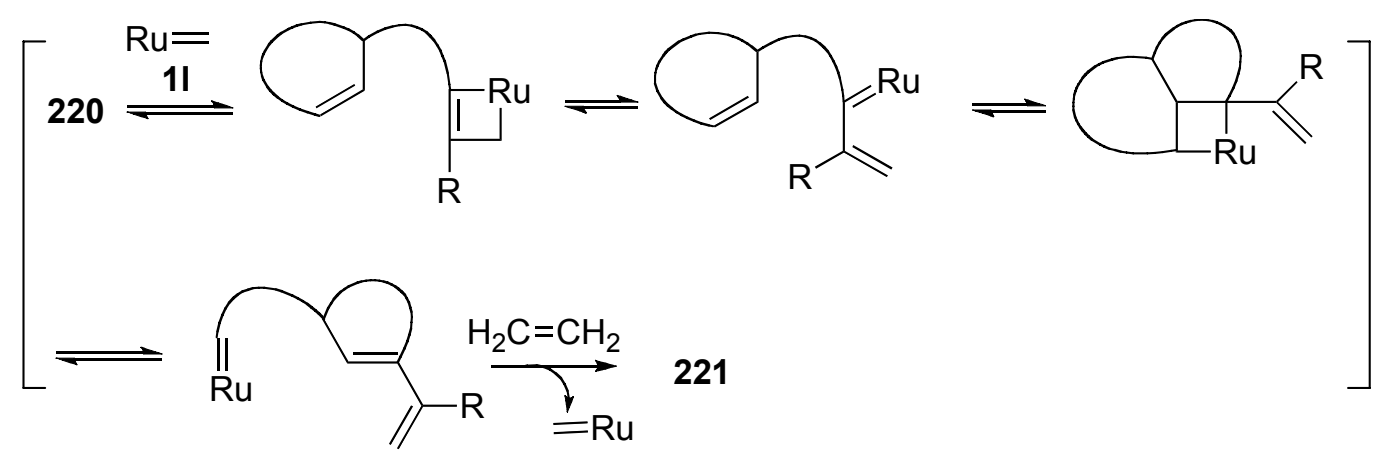

Blechert reported the same type of ROM-CM. Reaction of cyclopentene derivative 222a having a propargyloxy group at the 3-position with 1c in the presence of diethyl allyl malonate afforded compound 223a in 75\% yield [119-120]. In this reaction, the cleaved alkylidene part of diethyl allyl malonate is introduced onto the cyclopentene carbon, and the methylene part is introduced onto the alkyne carbon to form furan derivative 223a (Figure 4). Furthermore, the five-membered ring of estrone $222 b$ or $222 c$ is cleaved using $1 \mathbf{c}$ in the presence of an alkene to give $223 \mathbf{b}$ or $223 \mathbf{c}$, and an alkene part is introduced onto the C-ring (Scheme 57). 
Scheme 57. ROM-CM enyne in the presence of alkene.

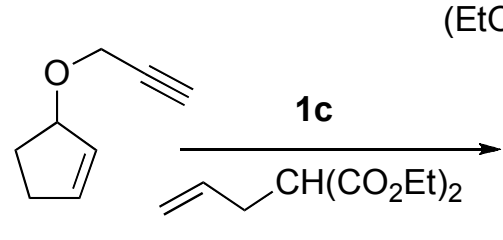

222a<smiles>C=CC1=CC(CC/C=C/CCCOCC)OC1</smiles>

$75 \%(E / Z=3 / 1)$

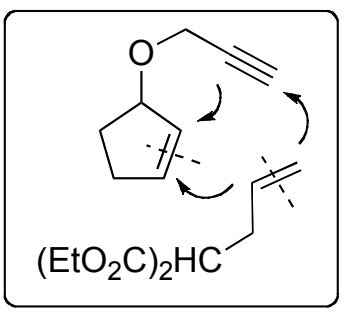

Figure 4

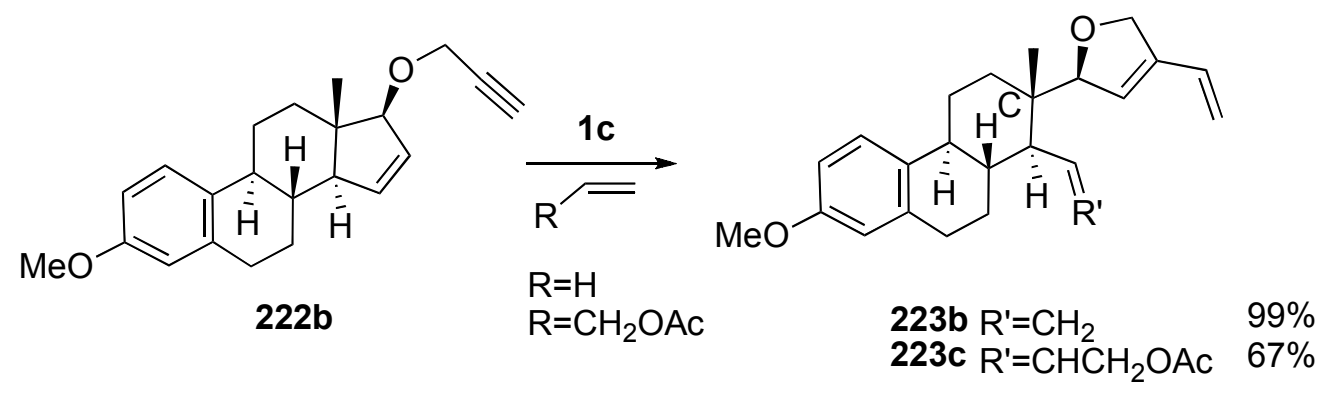

Scheme 58. Ring-opening metathesis of cycloalkene-yne.
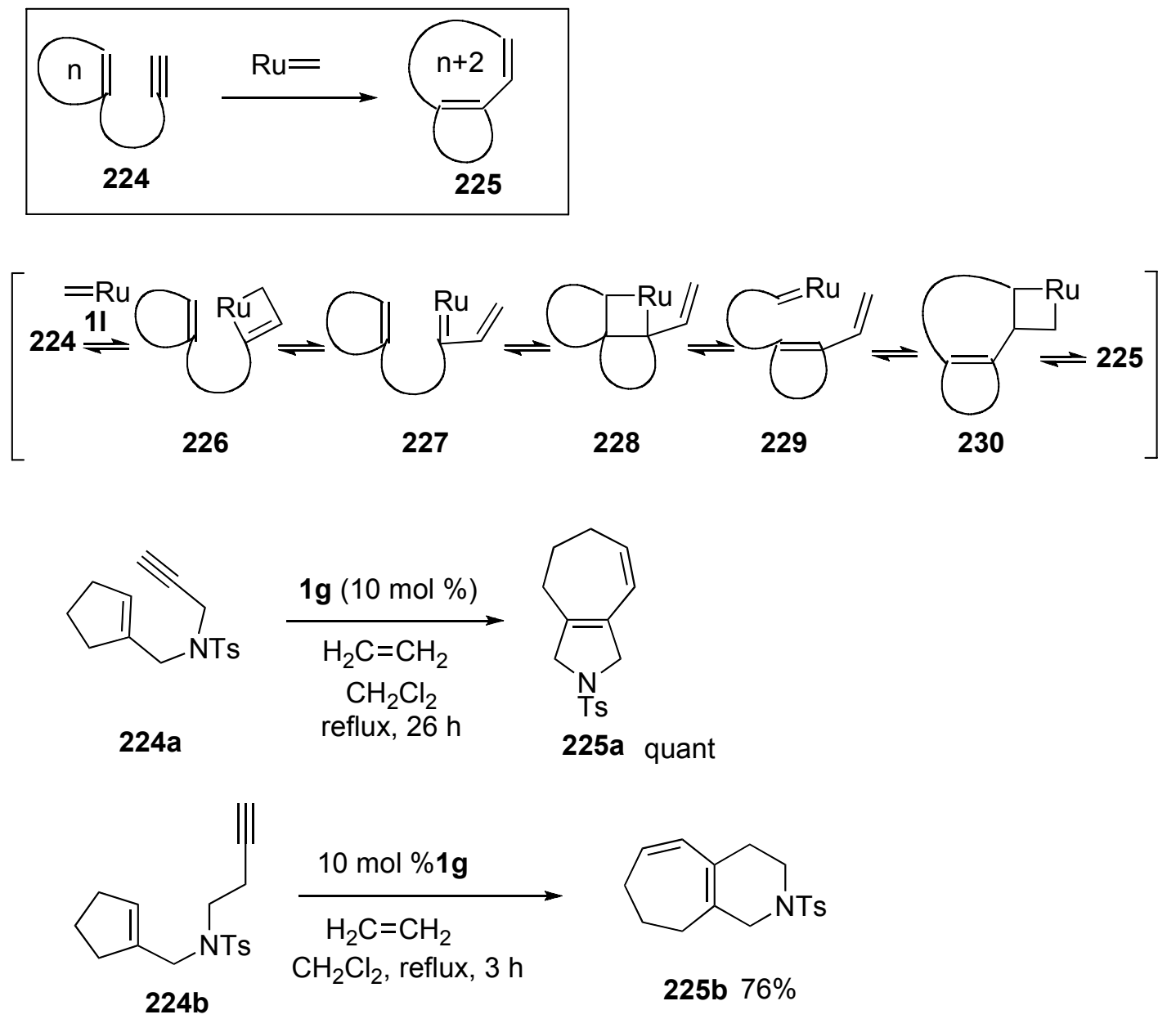

Ring-opening metathesis of 1-substituted cycloalkene-yne 224 with $\mathbf{1 g}$ afforded bicyclic compound 225 [121-122]. Reaction of an alkyne part of 224 with ruthenium carbene complex $\mathbf{1 l}$ gives 
ruthenacyclobutene 226. Ring opening of this gives ruthenium carbene complex 227, which reacts with cycloalkene to afford highly strained ruthenacyclobutane 228. Ring opening of this affords ruthenium carbene complex 229 and then it reacts with alkene part to afford ruthenacyclobutane 230, ring-opening of which gives bicyclic compound 225. When a $\mathrm{CH}_{2} \mathrm{Cl}_{2}$ solution of cyclopentene derivatives 224a was stirred in the presence of $\mathbf{1 g}$ under ethylene gas for $26 \mathrm{~h}$, bicyclic compound 225a was obtained in quantitative yield. In a similar manner, cyclopentene-yne $\mathbf{2 2 4 b}$, the side chain of which was elongated, was reacted with $1 \mathrm{~g}$ to give bicyclic compound $\mathbf{2 2 5} \mathrm{b}$ in $76 \%$ yield. These results indicated that the initial ring $(n)$ was enlarged to $(n+2)$ ring and the size of the other ring corresponds to the carbon chain length from an alkyne carbon to an alkene carbon (Scheme 58).

To synthesize an isoquinoline derivative using this method, the initial cycloalkene would be cyclobutene and the chain length between alkyne and alkene carbons containing nitrogen would be four. Treatment of cyclobutene-yne 231a with $1 \mathrm{~g}$ afforded isoquinoline derivative 232a in 60\% yield in one step. Furthermore, glycine derivative $\mathbf{2 3 1 b}$ having a cyclobutene ring in a tether afforded cyclic amino acid 232b in $76 \%$ yield. This procedure was further extended to the synthesis of biaryl compound 232c from cyclobutene-yne 231c. It was interesting that in this case, an aryl group on the alkyne of 231c is placed at the 5-position of isoquinoline 232c (Scheme 59) [123].

Scheme 59. Synthesis of isoquinoline derivatives using ROM of cyclobutene-yne.
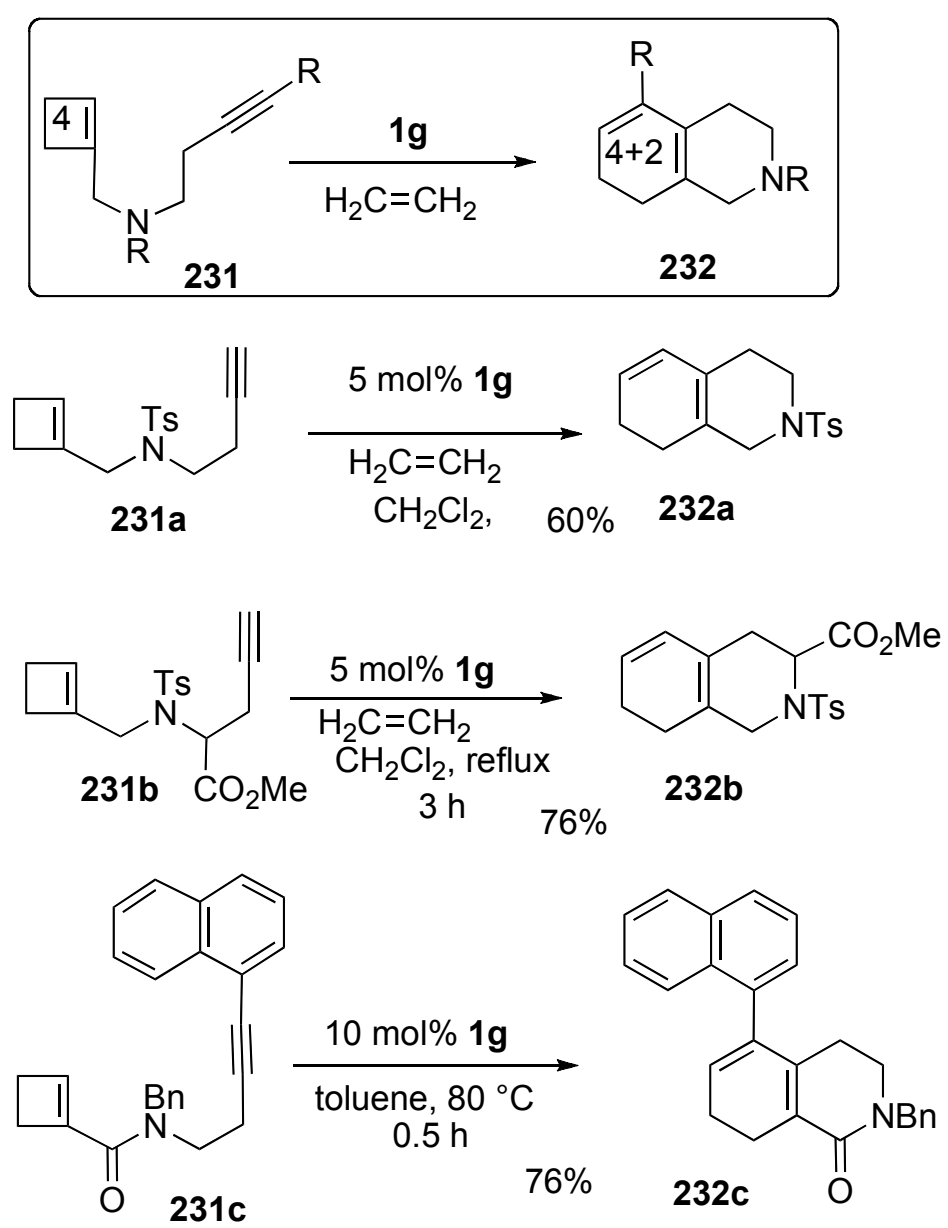

Plumet et al. described domino metathesis of propargyl (2-endo-7-oxanorborn-5-enyl) ethers 233a-c with allyl acetate in the presence of Grubbs' ruthenium catalyst 1c (Scheme 60) [124-125]. The reaction 
proceeded stereoselectively to produce substituted cis-fused bicyclic ethers 234a-c. In a similar manner, indolizidinone derivative 234d was obtained from azabicyclo[2.2.1] heptenone 233d in high yield. Later, the substituent effect of this reaction was further investigated and pyrrolizidinone derivative 234e was obtained in $40 \%$ yield along with indolizidinone derivative $234 \mathrm{e}^{\prime}$ in $30 \%$ yield when the toluene solution of 233e $(\mathrm{R}=\mathrm{Me})$ and $1 \mathrm{~g}$ was warmed at $80^{\circ} \mathrm{C}$ for 30 min under ethylene gas [126].

North and Banti observed double ring-opening metathesis of dialkynyl cycloalkenes $233 \mathbf{f}$ affording tricyclic compound 234f in high yield (Scheme 61) [127-128].

Scheme 60. ROM-RCM followed by CM of cycloalkene-yne.
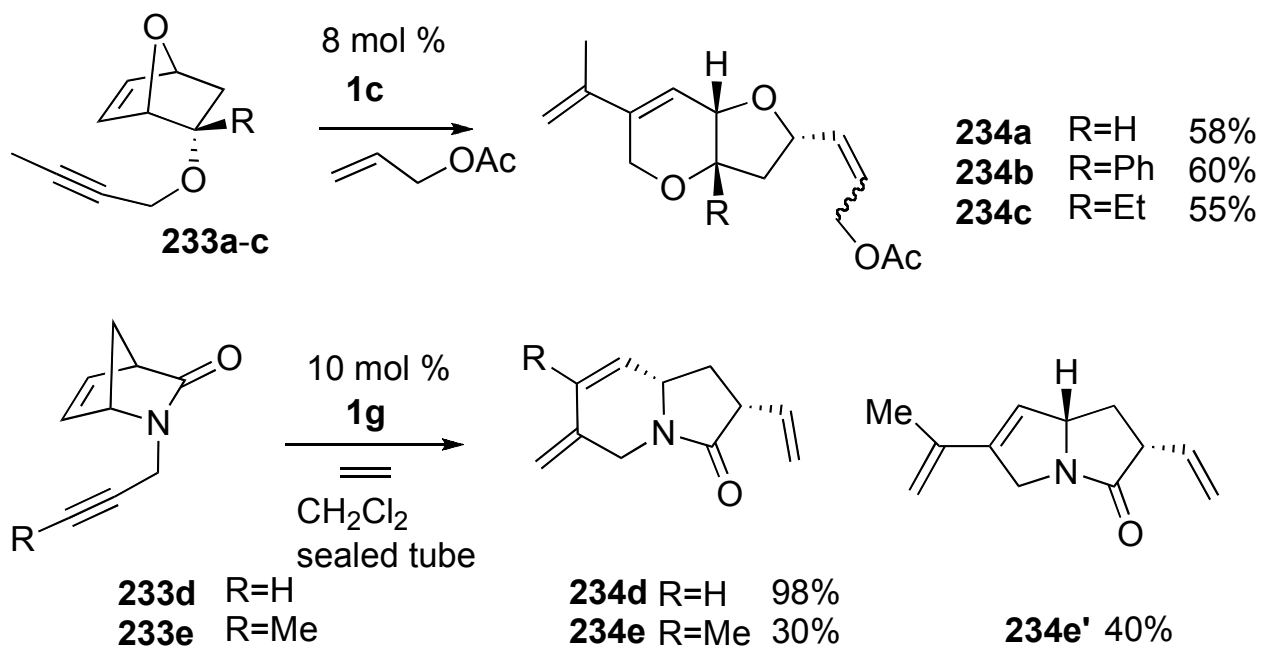

234e $R=$ Me $30 \%$

$234 e^{\prime} 40 \%$

Scheme 61. ROM-RCM of norbornene derivative.

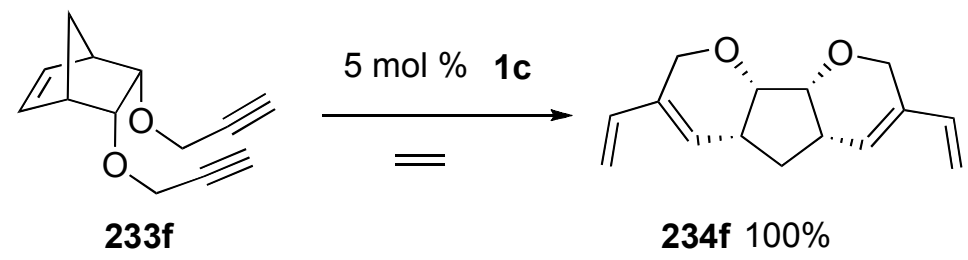

\section{Skeletal Reorganization Using Transition Metals}

Trost discovered palladium-catalyzed enyne metathesis during the course of his study on palladium-catalyzed enyne cyclization [129-135]. Treatment of Z-235 with palladacyclopentadiene (TCPT, 236a) in the presence dimethyl acetylene dicarboxylate (DMAD) in dichloroethane at $60{ }^{\circ} \mathrm{C}$ led to metathesis product $E$-238 in $68 \%$ yield, which consisted of only $E$-isomer $E$-238. Similarly, the $E$-substrate $E$-235 gave predominantly Z-238 (Scheme 62) [129].

This method provides a very simple route to bridged bicycles possessing bridgehead olefins (Scheme 63). When enyne 239a was treated with $\mathrm{TCPC}^{\mathrm{TFE}} \mathbf{2 3 6}$ b, bicyclo[6.2.1] undecadiene 240a was formed in $53 \%$ yield. When a mixture of $4 \% \mathrm{TCPC}^{\mathrm{HFB}} \mathbf{2 3 6 c}, 4 \%$ tri-o-tolylphosphate, bis(heptafluorobutyl)-acetylenedicarboxylate and enyne 239b in dichloroethane was heated at $80{ }^{\circ} \mathrm{C}$, tricyclic compound $\mathbf{2 4 0 b}$ was obtained in $85 \%$ yield. It means that the reaction proceeds via the formation of the four-membered-ring [132]. 
Scheme 62. Enyne metathesis using palladium catalyst.

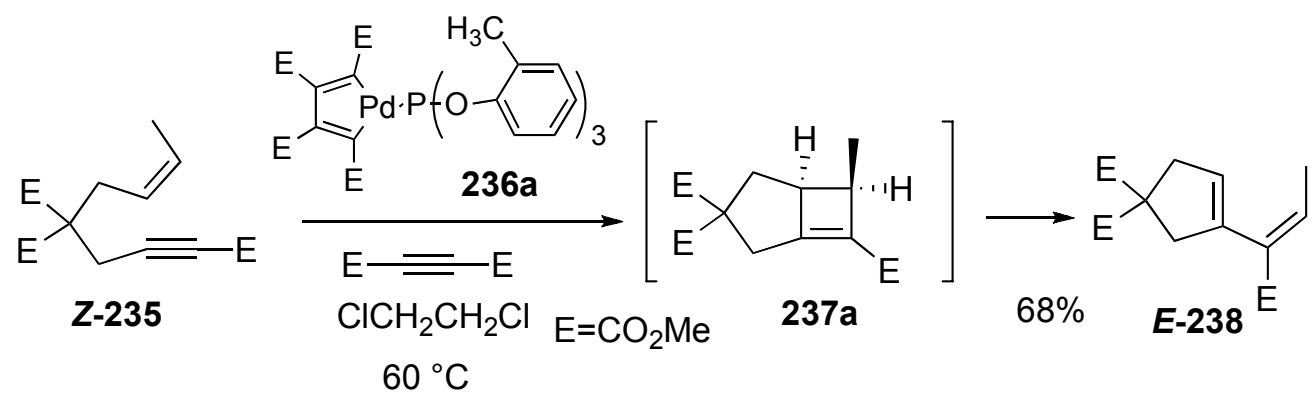

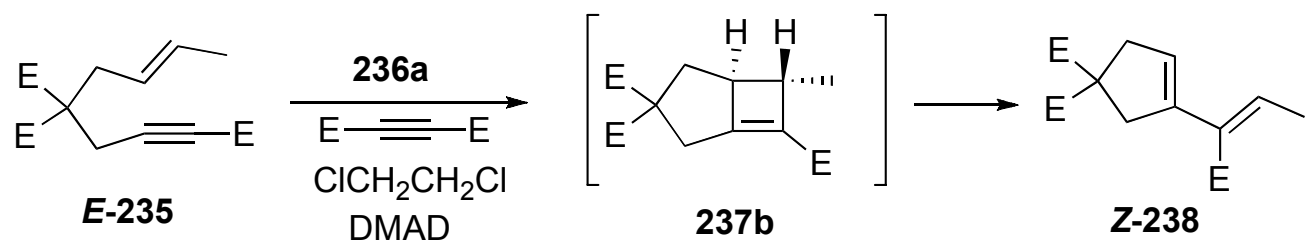

Scheme 63. Confirmation of four-membered ring.
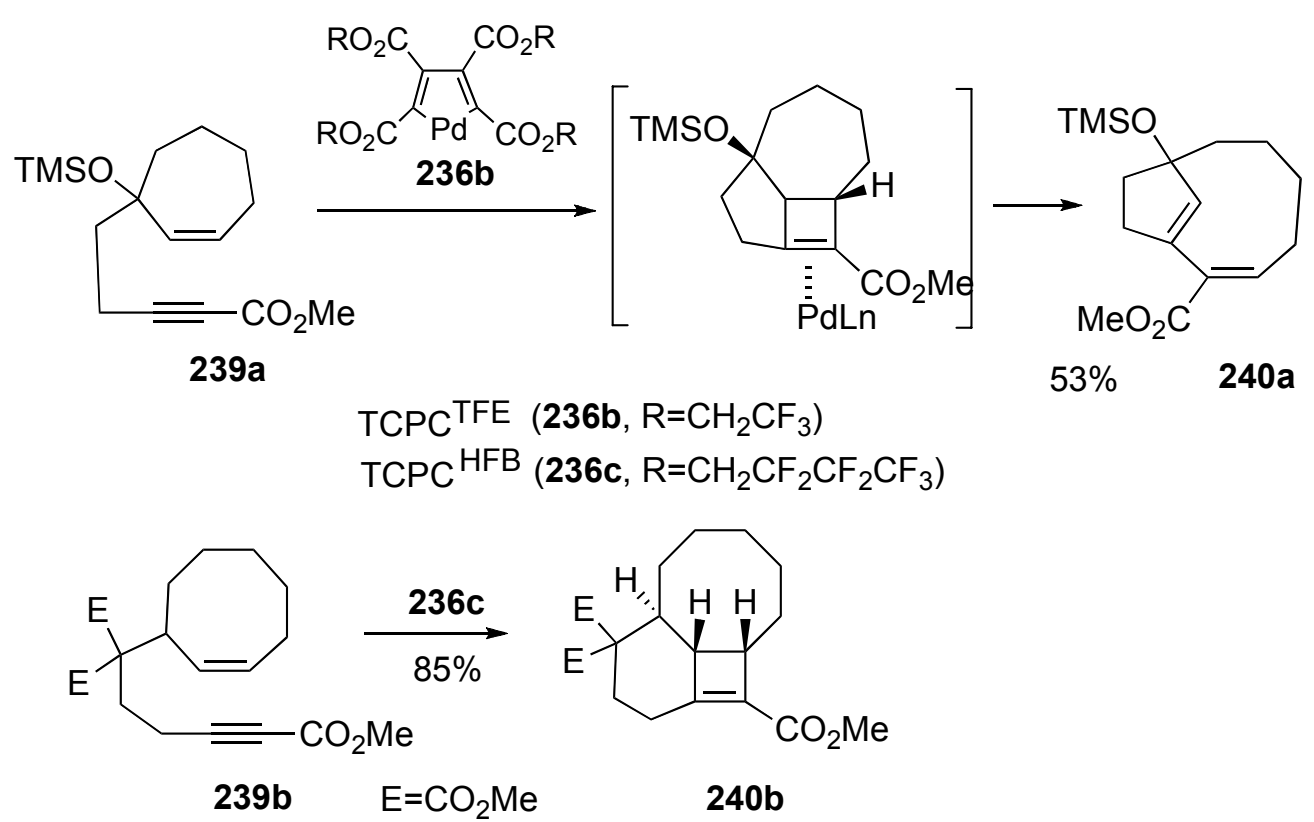

The simple platinum complex $\left(\mathrm{Ph}_{3} \mathrm{P}\right)_{2} \mathrm{Pt}(\mathrm{OAc})_{2}$ effected metathesis of enyne. Enyne 241a gave cyclized compound 242a, and the yield was comparable to that of TCPC but significantly faster. Murai and Chatani [136] also reported the $\mathrm{PtCl}_{2}$-catalyzed reaction of cycloalkene-yne 241b. In this case, exclusively bicyclic compound $\mathbf{2 4 2 b}$ was obtained in 97\% yield (Scheme 64).

In 1994, Murai and Chatani reported skeletal reorganization of 1,6-enyne using $\left[\mathrm{RuCl}_{2}(\mathrm{CO})_{3}\right]_{2}$ as a catalyst (Scheme 65) [137-138]. When the reaction of $\boldsymbol{E - 2 4 3 a}(E / Z=80 / 20)$ was carried out in the presence of $\left[\mathrm{RuCl}_{2}(\mathrm{CO})_{3}\right]_{2}$ under carbon monoxide, $E$-isomer 244a was produced predominantly. It is interesting that from $Z$-243a $(E / Z=11 / 89), E$-244a was formed. An $E / Z$ mixture of 1,7 -enyne 243b afforded only $E$-isomer of $\mathbf{2 4 4 b}$ in $86 \%$ yield. 
Scheme 64. Platinum-catalyzed skeletal reorganization.

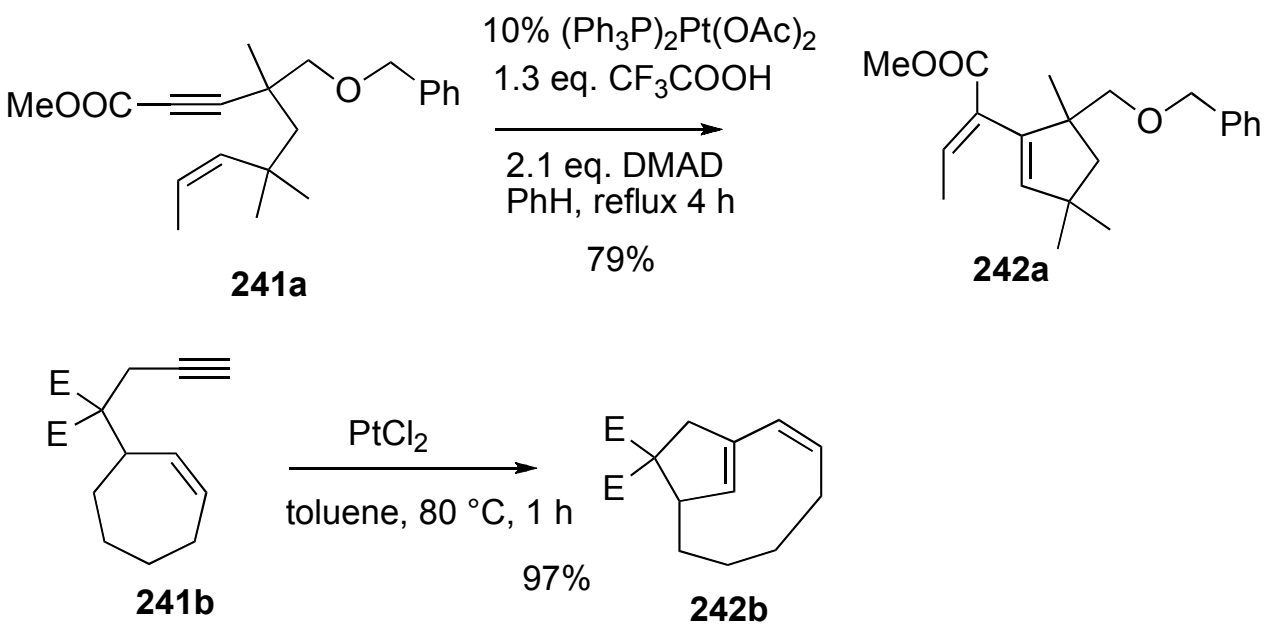

Scheme 65. Ruthenium-catalyzed skeletal reorganization.

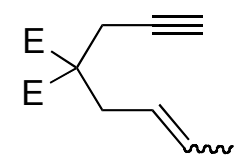

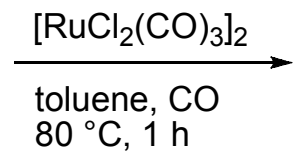

243a $80^{\circ} \mathrm{C}, 1 \mathrm{~h}$

from $E-243 a(E / Z=80 / 20)$

$Z-243 a \quad(E / Z=11 / 89)$

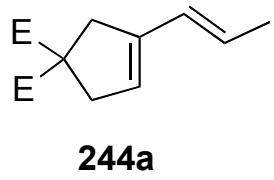

$95 \%$

$81 \%$

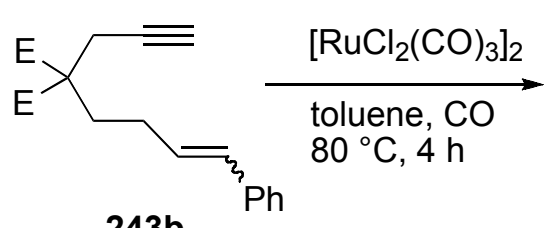

243b<smiles>FC1(F)CCC=C(C=Cc2ccccc2)C1</smiles>

$86 \% \quad 244 b$

Scheme 66. Trapping of carbenoid intermediate.

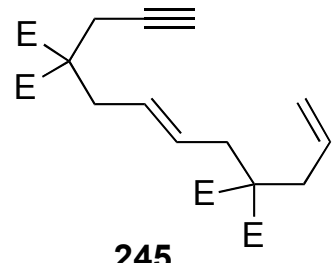

245

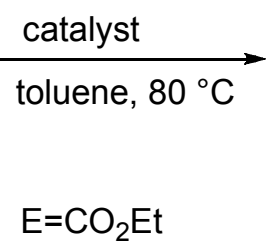

$\mathrm{E}=\mathrm{CO}_{2} \mathrm{Et}$<smiles>FC1(F)C[C@@H]2C[C@@H]2[C@@H]2CC(F)(F)C[C@@H]2C1</smiles>

246<smiles>[Y14]CC1(CC(F)(F)CC=C)CC(F)(F)C[C@H]1C</smiles>

247

\begin{tabular}{|c|c|c|}
\hline$\left[\mathrm{RuCl}_{2}(\mathrm{CO})_{3}\right]_{2}$ & $4 \mathrm{~h}$ & $84 \%$ \\
\hline $\mathrm{PtCl}_{2}$ & $4 \mathrm{~h}$ & $75 \%$ \\
\hline$\left[\mathrm{Rh}\left(\mathrm{OCOCCF}_{3}\right)_{2}\right]_{2}$ & $1 \mathrm{~h}$ & $72 \%$ \\
\hline$\left[\mathrm{IrCl}(\mathrm{CO})_{3}\right]_{\mathrm{n}}$ & $4 d$ & $54 \%$ \\
\hline $\mathrm{ReCl}(\mathrm{CO})_{5}$ & $1 d$ & $74 \%$ \\
\hline
\end{tabular}

They speculated that complex $\mathbf{2 4 7}$ having two carbenoid carbons would be generated on the alkyne carbons during the reaction [138]. To trap this intermediate, the reaction of 6,11-dien-1-yne 245, which has an olefin moiety in a tether, was carried out in the presence of $\left[\mathrm{RuCl}_{2}(\mathrm{CO})_{3}\right]_{2}$ in toluene at $80{ }^{\circ} \mathrm{C}$ for 
$4 \mathrm{~h}$ to give tetracyclic compound $\mathbf{2 4 6}$ containing two cyclopropane rings in $84 \%$ yield. It is interesting to note that other transition-metal complexes, such as $\mathrm{PtCl}_{2},\left[\mathrm{Rh}(\mathrm{OOCCF})_{2}\right]_{2},\left[\operatorname{IrCl}(\mathrm{CO})_{3}\right]_{\mathrm{n}}$, and $\mathrm{ReCl}(\mathrm{CO})_{5}$ also showed catalytic activity for this very complex transformation.

$\mathrm{Rh}$ (II)-catalyzed skeletal reorganization of 1,6- and 1,7-enynes through electrophilic activation of alkynes was also reported [139-140].

Surprisingly, in some cases, simple Lewis or Brønsted acids as the catalysts could replace $\mathrm{PtCl}_{2}$ (Scheme 67). Treatment of $\mathbf{2 4 8}$ with $\mathrm{BF}_{3} \cdot \mathrm{Et}_{2} \mathrm{O}$ or $\mathrm{HBF}_{4}$ gave skeletal reorganization product $\mathbf{2 4 9}$ in good yield [141].

Scheme 67. Lewis and Bronsted acids catalyzed skeletal reorganization.

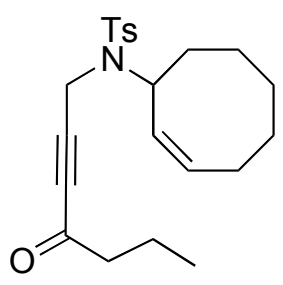

248

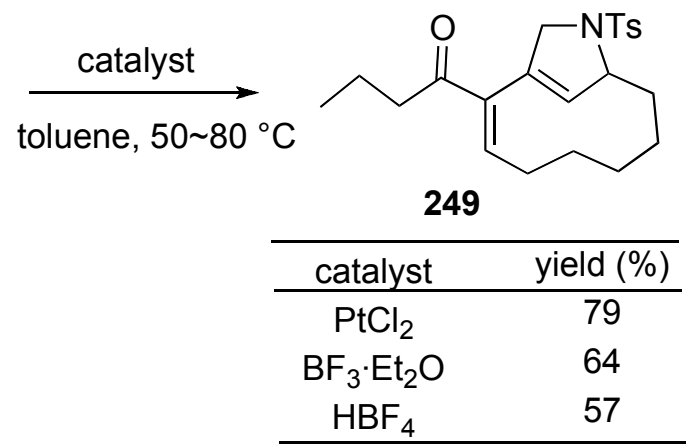

Murai and Chatani group reported skeletal reorganization of enynes to 1-vinylcycloalkene by $\mathrm{GaCl}_{3}$ [142]. The reaction of 250a proceeded in methylcyclohexene at $0{ }^{\circ} \mathrm{C}$ and was completed within $1 \mathrm{~h}$ to give 251a. It is interesting that highly strained cyclobutene derivative $\mathbf{2 5 1 b}$ was obtained from 1,7-enyne 251a in high yield (Scheme 68).

Scheme 68. Skeletal reorganization by $\mathrm{GaCl} 3$.

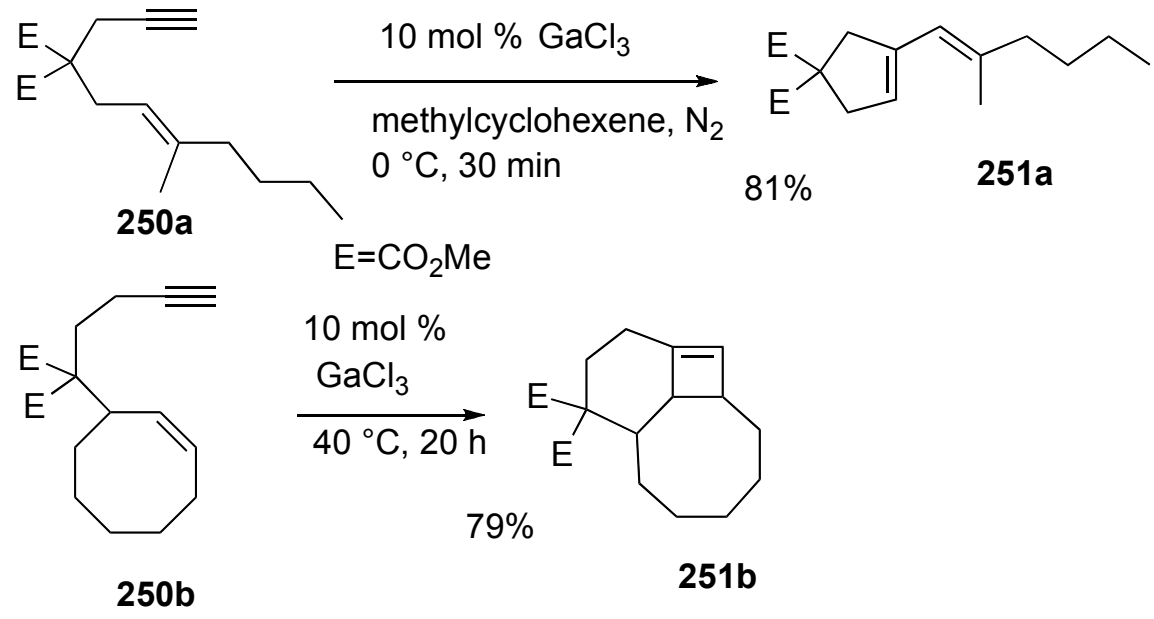

Presumably, each skeletal reorganization reaction starts by coordination of the metal to the alkyne part, and then the alkene part would attack the cation center of the alkyne coordinated by metals. However, the reaction mechanism is still not clear, and it is thought that each reaction mechanism differs depending on the metal used [143]. 


\section{Synthesis of Natural products Using Skeletal Reorganization}

Skeletal reorganization is a useful tool for the synthesis of complicated natural products. Fürstner achieved formal total syntheses of the antibiotics metacycloprodigiosin and streptorubin B by a platinum-catalyzed skeletal reorganization reaction (Scheme 69) [144]. The key step leading to the meta-bridged pyrrole core structures consisted of a metathesis reaction of electron-deficient enynes 252a and 252b catalyzed by $\mathrm{PtCl}_{2}$. The skeletal reorganization products 253a and 253b were converted into the respective target molecules.

Scheme 69. Formal total synthesis of streptorubin B and metacycloprodigiosin.

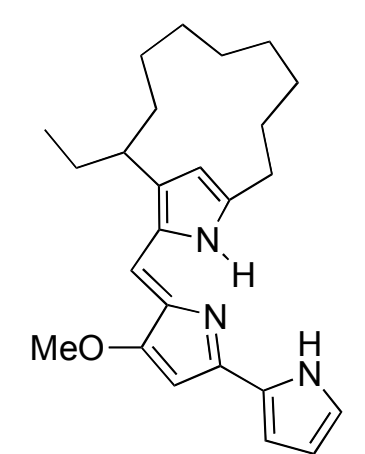

Metacycloprodigiosin

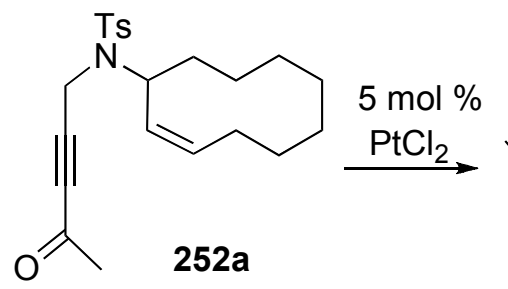<smiles></smiles>

Streptorubin B
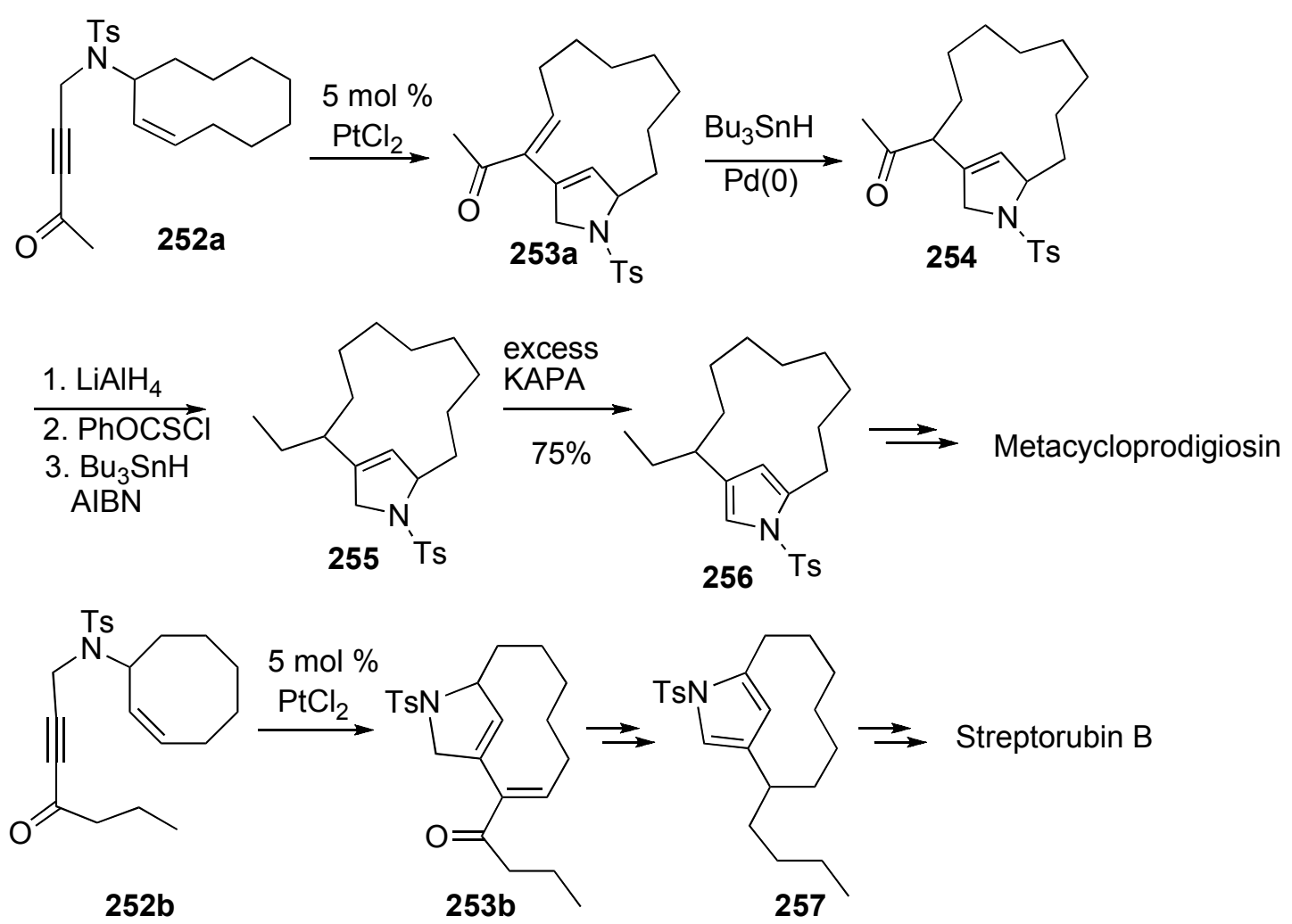

Trost succeeded in formal total synthesis of roseophilin [145]. Macrocyclic compound 260 was synthesized from enyne $\mathbf{2 5 9}$ by platinum-catalyzed skeletal reorganization. Compound $\mathbf{2 6 0}$ was converted into 261, which was led to pyrrole derivative 258 and it was already converted into roseophilin (Scheme 70). 
Scheme 70. Formal total synthesis of roseophilin.<smiles>COc1cc(-c2[nH]ccc2Cl)oc1C1=C2N=C(CCCCCCOC(=O)O[Na])C=C2[C@H]1C1CC2CCCCC1C2</smiles>

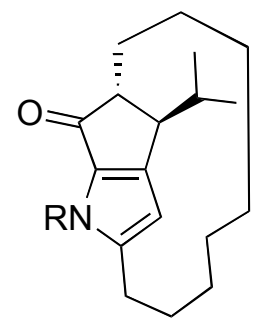

$\mathrm{R}=\mathrm{SEM}$

258

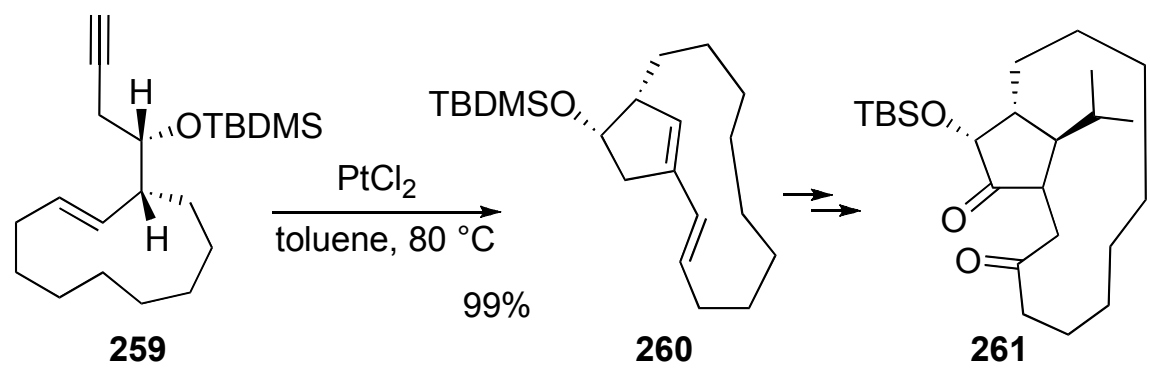

\section{Metallotropic Rearrangement}

The bond reorganization processes, defined as metallotropic shift, of various alkynyl carbene complexes with Rh [146], Mn [147], Re [148], Cr [149], Mo [149], and W [149] metals have been already reported. The rearrangement involving $\mathrm{Rh}, \mathrm{Cr}$, Mo, and $\mathrm{W}$ is a [1,3]-shift, while that with $\mathrm{Mn}$ and $\mathrm{Re}$ is formally defined as a [1,1.5]-shift. However, the metallotropic shift of ruthenium alkynyl carbene complexes has not been observed until recently (Scheme 71). The metallotropic [1,3]-shift of a transient ruthenium carbene complex is involved in the enyne ring-closing metathesis (RCM) of diyne containing substrates. On the basis of this concept, one-step construction of enediynes and oligoenynes was realized by the uniquely controlled repetitive metallotropic [1,3]-shift of ruthenium carbene species. Reaction of 262a with 19 gave ene-diyne 267a in high yield by one operation. Presumably, reaction of 262a with $1 \mathrm{~g}$ gives ruthenium carbene complex 263a, which is converted into ruthenium carbene complex 264a via [1,3]-shift. [2+2] Cycloaddition followed by ring opening gives 265a, which is converted into 266a via [1,3]-shift. From this complex 266a, ene-diyne 267a is formed. In a similar manner, 262b and 262c gave oligoenynes $267 \mathrm{~b}$ and 267c, respectively, in one operation (Scheme 72) [150].

Scheme 71. Metalotropic rearrangement.

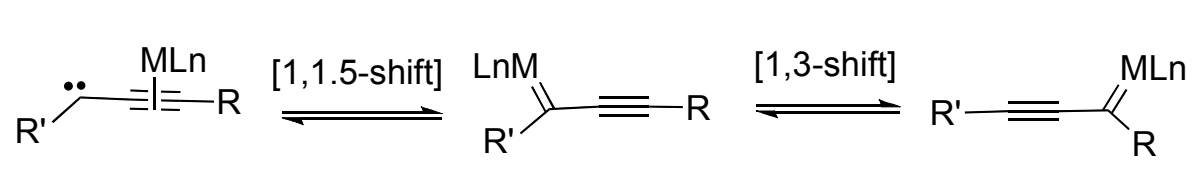


Scheme 72. Synthesis of oligoenynes by metathesis of metallotropy.

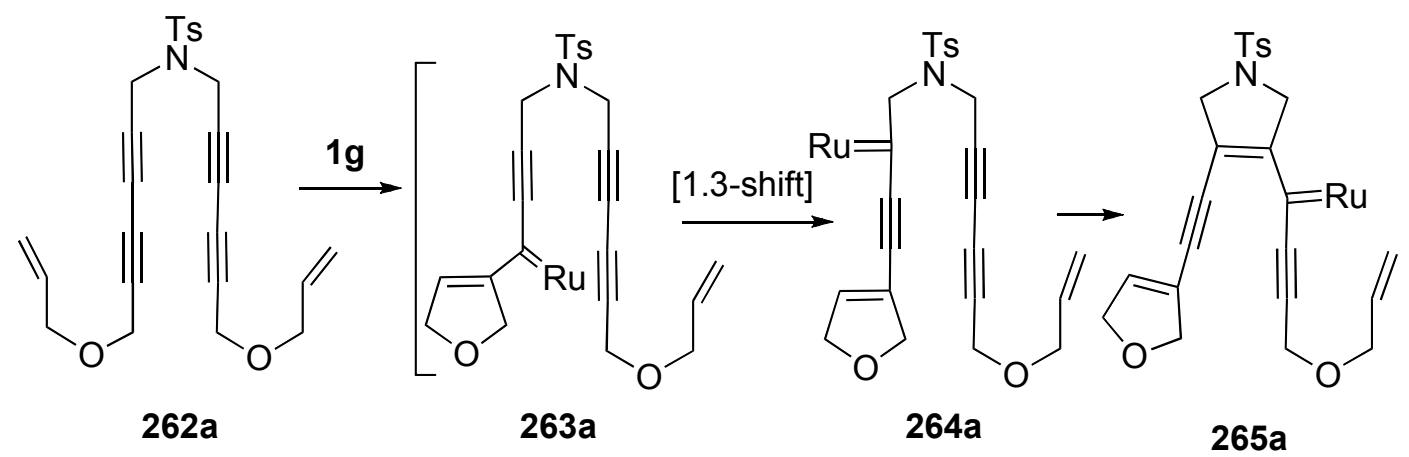<smiles>[R16]c1ccc(CCCOCC([R16])C#CC2=C(C#CC3=CCOC3)CN([As])C2)cc1</smiles>

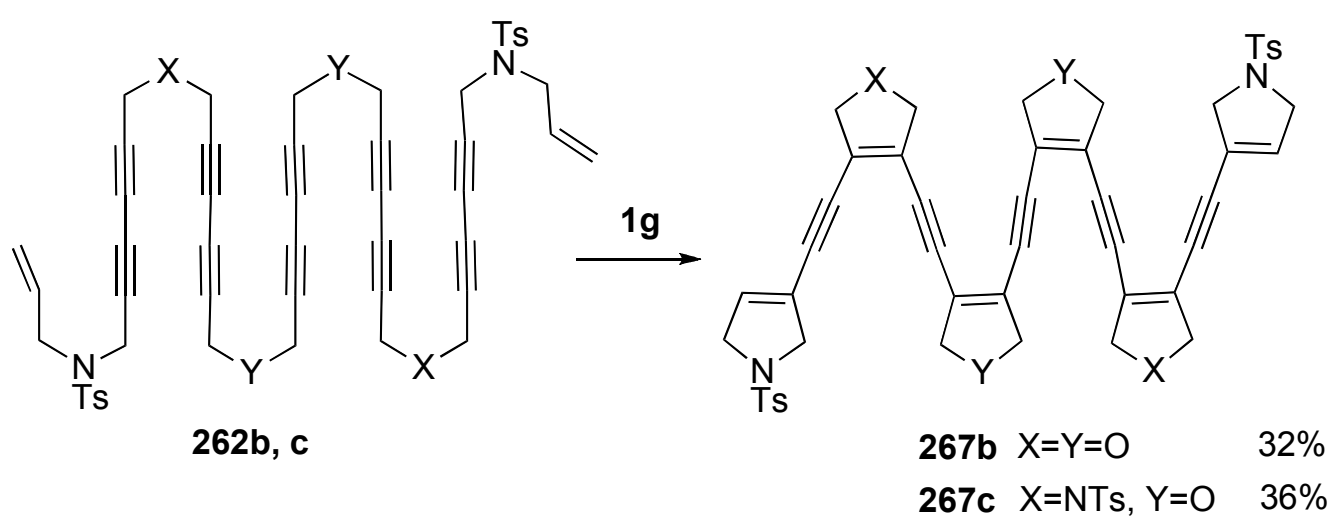

Synthesis of Natural Products Using Metallotropic Rearrangement

The metallotropic [1,3] shift of a transient ruthenium carbene complex is involved in the enyne ring-closing metathesis of diyne containing substrates. Ring-closing metathesis followed by metallotropic [1,3]-shift and cross metathesis allowed for the development of novel strategy for the total synthesis of conjugated 1,3-diyne-containing natural product $(3 R, 9 R, 10 R)$-panaxytriol [151]. When compound 268 was treated with $\mathbf{1 g}$ in the presence of 2.0 equiv. of alkene $\mathbf{2 6 9}$, the expected product $\mathbf{2 7 0}$ was obtained in $61 \%$ yield as a mixture of $Z / E$-isomers $(5: 1)$ together with 268 (10\%). Metathesis of diene in $\mathbf{2 6 8}$ gave ruthenium carbene complex 271, metallotropic [1,3] shift of which gave ruthenium carbene complex 272. Cross metathesis of 272 and alkene 269 afforded compound 270. From this compound 270, $(3 R, 9 R, 10 R)$-panaxytriol could be synthesized (Scheme 73). 
Scheme 73. Total synthesis of (3R,9R,10R)-panaxytriol.<smiles>C#CC#C/C(=C\COCC=C)CC1OC(C)(C)OC1CCc1ccccc1</smiles>

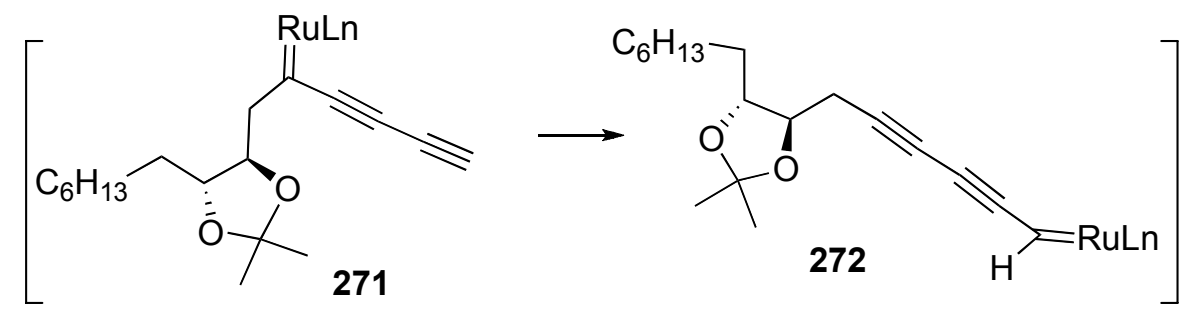

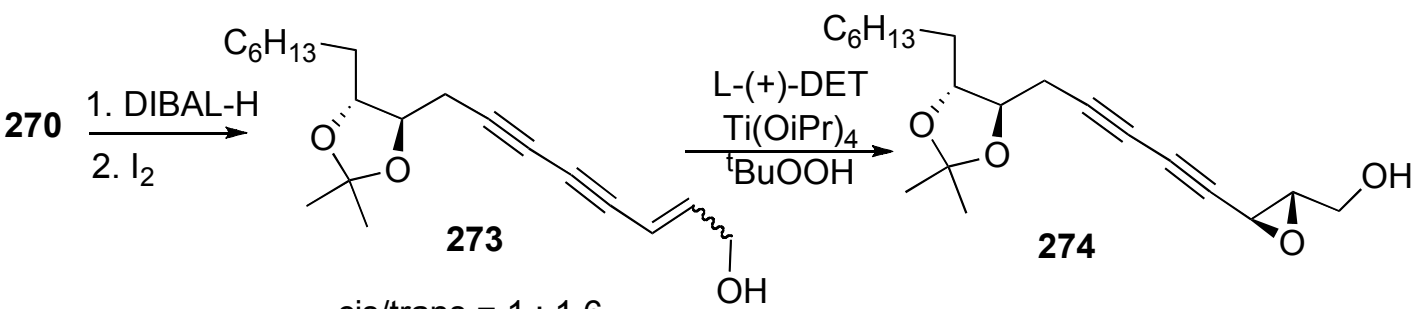
cis/trans $=1: 1.6$<smiles>C=C[C@H](O)C#CC#CC[C@H](O)[C@H](O)CCCCCCC</smiles>

$(3 R, 9 R, 10 R)$-Panaxytriol

Total synthesis of (+)-asperpentyn and (-)-tricholomenyn A have been accomplished by implementing this metathesis-based tandem reaction sequence as the key step [152]. Compound 276, which was prepared from $\mathbf{2 7 5}$ and diyne, was treated with $1 \mathrm{~g}$ under ethylene atmosphere gave 279a and 279b via 277 and 278. From 279a, asperpentyn was synthesized. When compound 280 was reacted with ethylene in the presence of $\mathbf{1 g}$, the reaction did not proceed. In a similar method, compound $\mathbf{2 8 1}$ was treated with $\mathbf{1 g}$ under ethylene to give $\mathbf{2 8 2}$, which was led to $(+)$-tricholomenyn. 
Scheme 74. Synthesis of (+)-asperpentyn and (+)-tricholomenyn A using tandem enyne metathsis.

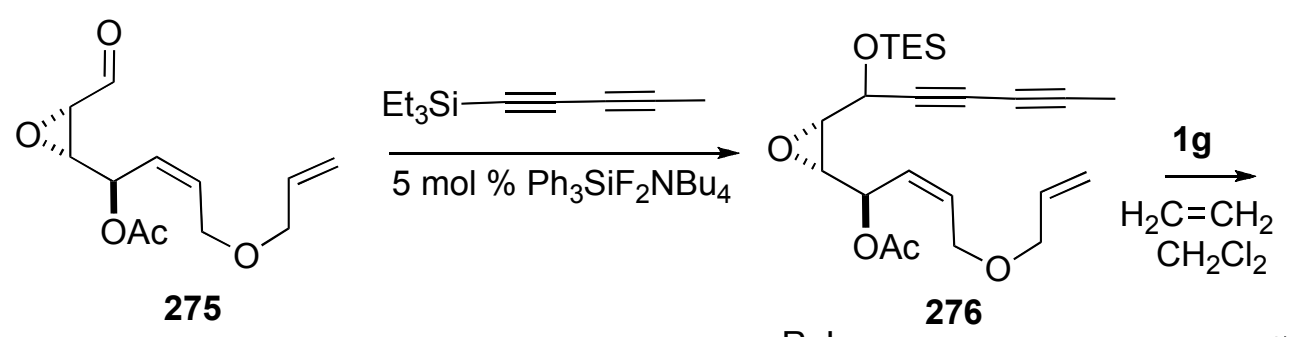

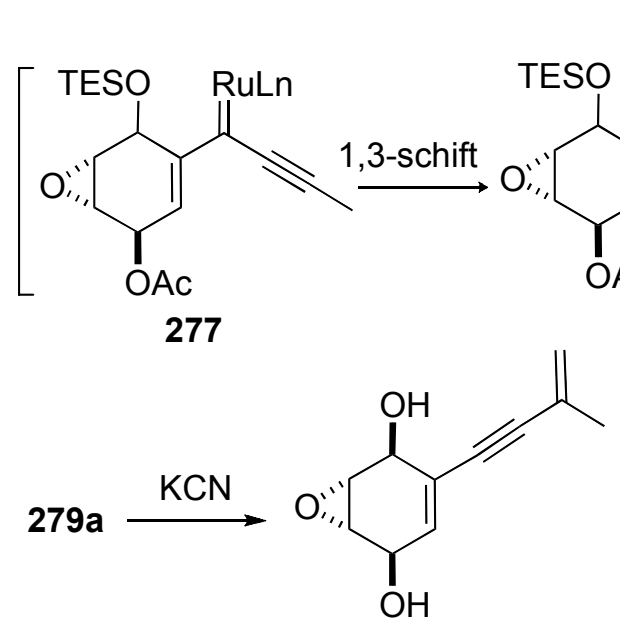

(+)-Asperpentyn

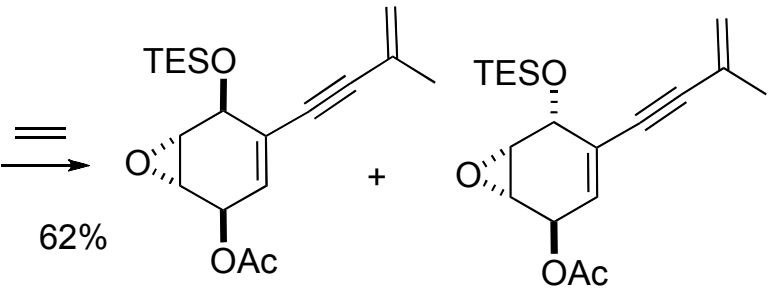

279a

279b

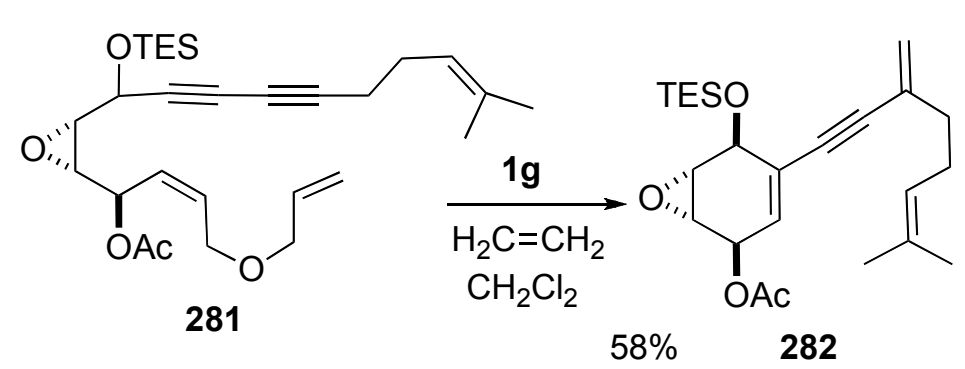

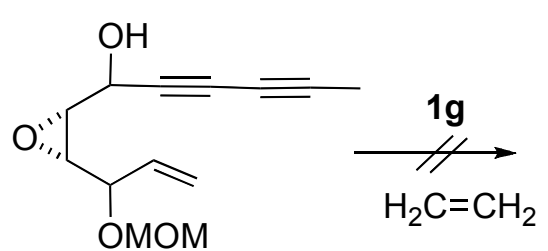

280

\section{Perspective}

Since the discovery of stable and isolable catalysts for metathesis by Schrock and Grubbs, a wide range of olefin metatheses have been reported, and olefin metathesis now plays an important role in natural product syntheses. Enyne metathesis, dienyne metathesis, cross enyne metathesis, and ROM of cycloalkene-yne have also been developed. Furthermore, skeletal reorganization using the transition metals or metallotropic rearrangement is a unique reaction. Novel procedures for the synthesis of the natural products and related compound, various complex molecules and macrocyclic compounds would be further developed using these various enyne metatheses. The retrosynthetic analysis of the natural products using these enyne metatheses would be completely different from that of the previous synthesis and the steps for the synthesis of these compounds would be shortened.

\section{References}

1. Schrock, R.R.; Murdzek, J.S.; Bazan, G.C.; Robbins, J.; DiMare, M.; O’Regan, M. Synthesis of molybdenum imido alkylidene complexes and some reactions involving acyclic olefins. $J$. Am.

Chem. Soc. 1990, 112, 3875-3886. 
2. Nguyen, S.-B.T.; Johnson, L.K.; Grubbs, R.H.; Ziller, J.W. Ring-opening metathesis polymerization (ROMP) of norbornene by a group VIII carbene complex in protic media $\mathrm{J}$. Am. Chem. Soc. 1992, 114, 3974-3975.

3. Fu, G.C.; Grubbs, R.H. The application of catalytic ring-closing olefin metathesis to the synthesis of unsaturated oxygen heterocycles. J. Am. Chem. Soc. 1992, 114, 5426-5427.

4. Fu, G.C.; Grubbs, R.H. The synthesis of nitrogen heterocycles via catalytic ring-closing metathesis of dienes. J. Am. Chem. Soc. 1992, 114, 7324-7325.

5. Fu, G.C.; Grubbs, R.H. Synthesis of cycloalkenes via alkylidene-mediated olefin metathesis and carbonyl olefination. J. Am. Chem. Soc. 1993, 115, 3800-3801.

6. Fu, G.C.; Nguyen, S.-B.T.; Grubbs, R.H. Catalytic ring-closing metathesis of functionalized dienes by a ruthenium carbene complex. J. Am. Chem. Soc. 1993, 115, 9856-9857.

7. Schwab, P.; France, M.B.; Ziller, J.W.; Grubbs, R.H. A series of well-defined metathesis catalysts-synthesis of $\left[\mathrm{RuCl}_{2}(\mathrm{CHR})\left(\mathrm{PR}_{3}\right)_{2}\right]$ and its reactions. Angew. Chem. Int. Ed. Engl. 1995, 34, 2039-2041.

8. Weskamp, T.; Schattenmann, W.C.; Spiegler, M.; Herrmann, W.A. A novel class of ruthenium catalysts for olefin metathesis. Angew. Chem. Int. Ed. 1998, 37, 2490-2493.

9. Weskamp, T.; Kohl, F.J.; Hieringer, W.; Gleich, D.; Herrmann, W.A. highly active ruthenium catalysts for olefin metathesis: The synergy of N-heterocyclic carbenes and coordinatively labile ligands. Angew. Chem. Int. Ed. 1999, 38, 2416-2419.

10. Huang, J.; Stevens, E.D.; Nolan, S.P.; Peterson, J.L. Olefin metathesis-active ruthenium complexes bearing a nucleophilic carbene ligand. J. Am. Chem. Soc. 1999, 121, 2674-2678.

11. Huang, J.; Schanz, H.-J.; Stevens, E.D.; Nolan, S.P. Influence of sterically demanding carbene ligation on catalytic behavior and thermal stability of ruthenium olefin metathesis catalysts. Organometallics 1999, 18, 5375-5380.

12. Scholl, M.; Ding, S.; Lee, C.W.; Grubbs, R.H. Synthesis and activity of a new generation of ruthenium-based olefin metathesis catalysts coordinated with 1,3-dimesityl-4,5-dihydroimidazol-2-ylidene ligands. Org. Lett. 1999, 1, 953-956.

13. Scholl, M.; Trnka, T.M.; Morgan, J.P.; Grubbs, R.H. Increased ring closing metathesis activity of ruthenium-based olefin metathesis catalysts coordinated with imidazolin-2-ylidene ligands. Tetrahedron Lett. 1999, 40, 2247-2250.

14. Chaterjee, A.K.; Morgan, J.P.; Scholl, M.; Grubbs, R.H. Synthesis of functionalized olefins by cross and ring-closing metatheses. J. Am. Chem. Soc. 2000, 122, 3783-3784.

15. Choi, T.-L.; Lee, C.W.; Chatterjee, A.K.; Grubbs, R.H. Olefin metathesis involving ruthenium enoic carbene complexes. J. Am. Chem. Soc. 2001, 123, 10417-10418.

16. Chatterjee, A.K.; Grubbs, R.H. Formal vinyl $\mathrm{CH}$ activation and allylic oxidation by olefin metathesis. Angew. Chem. Int. Ed. 2002, 41, 3171-3174.

17. For 1h: Garber, S.B.; Kingsbury, J.S.; Gray, B.L.; Hoveyda, A.H. Efficient and recyclable monomeric and dendritic Ru-based metathesis catalysts. J. Am. Chem. Soc. 2000, 122, 8168-8179.

18. For 1i: Michrowska, A.; Bujok, R.; Harutyunyan, S.; Sashuk, V.; Dolgonos, G.; Grela, K.Nitro-substituted Hoveyda-Grubbs ruthenium carbenes: Enhancement of catalyst activity through electronic activation. J. Am. Chem. Soc. 2004, 126, 9318-9325. 
19. For 1i: Michrowska, A.; Mennecke, K.; Kunz, U.; Kirschning, A.; Grela, K. A new concept for the noncovalent binding of a ruthenium-based olefin metathesis catalyst to polymeric phases: Preparation of a catalyst on raschig rings. J. Am. Chem. Soc. 2006, 128, 13261-13267.

20. For 1j: Wakamatsu, H.; Blechert, S. A new highly efficient ruthenium metathesis catalyst. Angew. Chem., Int. Ed. 2002, 41, 2403-2405.

21. For 1j: Zaja, M.; Connon, S.J.; Dunne, A.M.; Rivard, M.; Buschmann, N.; Jiricek, J.; Blechert, S. Ruthenium olefin metathesis catalysts with modified styrene ethers: Influence of steric and electronic effects. Tetrahedron 2003, 59, 6545-6558.

22. For 1k: Love, J.A.; Morgan, J.P.; Trnka, T.M.; Grubbs, R.H. A practical and highly active ruthenium-based catalyst that effects the cross metathesis of acrylonitrile. Angew. Chem. Int. Ed. 2002, 41, 4035-4037.

23. Mori, M. Enyne metathesis. Top. Organomet. Chem. 1998, 1, 133-154.

24. Poulsen, C.S.; Madsen, R. Enyne metathesis catalyzed by ruthenium carbene complexes. Synthesis 2003, 1-18.

25. Mori, M. Handbook of Metathesis; Grubbs, R.H., Ed.; WILEY-VCH: Weinheim, Germany, 2003; Volume 2, pp. 176-204.

26. Giessert, A.J.; Diver, S.T. Enyne metathesis (enyne bond reorganization). Chem. Rev. 2004, 104, $1317-1382$.

27. Mori, M.; Kitamura, T. Ene-yne and alkyne metathesis. In Comprehensive Organometallic Chemistry III, Transition Metal Organometallics in Organic Synthesis; Hiyama, T., Ed.; Elsevier: London, UK, 2005; pp. 271-310.

28. Katz, T.J.; Sivavec, T.M. Metal-catalyzed rearrangement of alkene-alkynes and the stereochemistry of metallacyclobutene ring opening. J. Am. Chem. Soc. 1985, 107, 737-738.

29. Sivavec, T.M.; Katz, T.J.; Chiang, M.Y.; Yang, G.X.-Q. A metal pentadienyl prepared by reacting a metal carbyne with an enyne. Organometallics 1989, 8, 1620-1625.

30. Katz, T.J.; Yang, G.X.-Q. Reactions of enynes with adsorbed metal-carbenes. Tetrahedron Lett. 1991, 32, 5895-5898.

31. Watanuki, S.; Ochifuji, N.; Mori, M. Chromium-catalyzed intramolecular enyne metathesis. Organometallics 1994, 13, 4129-4130.

32. Watanuki, S.; Ochifuji, N.; Mori, M. Chromium-catalyzed intramolecular enyne metathesis. Organometallics 1995, 14, 5062-5067.

33. Mori, M.; Watanuki, S. New synthesis of pyrrolidine derivatives via the chromacyclobutanes generated from enynes and Fischer carbene complexes. J. Chem. Soc., Chem. Commun. 1992, 1082-1084.

34. Watanuki, S.; Mori, M. New synthesis of piperidine derivatives via the chromacyclobutane. Heterocycles 1993, 35, 679-682.

35. Kinoshita, A.; Mori, M. Ruthenium catalyzed enyne metathesis. Synlett 1994, 1020-1022.

36. Kinoshita, A.; Sakakibara, N.; Mori, M. Novel 1,3-diene synthesis from alkyne and ethylene by ruthenium-catalyzed enyne metathesis. Tetrahedron 1999, 55, 8155-8167.

37. Lippstreu, J.J.; Straub, B.F. Mechanism of enyne metathesis catalyzed by Grubbs ruthenium-carbene complexes: A DFT study. J. Am. Chem. Soc. 2005, 127, 7444-7457. 
38. Mori, M.; Sakakibara, N.; Kinoshita, A. Remarkable effect of ethylene gas in the intramolecular enyne metathesis of terminal alkynes. J. Org. Chem. 1998, 63, 6082-6083.

39. Kitamura, T.; Sato, Y.; Mori, M. Unexpected results of enyne metathesis using a ruthenium complex containing an $N$-heterocyclic carbene ligand. Chem. Commun. 2001, 1258-1259.

40. Kitamura, T.; Sato, Y.; Mori, M. Effects of Substituents on the multiple bonds on ring-closing metathesis of enynes. Adv. Synth. Catal. 2002, 344, 678-693.

41. Debleds, O.; Campagne, J.-M. 1,5-Enyne metathesis. J. Am. Chem. Soc. 2008, 130, 1562-1563.

42. Micalizio, G. C.; Schreiber, S.L. A boronic ester annulation strategy for diversity-oriented organic synthesis. Angew. Chem. Int. Ed. 2002, 41, 152-154.

43. Micalizio, G.C.; Schreiber, S.L. An alkynylboronic ester annulation: Development of synthetic methods for application to diversity-oriented organic synthesis. Angew. Chem. Int. Ed. 2002, 41, 3272-3276.

44. Yao, Q. Rapid assembly of structurally defined and highly functionalized conjugated dienes via tethered enyne metathesis. Org. Lett. 2001, 3, 2069-2072.

45. Miller, R.L.; Maifeld, S.V; Lee, D. Ruthenium-catalyzed silyl ether formation and enyne metathesis sequence: Synthesis of siloxacycles from terminal alkenyl alcohols and alkynylsilanes. Org. Lett. 2004, 6, 2773-2776.

46. Schramm, M.P.; Reddy, D.S.; Kozmin, S.A. siloxyalkyne-alkene metathesis: Rapid access to highly functionalized enones. Angew. Chem. Int. Ed. 2001, 40, 4274-4277.

47. Clark, J.S.; Trevitt, G.P.; Boyall, D.; Stammen, B. Synthesis of alkenyl-substituted cyclic enol ethers by catalytic ring-closing metathesis of alkynyl ethers. Chem. Commun. 1998, 2629-2630.

48. Saito, N.; Sato, Y.; Mori, M. Synthesis of cyclic dienamide using ruthenium-catalyzed ring-closing metathesis of ene-ynamide. Org. Lett. 2002, 4, 803-806.

49. Mori, M.; Wakamatsu, H.; Saito, N.; Sato, Y.; Narita, R.; Sato, Y.; Fujita, R. Synthesis of cyclic dienamide using ruthenium-catalyzed ring-closing metathesis of ene-ynamide. Tetrahedron 2006, $62,3872-3881$.

50. Villar, H.; Frings, M.; Bolm, C. Ring closing enyne metathesis: A powerful tool for the synthesis of heterocycles, Chem. Soc. Rev. 2007, 36, 55-66.

51. Kotha, S.; Meshram, M.; Tiwari, A. Advanced approach to polycyclics by a synergistic combination of enyne metathesis and Diels-Alder reaction. Chem. Soc. Rev. 2009, 38, 2065-2092.

52. Kang, B.; Kim, D.H.; Do, Y.; Chang, S. Conjugated enynes as a new type of substrates for olefin metathesis. Org. Lett. 2003, 5, 3041-3043.

53. Peppers, B.P.; Diver, S.T. Tandem cyclopropanation/ring-closing metathesis of dienynes. J. Am. Chem. Soc. 2004, 126, 9524-9525.

54. Yoshida, K.; Shishikura, Y.; Takahashi, H.; Imamoto, T. Synthesis of styrenes using ruthenium-catalyzed ring-closing enyne metathesis. Org. Lett. 2008, 10, 2777-2780.

55. Takahashi, H.; Yoshida, K.; Yanagisawa, A. Synthesis of carbocyclic aromatic compounds using ruthenium-catalyzed ring-closing enyne metathesis. J. Org. Chem. 2009, 74, 3632-3640.

56. Murakami, M.; Kadowaki, S.; Matsuda, T. Molybdenum-catalyzed ring-closing metathesis of allenynes. Org. Lett. 2005, 7, 3953-3956.

57. Kinoshita, A.; Mori, M. Total synthesis of (-)-stemoamide using ruthenium-catalyzed enyne metathesis reaction. J. Org. Chem. 1996, 61, 8356-8357. 
58. Kinoshita, A.; Mori, M. Total synthesis of (-)-stemoamide using ruthenium-catalyzed enyne metathesis reaction. Heterocycles 1997, 46, 287-299.

59. Barrett, A.G.M.; Baugh, S.P.D.; Braddock, D.C.; Flack, K.; Gibson, V.C.; Giles, M.R.; Marshall, E.L.; Procopiou, P.A.; White, A.J.P.; Williams, D.J. Rapid entry into mono-, bi-, and tricyclic $\beta$-lactam arrays via alkene metathesis. J. Org. Chem. 1998, 63, 7893-7907.

60. Duboc, R.; Henaut, C.; Savignac, M.; Genet, J.-P.; Bhatnagar, N. Synthetic approach to tricyclic $\beta$-lactams using metathesis and Diels-Alder reactions. Tetrahedron Lett. 2001, 42, 2461-2464.

61. Hoye, T.R.; Donaldson, S.M.; Vos, T.J. An enyne metathesis/(4 + 2)- dimerization Route to ( \pm )-differolide. Org. Lett. 1999, 1, 277-279.

62. Layton, M.E.; Morales, C.A.; Shair, M.D. Biomimetic synthesis of (-)-Longithorone A. J. Am. Chem. Soc. 2002, 124, 773-775.

63. Brenneman, J.B.; Martin, S.F. Application of intramolecular enyne metathesis to the synthesis of aza[4.2.1]bicyclics: Enantiospecific total synthesis of (+)-anatoxin-a. Org. Lett. 2004, 6, 1329-1331.

64. Brenneman, J.B.; Machauer, R.; Martin, S.F. Enantioselective synthesis of (+)-anatoxin-a via enyne metathesis. Tetrahedron 2004, 60, 7301-7314.

65. Mori, M.; Tomita, T.; Kita, Y.; Kitamura, T. Synthesis of (+)-anatoxin- $a$ using enyne metathesis. Tetrahedron Lett. 2004, 45, 4397-4399.

66. Tomita, T.; Kita, Y.; Kitamura, T.; Sato, Y.; Mori, M. Synthesis of (+)-anatoxin- $a$ using enyne metathesis. Tetrahedron 2006, 62, 10518-10527.

67. Aggarwal, V.K.; Astle, C.J.; Roger-Evans, M. A concise asymmetric route to the bridged bicyclic tropane alkaloid ferruginine using enyne ring-closing metathesis. Org. Lett. 2004, 6, 1469-1471.

68. Reddy, D.S.; Kozmin, S.A. Efficient and general approach to eremophilanes using siloxyalkyne-alkene metathesis. J. Org. Chem. 2004, 69, 4860-4862.

69. Boyer, F.-D.; Hanna, I. Synthesis of allocolchicines using sequential ring-closing enyne metathesis-Diels-Alder reactions. Org. Lett. 2007, 9, 715-718.

70. Bedel, O.; Francais, A.; Haudrechy, A. Diastereoselective access to the spirotetronate subunit of the quartromicins. Synlett, 2005, 2313-2316.

71. Satcharoen, V.; McLean, N.J.; Kemp, S.C.; Camp, N.P.; Brown, R.C.D. Stereocontrolled synthesis of (-)-galanthamine. Org. Lett. 2007, 9, 1867-1869.

72. Kaliappan, K.P.; Ravikumar, V. Angucyclinone Antibiotics: Total syntheses of YM-181741, (+)-ochromycinone, (+)-rubiginone $\mathrm{B}_{2}$, (-)-tetrangomycin, and MM-47755. J. Org. Chem. 2007, 72, 6116-6126.

73. Krishna, P.R.; Reddy, P.S. Stereoselective total synthesis of (+)-valienamine and (+)-4-epi-valienamine via a ring-closing enyne metathesis protocol. Synlett, 2009, 209-212.

74. Imahori, T.; Ojima, H.; Yoshimura, Y.; Takahata, H. Acceleration effect of an allylic hydroxy group on ring-closing metathesis of terminal alkynes: Scope, application, and mechanistic insights. Chem. Eur. J. 2008, 14, 10762-10771.

75. Zuercher, W.J.; Scholl, M.; Grubbs, R.H. Ruthenium-catalyzed polycyclization reactions. J. Org. Chem. 1998, 63, 4291-4298. 
76. Royer, F.; Vilain, C.; Elkaiem, L.; Grimaud, L. Selective domino ring-closing metathesis-cross-metathesis reactions between enynes and electron-deficient alkenes. Org. Lett. 2003, 5, 2007-2009.

77. Kitamura, T.; Sato, Y.; Mori, M. Synthetic study of (+)-anthramycin using ring-closing enyne metathesis and cross-metathesis. Tetrahedron 2004, 60, 9649-9657.

78. Evans, M.A.; J.P. Morken, Asymmetric synthesis of (-)-dihydroxanthatin by the stereoselective Oshima-Utimoto reaction. Org. Lett. 2005, 7, 3371-3373.

79. Kummer, D.A.; Brenneman, J.B.; Martin, S.F. Application of a domino intramolecular enyne metathesis/cross metathesis reaction to the total synthesis of (+)-8-epi-xanthatin. Org. Lett. 2005, 7, 4621-4623.

80. Paquette L.A.; Lai, K.W. Studies directed toward the total synthesis of lancifodilactone G: An expeditious route to the ABC subunit. Org. Lett. 2008, 10, 2111-2113.

81. Kim, S.-H.; Bowden, N.; Grubbs, R.H. Catalytic ring closing metathesis of dienynes: Construction of fused bicyclic rings. J. Am. Chem. Soc. 1994, 116, 10801-10802.

82. Kim, S.-H.; Zuercher, W.J.; Bowden, N.; Grubbs, R.H. Catalytic ring closing metathesis of dienynes: Construction of fused bicyclic [n.m.0] rings. J. Org. Chem. 1996, 61, 1073-1081.

83. Renaud, J.; Graf, C.-D.; Oberer, L. Ruthenium-catalyzed enyne metathesis of acetylenic boronates: A concise route for the construction of cyclic 1,3-dienylboronic esters. Angew. Chem. Int. Ed. 2000, 39, 3101-3104.

84. Timmer, M.S.M.; Ovaa, H.; Filippov, D.V.; van der Marel, G.A.; van Boom, J.H. Synthesis of phosphorus mono- and bicycles by catalytic ring-closing metathesis. Tetrahedron Lett. 2001, 42, 8231-8233.

85. Huang, J.; Xiong, H.; Hsung, R.P.; Rameshkumar, C.; Mulder, J.A.; Grebe, T.P. The first successful base-promoted isomerization of propargyl amides to chiral ynamides. Applications in ring-closing metathesis of ene-ynamides and tandem RCM of diene-ynamides. Org. Lett. 2002, 4, 2417-2420.

86. Gonzalez-Gomez, A.; Dominguez, G.; Perez-Castells, J. Enyne and dienyne metathesis reactions in $\beta$-carbolines. Tetrahedron Lett. 2005, 46, 7267-7270.

87. Codesido, E.M.; Castedo, L.; Granja, J.R. Access to [6.4.0]carbocyclic systems by tandem metathesis of dienynes. A step toward the synthesis of a $\mathrm{PreD}_{3}-\mathrm{D}_{3}$ transition state analogue. Org. Lett. 2001, 3, 1483-1486.

88. Boyer, F.-D.; Hanna, I.; Ricard, L. Formal synthesis of ( \pm )-guanacastepene A: A tandem ring-closing metathesis approach. Org. Lett. 2004, 6, 1817-1820.

89. Krishna, P.R.; Narsingam, M. Studies directed towards the stereoselective total synthesis of ilexlactone via a tandem ring-closing enyne metathesis protocol. Tetrahedron Lett. 2007, 48, 8721-8724.

90. Shimizu, K.; Takimoto, M.; Mori, M. Novel synthesis of heterocycles having a functionalized carbon center via nickel-mediated carboxylation: Total synthesis of erythrocarine. Org. Lett. 2003, $5,2323-2325$.

91. Fukumoto, H.; Esumi, T.; Ishihara, J.; Hatakeyama, S. Total synthesis of ( \pm )-erythravine based on ring closing dienyne metathesis. Tetrahedron Lett. 2003, 44, 8047-8049. 
92. Honda, T.; Namiki, H.; Kaneda, K.; Mizutani, H. First diastereoselective chiral synthesis of (-)-securinine. Org. Lett. 2004, 6, 87-89.

93. Honda, T.; Namiki, H.; Watanabe, M.; Mizutani, H. First total synthesis of (+)-viroallosecurinine. Tetrahedron Lett. 2004, 45, 5211-5213.

94. Fukumoto, H.; Takahashi, K.; Ishihara, J.; Hatakeyama, S. Total synthesis of (+)- $\beta$-erythroidine. Angew. Chem. Int. Ed. 2006, 45, 2731-2734.

95. Movassaghi, M.; Piizzi, G.; Siegel, D.S.; Piersanti, G.; Enantioselective total synthesis of (-)-acylfulvene and (-)-irofulven. Angew. Chem. Int. Ed. 2006, 45, 5859-5863.

96. Mukherjee, S.; Lee, D. Application of tandem ring-closing enyne metathesis: Formal total synthesis of (-)-cochleamycin A. Org. Lett. 2009, 11, 2916-2919.

97. Kinoshita, A.; Sakakibara, N.; Mori, M. Novel 1,3-diene synthesis from alkyne and ethylene by ruthenium-catalyzed enyne metathesis. J. Am. Chem. Soc. 1997, 119, 12388-12389.

98. Kinoshita, A.; Sakakibara, N.; Mori, M. Novel 1,3-diene synthesis from alkyne and ethylene by ruthenium-catalyzed enyne metathesis. Tetrahedron 1999, 55, 8155-8167.

99. Mori, M.; Tonogaki, K.; Kinoshita, A. Synthesis of 1,3-diene from alkyne and ethylene : Acetic acid 2-methylene-3-phenethyl-but-3-enyl ester. Org. Synth. 2004, 81, 1-13.

100. Tonogaki, K.; Mori, M. An improved 1,3-diene synthesis from alkyne and ethylene using cross-enyne metathesis. Tetrahedron Lett. 2002, 43, 2235-2238.

101. Smulik, J.A; Diver, S.T. Terminal alkyne-ethylene cross-metathesis: Reaction of 1-substituted propargyl esters at elevated ethylene pressure. J. Org. Chem. 2000, 65, 1788-1792.

102. Smulik, J.A.; Diver, S.T. Expanded scope in ethylene-alkyne cross-metathesis: Coordinating heteroatom functionality at the propargylic position. Org. Lett. 2000, 2, 2271-2274.

103. Smulik, J.A.; Giessert, A.J.; Diver S.T. Ethylene metathesis of sulfur-containing alkynes. Tetrahedron Lett. 2002, 43, 209-211.

104. Stragies, R.; Schuster, M.; Blechert, S. A crossed yne-ene metathesis showing atom economy. Angew. Chem. Int. Ed. 1997, 36, 2518-2520.

105. Kotha, S.; Halder, S.; Brahmachary, E. Synthesis of highly functionalized phenylalanine derivatives via cross-enyne metathesis reactions. Tetrahedron 2002, 58, 9203-9208.

106. Schürer, S.C.; Blechert, S. A versatile synthesis of substituted tetrahydropyridines. Tetrahedron Lett. 1999, 40, 1877-1880.

107. Mix, S.; Blechert, S. Synthesis of cis-fused carbo-bicycles by domino enyne cross-metathesis/intramolecular Diels-Alder reaction. Org. Lett. 2005, 7, 2015-2018.

108. Kalbarczyk, K.P.; Diver, S.T. Enyne metathesis/brønsted acid-promoted heterocyclization. J. Org. Chem. 2009, 74, 2193-2196.

109. Kulkarni, A.A.; Diver, S.T. Cycloheptadiene ring synthesis by tandem intermolecular enyne metathesis. Org. Lett. 2003, 5, 3463-3466.

110. Mori, M.; Tonogaki, K.; Nishiguchi, N. Syntheses of anolignans A and B using ruthenium-catalyzed cross-enyne metathesis. J. Org. Chem. 2002, 67, 224-226.

111. Saito, N.; Masuda, M.; Saito, H.; Takenouchi, K.; Ishizuka, S.; Namekawa, J.; Takimoto-Kamimura, M.; Kittaka, A. synthesis of 24,24-ethanovitamin $\mathrm{D}_{3}$ lactones using ruthenium-catalyzed intermolecular enyne metathesis: Potent vitamin D receptor antagonists. Synthesis 2005, 2533-2543. 
112. Kaliappan, K.P.; Subrahmanyam, A.V. A new versatile strategy for C-aryl glycosides. Org. Lett. 2007, 9, 1121-1124.

113. Kim, C.H.; An, H.J.; Shin, W.K.; Yu, W.; Woo, S.K.; Jung, S.K.; Lee, E. Stereoselective synthesis of (-)-amphidinolide E. E. Chem. Asian J. 2008, 3, 1523-1534.

114. Kim, C.H.; An, H.J.; Shin, W.K.; Yu, W.; Woo, S.K.; Jung. S.K.; Lee, E. Total synthesis of (-)-amphidinolide E. Angew. Chem. Int. Ed. 2006, 45, 8019-8021.

115. Ko, H.M.; Lee, C.W.; Kwon, H.K.; Chung, H.S.; Choi, S.Y.; Chung, Y.K.; Lee, E. Total synthesis of (-)-amphidinolide K. Angew. Chem. Int. Ed. 2009, 48, 2364-2366.

116. Fürstner, A.; Flügge, S.; Larionov, O.; Takahashi, Y.; Kubota, T.; Kobayashi, J. Total synthesis and biological evaluation of amphidinolide V and analogues. Chem. Eur. J. 2009, 15, 4011-4029.

117. Fürstner, A.; Larionov, O.; Flugge, S. What is amphidinolide V? Report on a likely conquest. Angew. Chem. Int. Ed. 2007, 46, 5545-5548.

118. Kitamura, T.; Mori, M. Ruthenium-catalyzed ring-opening and ring-closing enyne metathesis. Org. Lett. 2001, 3, 1161-1164.

119. Randl, S.; Lucas, N.; Connon, S.J.; Blechert, S. A mechanism switch in enyne metathesis reactions involving rearrangement: Influence of heteroatoms in the propargylic position. Adv. Synth. Catal. 2002, 344, 631-633.

120. Rückert, A.; Eisele, D.; Blechert, S. Domino metathesis of alkynyl substituted cycloolefins. Tetrahedron Lett. 2001, 42, 5245-5247.

121. Mori, M.; Kuzuba, Y.; Kitamura, T.; Sato, Y. Ruthenium-catalyzed ROM - RCM of cycloalkene-yne. Org. Lett. 2002, 4, 3855-3858.

122. Kitamura, T.; Kuzuba, Y.; Sato, Y.; Wakamatsu, H.; Fujita, R.; Mori, M. ROM-RCM of cycloalkene-yne. Tetrahedron 2004, 60, 7375-7389.

123. Mori, M.; Wakamatsu, H.; Tonogaki, K.; Fujita, R.; Kitamura, T.; Sato, Y. Synthesis of isoquinoline derivatives using ROM-RCM of cyclobutene-yne. J. Org. Chem. 2005, 70, 1066-1069.

124. Arjona, O.; Csaky, A.G.; Murcia, M.C.; Plumet, J. Regioselective domino metathesis of 7-oxanorbornene derivatives as a new stereoselective entry into 2,6-dioxabicyclo[4.3.0]nonenes. Tetrahedron Lett. 2000, 41, 9777-9779.

125. Arjona, O.; Csaky, A.G.; Leon, V.; Medel, R.; Plumet, J. Control of product distribution in the domino metathesis reactions of $N$-alkynyl 2-azabicyclo[2.2.1]hept-5-en-3-ones. A convenient synthesis of functionalized $\gamma$-lactams and indolizidinones. Tetrahedron Lett. 2004, 45, 565-567.

126. Mori, M.; Wakamatsu, H.; Sato, Y.; Fujita, R. ROM-RCM of azabicycloheptene derivatives: Study of products distribution by the substituent on alkyne. J. Mol. Cat. A: Chem. 2006, 254, 64-67.

127. Banti, D.; North, M. Totally atom economical tandem-metathesis and Diels-Alder approach to polycyclic compounds. Tetrahedron Lett. 2002, 43, 1561-1564.

128. Banti, D.; North, M. Enyne Metathesis of Norbornene Derivatives: A facile approach to polycyclic heterocycles. Adv. Synth. Catal. 2002, 344, 694-704.

129. Trost, B.M.; Tanoury, G.J. An unusual mechanism of a palladium-catalyzed intramolecular carbametalation. A novel palladium-catalyzed rearrangement. J. Am. Chem. Soc. 1988, 110, 1636-1638 
130. Trost, B.M.; Trost, M.K. Intramolecular enyne metathesis reaction. Route to bridged bicycles with bridgehead olefins. J. Am. Chem. Soc. 1991, 113, 1850-1852.

131. Trost, B.M.; Trost, M.K. Mechanistic dichotomies in Pd-catalyzed enyne metathesis of cyclic olefins. Tetrahedron Lett. 1991, 32, 3647-3650.

132. Trost, B.M.; Yanai, M.; Hoogsteen, K. A palladium-catalyzed [2 + 2] cycloaddition. Mechanism of a Pd-catalyzed enyne metathesis. J. Am. Chem. Soc. 1993, 115, 5294-5295.

133. Trost, B.M.; Hashmi, A.S.K. A Cycloaddition approach to cyclopentenes via metalladienes as 4.pi. partners. J. Am. Chem. Soc. 1994, 116, 2183-2184.

134. Trost, B.M.; Hashmi, A.S.K. On the mechanism of the TCPCHFB-catalyzed metathesis of 1,6-enyne: Evidence for alkylidenepalladium intermediates. Angew. Chem. Int. Ed. 1993, 32, 1085-1087.

135. Trost, B.M.; Chang V.K. An Approach to Botrydianes: On the steric demands of a metal catalyzed enyne metathesis. Synthesis 1993, 824-832.

136. Chatani, N.; Furukawa, N.; Sakurai, H.; Murai, S. $\mathrm{PtCl}_{2}$-catalyzed conversion of 1,6- and 1,7-enynes to 1-vinylcycloalkenes. Anomalous bond connection in skeletal reorganization of enynes. Organometallics, 1996, 15, 901-903.

137. Chatani, N.; Morimoto, T.; Muto, T.; Murai, S. Highly selective skeletal reorganization of 1,6- and 1,7-enynes to 1-vinylcycloalkenes catalyzed by $\left[\mathrm{RuCl}_{2}(\mathrm{CO})_{3}\right]_{2}$. J. Am. Chem. Soc. 1994, 116, 6049-6050.

138. Chatani, N.; Kataoka, K.; Murai, S.; Furukawa, N.; Seki, Y. Construction of novel polycyclic ring systems by transition-metal-catalyzed cycloisomerization of ene-ene-ynes. Interception of a carbenoid intermediate in skeletal reorganization of enynes. J. Am. Chem. Soc. 1998, 120, 9104-9105.

139. Ota, K.; Lee, S.I.; Tang, J.-M.; Takachi, M.; Nakai, H.; Morimoto, T.; Sakurai, H.; Kataoka, K.; Chatani, N. Rh(II)-catalyzed skeletal reorganization of 1,6- and 1,7-enynes through electrophilic activation of alkynes. J. Am. Chem. Soc. 2009, 131, 15203-15211.

140. Ota, K.; Chatani, N. Rh(II)-catalyzed skeletal reorganization of enynes involving selective cleavage of C-C triple bonds. Chem. Commun. 2008, 2906.

141. Fürstner, A.; Stelzer, F.; Szillat, H. Platinum-catalyzed cycloisomerization reactions of enynes. $J$. Am. Chem. Soc. 2001, 123, 11863-11869.

142. Chatani, N.; Inoue, H.; Kotsuma, T.; Murai, S. Skeletal reorganization of enynes to 1-vinylcycloalkenes catalyzed by $\mathrm{GaCl}_{3}$. J. Am. Chem. Soc. 2002, 124, 10294-10295.

143. Jiménez-Núñez, E.; Claverie, C.K.; Bour, C.; Cárdenas, D.J.; Echavarren, A.M. cis-Selective single-cleavage skeletal rearrangement of 1,6-enynes reveals the multifaceted character of the intermediates in metal-catalyzed cycloisomerizations. Angew. Chem. Int. Ed. 2008, 47, 7892-7895.

144. Fürstner, A.; Szillat, H.; Gabor, B.; Mynott, R. Platinum- and acid-catalyzed Enyne metathesis reactions: Mechanistic studies and applications to the syntheses of streptorubin $B$ and metacycloprodigiosin. J. Am. Chem. Soc. 1998, 120, 8305-8314.

145. Trost, B.M.; Doherty, G.A. An asymmetric synthesis of the tricyclic core and a formal total synthesis of roseophilin via an enyne metathesis J. Am. Chem. Soc. 2000, 122, 3801-3810. 
146. Padwa, A.; Austin, D.J.; Gareau, Y.; Kassir, J.M.; Xu, S.L. Rearrangement of alkynyl and vinyl carbenoids via the rhodium(II)-catalyzed cyclization reaction of .alpha.-diazo ketones. J. Am. Chem. Soc. 1993, 115, 2637-2647.

147. Casey, C.P.; Dzwiniel, T.L. Manganese trifluoroacetoxycarbene complexes are convenient intermediates in the synthesis of cyclic enediynes. Organometallics, 2003, 22, 5285-5290.

148. Casey, C.P.; Kraft, S.; Powell, D.R. Formation of cis-enediyne complexes from rhenium alkynylcarbene complexes. J. Am. Chem. Soc. 2002, 124, 2584-2594.

149. Barluenga, J.; de la Rua, R.B.; de Saa, D.; Ballesteros, A.; Tomas, M. Formal alkyne insertion into alkoxycarbene complexes: Simple access to enantiopure group 6 alkynyl(alkoxy)carbene complexes. Angew. Chem. Int. Ed. 2005, 44, 4981-4983.

150. Kim, M.; Lee, D. Metathesis and metallotropy: A versatile combination for the synthesis of oligoenynes. J. Am. Chem. Soc. 2005, 127, 18024-18025.

151. Cho, E.J.; Lee, D. Total synthesis of $(3 R, 9 R, 10 R)$-panaxytriol via tandem metathesis and metallotropic [1,3]-shift as a key step. Org. Lett. 2008, 10, 257-259.

152. Li, J.; Park, S.; Miller, R.L.; Lee, D. Tandem enyne metathesis-metallotropic [1,3]-shift for a concise total syntheses of (+)-asperpentyn, (-)-harveynone, and (-)-tricholomenyn A. Org. Lett. 2009, 11, 571-574.

(C) 2010 by the authors; licensee Molecular Diversity Preservation International, Basel, Switzerland. This article is an open-access article distributed under the terms and conditions of the Creative Commons Attribution license (http://creativecommons.org/licenses/by/3.0/). 